Andrews University

Digital Commons @ Andrews University

\title{
Measures of Student Engagement as Predictors of Grade Point Average (GPA) and Degree Completion at Andrews University
}

Michael D. Milmine

Andrews University, milmine@andrews.edu

Follow this and additional works at: https://digitalcommons.andrews.edu/dissertations

Part of the Higher Education Commons

\section{Recommended Citation}

Milmine, Michael D., "Measures of Student Engagement as Predictors of Grade Point Average (GPA) and Degree Completion at Andrews University" (2021). Dissertations. 1750.

https://digitalcommons.andrews.edu/dissertations/1750

https://dx.doi.org/10.32597/dissertations/1750

This Dissertation is brought to you for free and open access by the Graduate Research at Digital Commons @ Andrews University. It has been accepted for inclusion in Dissertations by an authorized administrator of Digital Commons@ Andrews University. For more information, please contact repository@andrews.edu. 
ABSTRACT

MEASURES OF STUDENT ENGAGEMENT AS PREDICTORS OF GRADE POINT AVERAGE (GPA) AND DEGREE COMPLETION AT ANDREWS UNIVERSITY

by

Michael D. Milmine

Chair: Nadia Nosworthy 


\title{
ABSTRACT OF GRADUATE STUDENT RESEARCH
}

\author{
Dissertation \\ Andrews University \\ College of Education \& International Services
}

\section{Title: MEASURES OF STUDENT ENGAGEMENT AS PREDICTORS OF GRADE POINT AVERAGE (GPA) AND DEGREE COMPLETION AT ANDREWS UNIVERSITY}

Name of researcher: Michael D. Milmine, M.A.

Name and degree of faculty chair: Nadia Nosworthy, Ph.D.

Date completed: March 2021

Purpose of the Study

In a time of rising costs, social discourse questioning value of an undergraduate degree, and declining enrollment, institutions of higher education are under increasing pressure to provide stakeholders and potential students with measures of accountability and student success. These pressures renew the need to leverage student engagement data to understand what makes undergraduates successful in their academic programs. An understanding of student engagement factors is key to helping all students succeed, but especially to identifying areas that colleges and universities can devote their attention in order to improve their students' likelihood of success. The purpose of this study was to investigate the relationship between student engagement and both academic performance and degree completion. 


\section{Method}

The present study was designed as a secondary quantitative analysis of non-experimental descriptive data collected using survey methodology. The instrument, referred to as the NSSE, was used to gather information on students' engagement with their coursework, peers, professors, and academic institution. The data was gathered from 375 first-year and senior undergraduate students attending Andrews University in 2013 and 2015. Structural Equation Modeling (SEM) was used to determine a statistical model to use student engagement variables to predict for student GPA scores. Discriminant Function Analysis (DFA) was used to determine which student engagement variables were best able to discriminate between students who would and those who would not complete their academic degree.

\section{Results}

Upon some revision, the SEM model for the first-year students predicted 19\% of GPA and indicated that the most important predictors were Academic Challenge and Student-Faculty Interaction. Also, upon some revision, the SEM model for the senior students predicted $9 \%$ of GPA. This senior model indicated that the only significant predictor of GPA was Quality of Interactions. DFA for first-year students was statistically significant and predicted degree completion at a rate of $66.9 \%$, with the best predictors (both positive) being Learning Strategies and Reflective \& Integrative Learning. DFA for senior students was not statistically significant.

\section{Conclusions}

Engagement factors are important in predicting first-year student GPA and likelihood of degree completion. Engagement factors that predict GPA are different and weaker for senior students, and do not predict likelihood of degree completion. This study provides evidence for the increase of specific types of engagement to improve student success and graduation rates. 
Andrews University

Graduate Department of Psychology and Counseling

MEASURES OF STUDENT ENGAGEMENT AS PREDICTORS OF GRADE POINT AVERAGE (GPA) AND DEGREE COMPLETION AT ANDREWS UNIVERSITY

\author{
A Dissertation \\ Presented in Partial Fulfillment \\ Of the Requirements for the Degree \\ Doctor of Philosophy
}

by

Michael D. Milmine

March 2021 
(C) Copyright by Michael D. Milmine 2021 All Rights Reserved 


\title{
MEASURES OF STUDENT ENGAGEMENT AS PREDICTORS OF GRADE POINT AVERAGE (GPA) AND DEGREE COMPLETION AT ANDREWS UNIVERSITY
}

\author{
A dissertation \\ presented in partial fulfillment \\ of the requirements for the degree \\ Doctor of Philosophy
}

by

Michael D. Milmine

APPROVAL BY THE COMMITTEE:

Chair: Nadia Nosworthy

Member: Elvin Gabriel

External: Lionel Matthews

\section{Member: Jimmy Kijai}

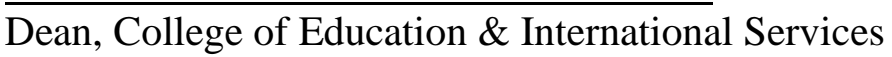
Alayne Thorpe

Date approved 


\section{TABLE OF CONTENTS}

LIST OF TABLES $\ldots \ldots \ldots \ldots \ldots \ldots \ldots \ldots \ldots \ldots \ldots \ldots \ldots \ldots \ldots$

LIST OF FIGURES $\ldots \ldots \ldots \ldots \ldots \ldots \ldots \ldots \ldots \ldots \ldots \ldots \ldots$ viii

ACKNOWLEDGMENTS $\ldots \ldots \ldots \ldots \ldots \ldots \ldots$ ix

Chapter

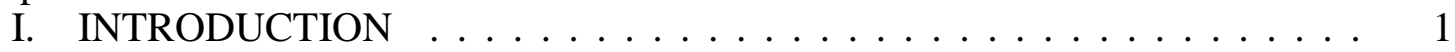

Introduction and Background $\ldots \ldots \ldots \ldots \ldots \ldots$

Rationale for the Study . . . . . . . . . . . . . . . . . 3

Statement of the Problem . . . . . . . . . . . . . . . . 4

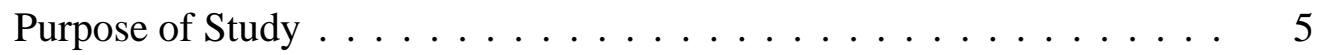

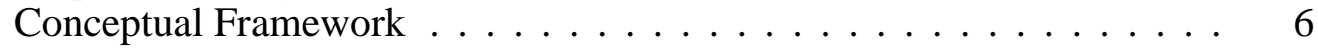

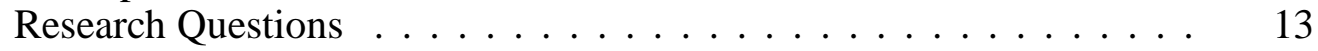

Hypotheses . . . . . . . . . . . . . . . . . . 13

Significance of the Study . . . . . . . . . . . . . . . . . 15

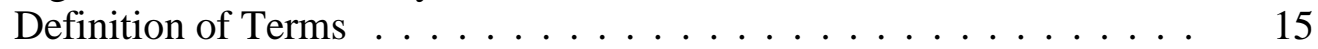

Limitations of the Study . . . . . . . . . . . . . . . . . 16

Delimitations of the Study . . . . . . . . . . . . . . . 17

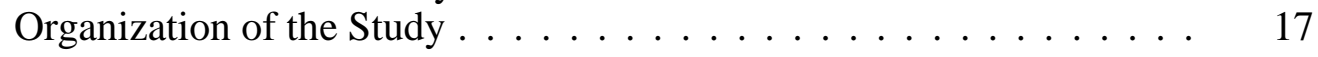

II. LITERATURE REVIEW . . . . . . . . . . . . . . . . . . . . . . . . 19

Student Engagement . . . . . . . . . . . . . . . 20

The History of Student Engagement Research . . . . . . . . . 22

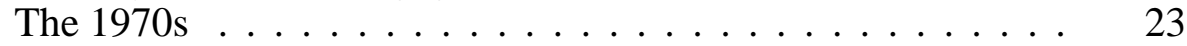

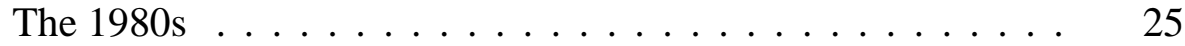

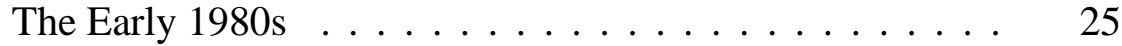

Alexander Astin . . . . . . . . . . . . . . . 27

Chickering and Gamson . . . . . . . . . . . . . 28

Vincent Tinto . . . . . . . . . . . . . . . . . . 30

The 1990 s . . . . . . . . . . . . . . . . . 31

Alexander Astin . . . . . . . . . . . . . . 31

Vincent Tinto . . . . . . . . . . . . . . . 33

Other Research . . . . . . . . . . . . . . . . . . 35

The National Survey of Student Engagement or NSSE . . . . . 35

Current Version . . . . . . . . . . . . . . . . . . . 36

Previous Version . . . . . . . . . . . . . . . . . . 38

Strengths \& Criticisms $\ldots \ldots \ldots \ldots \ldots \ldots$ 
Factors Related to Engagement . . . . . . . . . . . . . . . 44

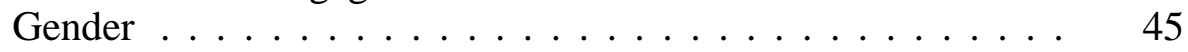

Race \& Ethnicity . . . . . . . . . . . . . . . . 46



Class Preparation . . . . . . . . . . . . . . . . . . . . 49

Faculty \& Peer Interaction . . . . . . . . . . . . . . . . . . 49

Institution Characteristics \& Practices . . . . . . . . . . . 50

Institution Size . . . . . . . . . . . . . . . . 51

Co-Curricular Activities . . . . . . . . . . . . . . . . . 52

The Measurement of Student Achievement . . . . . . . . . . 53

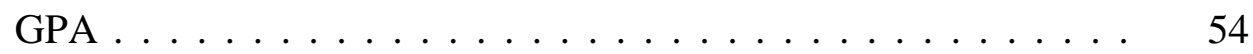

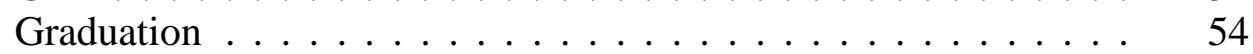

Engagement \& Achievement . . . . . . . . . . . . . . 55

The Relationship between Engagement \& GPA _ . . . . . . . 57

Academic Challenge \& Related Practices . . . . . . . . . . . . 58

Evidence Against Academic Challenge . . . . . . . . . . . 60

Learning with Peers . . . . . . . . . . . . . . . 60

Active and Collaborative Learning . . . . . . . . . . . 61

Co-Curricular Activities with Peers . . . . . . . . . . 61

Other Social Interaction . . . . . . . . . . . . . . . . 62

Experiences with Faculty . . . . . . . . . . . . . . 62

Enriching Experiences . . . . . . . . . . . . . . . 63

Campus Environment . . . . . . . . . . . . . . . 64

Engagement Factors Inversely Related to Achievement . . . . 65

The Relationship between Engagement and Graduation . . . . . . . 65

Student Differences, Student Engagement, and Achievement . . . 67

Race \& Ethnicity . . . . . . . . . . . . . . . . . . . 68

Black \& African American Students . . . . . . . . . . . 69

Support for Conceptual Framework \& Statistical Model Analyses . 71

Engagement, GPA, \& Degree Completion . . . . . . . . . 72

Engagement Indicator Intercorrelations . . . . . . . . . . . 74

Brief Analysis of the Literature . . . . . . . . . . . . . . 76

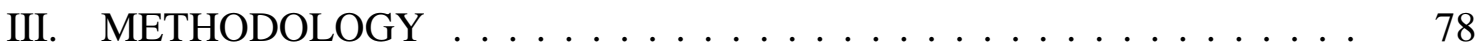

Research Hypotheses . . . . . . . . . . . . . . . . . 78

Research Design . . . . . . . . . . . . . . . . . 80

Population and Sample $\ldots \ldots \ldots \ldots \ldots \ldots$

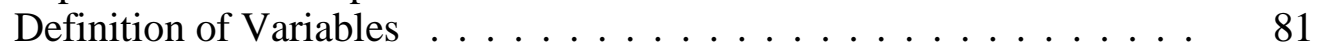



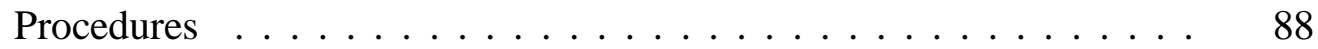

Treatment of the Data . . . . . . . . . . . . . . . . . . . 89

Data Analysis . . . . . . . . . . . . . . . . . . . . 89

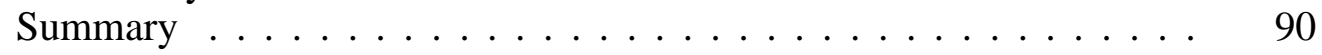

IV. DATA ANALYSIS AND RESULTS $\ldots \ldots \ldots \ldots$

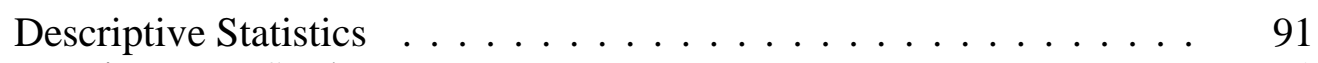

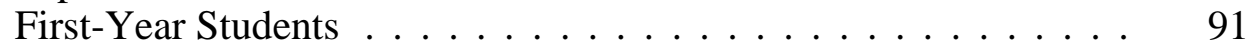


Senior Students . . . . . . . . . . . . . . . . . . . . . 94

Engagement Indicators . . . . . . . . . . . . . . . . . . 96

Engagement Indicator Questions . . . . . . . . . . . . . . . . . 99

Higher-Order Learning . . . . . . . . . . . . . . . . 100

Reflective \& Integrative Learning . . . . . . . . . . . . 101

Learning Strategies . . . . . . . . . . . . . . . . . . . 103

Quantitative Reasoning . . . . . . . . . . . . . . . . . 104

Collabortative Learning . . . . . . . . . . . . . . . . 105

Student-Faculty Interaction . . . . . . . . . . . . . . 106

Effective Teaching Practives . . . . . . . . . . . 108

Quality of Interactions . . . . . . . . . . . . . . . . . . 109

Supportive Environment . . . . . . . . . . . . 111

Hypothesis Testing . . . . . . . . . . . . . . . . . . . 113

Engagement \& Academic Achievement . . . . . . . . . . . . 113

First-Year Students . . . . . . . . . . . . . . . . . . . 114

Model 1 \& Model $2 \ldots \ldots$. . . . . . . . . . . . 117

Model 3 . . . . . . . . . . . . . . . . . . . 119

Senior Students . . . . . . . . . . . . . . . . . . 124

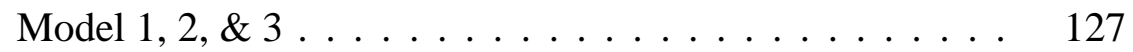

Model 4 . . . . . . . . . . . . . . . . . . 130

Engagement \& Degree Completion . . . . . . . . . . . . . . . 135

First-Year Students . . . . . . . . . . . . . . . . 135

Senior Students . . . . . . . . . . . . . . . 137

Summary of Major Findings . . . . . . . . . . . . . . . . 139

V. SUMMARY, DISCUSSION, CONCLUSION, \& RECOMMENDATIONS 142

Statement of the Problem . . . . . . . . . . . . . . . . . . 142

Purpose of the Study . . . . . . . . . . . . . . . . . . . . . . 143

Summary of the Literature . . . . . . . . . . . . . . . . . . . . 143

Engagement . . . . . . . . . . . . . . . . . . . . . 144

Measures of Student Achievement . . . . . . . . . . . . . . . 144

Engagement \& Achievement . . . . . . . . . . . . . . . . 145

Methodology . . . . . . . . . . . . . . . . . . . . . . 147

Design . . . . . . . . . . . . . . . . . . . 147

Sample . . . . . . . . . . . . . . . . . . 147

Instrumentation $\ldots \ldots \ldots \ldots \ldots \ldots \ldots \ldots \ldots \ldots$

Procedure . . . . . . . . . . . . . . . . . . . . . . 149

Results . . . . . . . . . . . . . . . . . . . . . . . . 149

Engagement Indicators . . . . . . . . . . . . . . . . . . . 149

Engagement \& GPA . . . . . . . . . . . . . . . . . 151

First-Year Students . . . . . . . . . . . . . . . . . . . 151

Senior Students . . . . . . . . . . . . . . . . . . . . . 153

Engagement \& Degree Completion . . . . . . . . . . . . . . . . 154

First-Year Students . . . . . . . . . . . . . . . . . . . . 154

Senior Students . . . . . . . . . . . . . . . . . . 154

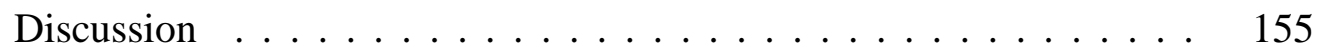

Engagement Indicators . . . . . . . . . . . . . . . 155

Engagement \& GPA . . . . . . . . . . . . . . 157 
Academic Challenge . . . . . . . . . . . . . . . . . . . . . 159

Student-Faculty Interaction . . . . . . . . . . . . . . 160

Campus Environment . . . . . . . . . . . . 163

Collaborative Learning . . . . . . . . . . . . . . . . . . 164

Other Model Similarities _. . . . . . . . . . . . . . . 165

Senior Students . . . . . . . . . . . . . . . . 166

Engagement \& Degree Completion . . . . . . . . . . . . . . 167

Limitations of the Study . . . . . . . . . . . . . . . . . 171

Conclusion ............................ 172

Recommendations .......................... 173

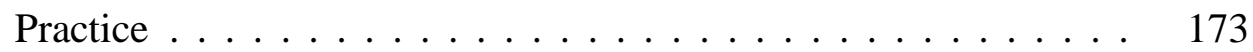

Future Research . . . . . . . . . . . . . . . 176

Appendix

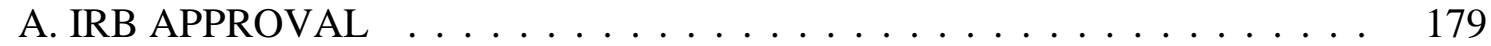

B. NSSE 2000-2012 \& 2013-PRESENT COMPARISON . . . . . . . . . . . 181

C. NSSE THE REPORT $2013 \ldots \ldots \ldots \ldots \ldots$. . . . . . . . . . . . . 183

D. NSSE THE REPORT $2015 \ldots \ldots \ldots \ldots$

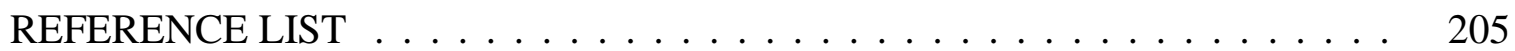

CURRICULUM VITAE . . . . . . . . . . . . . . . . . . . . . 222 


\section{LIST OF TABLES}

1. First-year Student Demographics . . . . . . . . . . . . . . 93

2. Senior Student Demographics _................... 95

3. Engagement Indicators for First-Year Students . . . . . . . . . . . . . . 97

4. Engagement Indicators for Senior Students . . . . . . . . . . . . . . . . 99

5. Higher-Order Learning Item Comparison: First-Year \& Senior Students . . 101

6. Reflective \& Integrative Learning Item Comparison: First-Year \& Senior... 103

7. Learning Strategies Item Comparison: First-Year \& Senior Students . . . 104

8. Quantitative Reasoning Item Comparison: First-Year \& Senior Students . . 105

9. Collaborative Learning Item Comparison: First-Year \& Senior Students . . 106

10. Student-Faculty Interaction Item Comparison: First-Year \& Senior.. . . . 107

11. Effective Teaching Practices Item Comparison: First-Year \& Senior... . . . 109

12. Quality of Interactions Item Comparison: First-Year \& Senior Students . 110

13. Supportive Environment Item Comparison: First-Year \& Senior Students 112

14. Correlation Matrix for Engagement Indicators: First-Year Students . . . . . 116

15. SEM Fit Indices: First-Year Students _ . . . . . . . . . . . . . . . 117

16. Path Coefficients: First-Year Students Model 3 . . . . . . . . . . . . . . 122

17. Standardized Direct and Indirect Effects: First-Year Students Model $3 \ldots$. . 123

18. Correlation Matrix for Engagement Indicators: Senior Students . . . . . . 126

19. SEM Fit Indices: Senior Students . . . . . . . . . . . . . . . . . . 127

20. Path Coefficients: Senior Students Model $4 \ldots \ldots$. . . . . . . . . . . 133

21. Standardized Direct and Indirect Effects: Senior Students Model 4 . . . . 133

22. Discriminant Function Summary: First-Year Students . . . . . . . . . . . 137

23. Discriminant Function Summary: Senior Students . . . . . . . . . . . . . 139 


\section{LIST OF FIGURES}

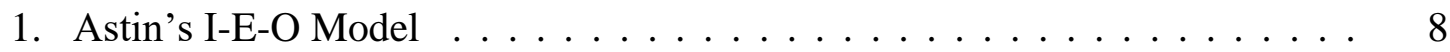

2. Conceptual Model $\ldots \ldots \ldots \ldots$. . . . . . . . . . . . . .

3. Student Engagement \& GPA: Hypothesized Model . . . . . . . . . . . . 14

4. Student Engagement \& GPA: Hypothesized Model . . . . . . . . . . . 79

5. Model 1: First-Year Students . . . . . . . . . . . . . . . 118

6. Model 2: First-Year Students . . . . . . . . . . . . . . . . . . . 119

7. Model 3: First-Year Students . . . . . . . . . . . . . . . . 121

8. Model 1: Senior Students . . . . . . . . . . . . . . . . 128

9. Model 2: Senior Students . . . . . . . . . . . . . . . . . . . . . 129

10. Model 3: Senior Students _ . . . . . . . . . . . . . . . . . 130

11. Model 4: Senior Students _. . . . . . . . . . . . . . . . . . 132 


\section{ACKNOWLEDGEMENTS}

The journey to complete my doctoral degree has been very long and challenging, and I am excited to finally have reached the end. To everyone who has supported me during this journey, I thank you from the bottom of my heart. There were some incredible people in my corner the whole way, and I could not have completed this degree without them. First and foremost is my wonderful wife Christine. She has been amazing, supporting me in every way that she could along the way despite the challenges we faced. Without her encouragement, support, and sacrifices I would not have reached this goal. I would also like to thank my Mom and Dad who instilled in me the importance of education and excellence in my work. Their sacrifices to provide me with a top-quality education paved the way for this achievement.

I would also like to thank my dissertation committee. I am so thankful for my dissertation

chair and advisor, Dr. Nadia Nosworthy. Her patience, time, encouragement, and humor kept me sane along the way, and helped make this report possible. She was always available to answer my questions, provide me with good advice, and to spend countless hours of her time providing feedback to make this research successful. I would also like to thank Dr. Jimmy Kijai, to whom I owe my statistics knowledge. His time, patience, and feedback were central to the shaping of this study and its contributions to research. I would like to thank Dr. Elvin Gabriel as well, who helped to anchor me and my expectations for this project. His listening ear, excellent advice, and eye for detail helped to make this project great. Also, thank you all for being outstanding teachers and mentors during this journey. 


\section{CHAPTER 1}

\section{INTRODUCTION}

\section{Introduction and Background}

In 2014, more than 20.2 million students were enrolled in American higher education institutions, which is almost a five million student increase compared with the year 2000. These numbers are only expected to increase, with 2016 projections at over 20.5 million (National Center for Education Statistics, 2016a). Despite rising costs, the increase in matriculation should not be surprising because of the wide variety of benefits that are associated with having a post-secondary degree. Some of these benefits include an increased earning potential, lower unemployment rates, and better health (National Center for Education Statistics, 2016b; National Center for Education Statistics, 2016c; Buckles, Malamud, Morrill, Sandler, \& Wozniak, 2012; Xu, Kochanek, Murphy, \& Tejada-Vera, 2010). While there seem to be limited benefits of attending college without graduating, far greater benefits exist for those that complete their degrees (National Center for Education Statistics, 2016b; National Center for Education Statistics, 2016c; Buckles et al., 2012). Colleges and universities have additional motivation to encourage their students to finish their degrees in the forms of increased enrollment and better graduation rates. With obvious benefits to graduating for both the student and their school, the need to better understand the factors that contribute to student success are crucial for everyone involved. 
While degree completion is one of the most recognizable and measurable indicators of academic success, another is grade-point-average (GPA). The first record of grading college students' in the United States occurred at Yale University in 1785, in which 58 students were graded on an examination. The four-level scale used then eventually developed into the four-point scale and letter grades that are presently used in higher education (Durm, 1993). GPA is a crucial measure because it has critical implications for the passing of courses, degree completion, further education, and even employment (Allen, Robbins, Casillas, \& Oh, 2008; Baird, 1985; Cabrera, Burkum, \& LaNasa, 2005; Carini, Kuh, \& Klein, 2006; Pascarella \& Terenzini, 2005; Tinto, 1993).

A large number of variables have been identified as predictors of college success. Many of these factors, including individual characteristics, finances, SAT/ACT scores, and high school academic records are outside the control of the college or university that may be attempting to help its students excel academically and graduate (Bowden, 2014; Conway, Zhao, \& Montgomery, 2011; Dexter, 2015; Furr \& Elling, 2002; Fursman, 2012; Kuh, 2003; Kuh, Kinzie, Buckley, Bridges, \& Hayek, 2006; Pascarella \& Terenzini, 2005; Pike, Kuh, \& Massa-McKinley, 2008; Schlinsog, 2010; Zhou, 2010). Instead, one area that colleges and universities have been working to improve is student engagement (Gonyea, Kinzie, \& McCormick, 2013). At present, The National Survey of Student Engagement (NSSE) survey is the most well-known and widely-used instrument to gather data on student engagement in the United States and Canada (National Survey of Student Engagement, 2019a; Kuh, 2009, Lutz \& Culver, 2010). Student engagement, as measured by the NSSE and in its various definitions, takes a number of forms in the higher education setting, including engaging in assignments and projects, in in-class 
discussions and activities, with faculty, and with peers both academically and socially (National Survey of Student Engagement, 2012; National Survey of Student Engagement, 2019e). Colleges and universities aim to improve student engagement in these areas with the assumption that students who are more engaged in their learning will be better equipped to achieve academically and to graduate. This effort is supported by a number of research studies that suggest engagement is related to better learning outcomes and high GPAs (Brown \& Burdsal, 2012; Carini et al., 2006; Fuller et al., 2011; Gordon et al., 2008; Kuh, 2001; Kuh, 2009; Kuh et al., 2008; Pascarella \& Terenzini, 2005; Pike et al., 2008; Svanum \& Bigatti, 2009; Zhou, 2010). In addition, research shows that students with higher GPAs are also more likely to graduate (Astin, 1993; Brown \& Burdsal, 2012; Hood, 2014; Kuh, 2009; Kuh et al., 2006; Pascarella \& Terenzini; 2005; Russell, et al., 2007; Svanum \& Bigatti, 2009; Tinto, 1987). While these studies are used to support efforts to improve student engagement, a more comprehensive exploration of the existing literature reveals a somewhat opaque and multifarious understanding of the relationship between student engagement and academic success. The following literature review was used to examine the research on student engagement and how it impacts the academic achievement and the persistence to graduation of students attending colleges and universities.

\section{Rationale for the Study}

Although the relationships between student engagement and academic achievement have been explored in a number of studies, some areas still need further research. The majority of studies have focused on large public research universities that have Carnegie classifications of R1 or R2, or on random samples of the total population 
of NSSE participants. Further research is needed on small private universities and colleges. Additionally, the majority of the students at these institutions identify as White, with the same holding true for the overall population of participants. This leaves a paucity of research on more diverse student populations. Also, very few studies examine the relationship between engagement and degree completion. With some research indicating that students from minority groups experience a stronger relationship between engagement and academic achievement, new research is needed to examine this relationship among the student populations of smaller, private, and more diverse institutions (Cole, 2010; Greene, Marti, \& McClenney, 2008).

This research study is important because the primary researcher aimed to investigate the relationship using GPA scores, the newest version of the NSSE, and the likelihood of degree completion. There is limited research on the newest version of the NSSE, and few studies examine the relationship between engagement and degree completion. While most studies on this topic employ regression analysis to predict student achievement, very few have attempted to use Structural Equation Modeling (SEM) to help understand the complex relationships between engagement and achievement. Student engagement has been the subject of study, however, higher education institutions still need improved clarity on how they can apply the understanding of their own students' engagement into practices for student success.

\section{Statement of Problem}

The rapidly rising costs of higher education have exerted a number of growing pressures on colleges and universities as their patrons demand greater accountability standards (National Center for Education Statistics, 2019c; Pascarella, Seifert, \& Blaich, 
2010; Zhou, 2010). To justify these price increases and maintain accountability, institutions of higher learning have had to search out ways of measuring and communicating their quality and the benefits that their students experience from attending (Pascarella et al., 2010; Zhou, 2010). One of the indicators which has become very popular to measure and report is student engagement. Student engagement has become recognized as a measure of institutional excellence, as students who are more engaged with their school should also learn better and succeed academically (Axelson \& Flick, 2011; Chickering \& Gamson, 1987; Coates, 2007; Hague-Palmer, 2013; Strayhon \& DeVita, 2010).

Research has indicated that engagement is more predictive of academic success for students belonging to racial and ethnic minority groups as well as lower performing students (Carini et al., 2006; Cole, 2010; Greene et al., 2008). Other research suggests that smaller institutions generate higher engagement scores (Conway et al., 2011; Kezar, 2006; Khaira, 2016; Kuh et al., 2006), and therefore it is important to discover if (1) this holds true in the present day, (2) it holds true with diverse student populations, and (3) a stronger relationship exists between engagement and achievement at small, diverse colleges and universities than has been found in research in larger institutions, or in participating institutions in general.

\section{Purpose of the Study}

The purpose of this study was to investigate the relationship between student engagement and both academic performance and degree completion. The primary researcher was interested in determining the nature of this relationship. The goal was to identify areas of engagement that are most important to student achievement and degree 
completion, so that post-secondary institutions can increase their students' success by improving student engagement in the identified areas. Students will benefit from better academic performance and increased likelihood of graduation. Institutions will benefit from having more successful students and higher graduation rates.

\section{Conceptual Framework}

The conceptual framework upon which this study is based is Alexander Astin's Student Involvement Theory. Astin developed his theory to address what he saw as a critical weakness in the traditional pedagogical theories at the time (Astin, 1984/1999). The mistake of the theories, educators, and educating institutions, as identified by Astin, was largely ignoring student variables from student education and outcomes equation. He believed that the focus was on the policies and methods that institutions and educators used for educating students, believing making changes in those areas would result in better student outcomes. While these are important, Astin wanted to bring individual student variables back into consideration. An understanding of a student's involvement in his/her education was also crucial to predict how well he/she would perform academically (Astin, 1984/1999). This conceptual framework is described in greater detail within the literature review.

This interest in students' behaviors and direct action on their education was key to Astin's Student Involvement Theory. In short, Astin defined involvement as the energy that a student dedicates to his/her educational pursuits. This includes both physical and psychology energy devoted to one's education (Astin, 1984/1999). The theory is built around five tenets. First, the energy applied by the student may be towards a general or specific endeavor. Second, involvement occurs along a scale, and a student's involvement 
will vary depending on the time and endeavor. Third, there are quantitative (e.g. time spent) and qualitative (e.g. understanding) elements to a student's involvement. Fourth, the quality and quantity of student involvement in an educational program is directly related to their learning. Fifth, the ability of a practice or policy put into use by an educator or institution to increase student involvement is directly related to its effectiveness (Astin, 1984/1999).

Upon this theory, Astin developed what became known as his I-E-O Model (Figure 1), which he theorized would predict student success (1993). The model is simple, and includes three broadly defined categories that reflect what a student brings to, and behaviors during, his/her education that may have an impact on his/her educational outcomes. The I stands for Inputs. Inputs was proposed to include a student's background; what they bring to their educational environment. This includes demographic characteristics, as well as existing abilities and behaviors that may help or hinder academic success. The E stands for Environment. Environment was broadly defined as the experiences that a student has while in his/her educational program. These include active behaviors on the part of the student, but also course activities, peer interactions, faculty interactions, institutional climate, and extra-curricular activities. The final letter, O, stands for Outputs. Outputs is the results from any measure of a student's learning or academic success (Astin, 1999). Astin believes that students enter educational settings with an individual background, which impacts how well they can be expected to do in school. This background, he believed, would also impact their educational experiences, which would in turn, also have a significant impact on the student's academic outcomes. 


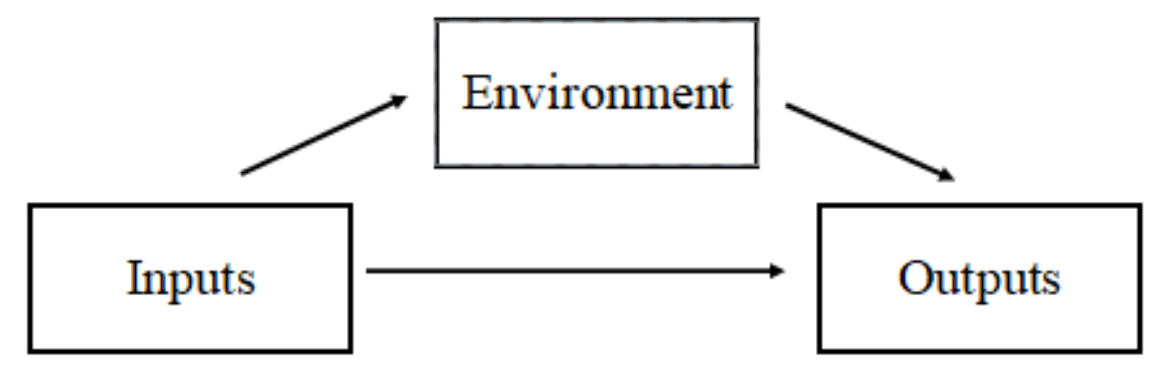

Figure 1. Astin's I-E-O Model

The Inputs considered for this study would be racial and ethnic diversity. While race and ethnicity are not variables in the current study, the population for this study was selected based on the need for research on more racially and ethnically diverse groups of students. Previous research has generally focused on less diverse samples. Many have used large college or university populations that are considered Carnegie R1 or R2 classifications. Carnegie R1 classification represents doctoral universities that are deemed to have very high research activity, while Carnegie R2 classification represents doctoral universities that are deemed to have high research activity. To be listed as an R1 or R2 institution, an institution must have “...awarded at least 20 research/scholarship doctoral degrees and had at least $\$ 5$ million in total research expenditures...” (The Carnegie Classification of Institutions of Higher Education, n.d., para. 3). The proposed population for this study does not meet Carnegie R1 or R2 classification requirements (Andrew University, n.d.).

The focus of the current study was on the Environment and Output elements of the I-E-O Model. While there is a plethora of variables that could fall within these two pieces of the model, the primary researcher has selected certain, measurable variables that 
are of greatest interest at the present time. For the purpose of this study, Outputs was represented by GPA score and degree completion. GPA is both a common measure of student academic success, and is readily available as a quantified variable. Degree completion is another reasonable measure of student success, as only students who have successfully completed their academic program are granted a degree in their field. The primary researcher is interested in degree completion for two primary reasons. First, degree completion is somewhat of a summative measure of student success. Admittedly, many students graduate after having barely passed their required coursework; however, data indicates that only 60 percent of undergraduate students seeking a bachelor's degree, who were both first-time and full-time students beginning in 2010, had completed their degree by 2016 (National Center for Education Statistics, 2019d). This suggests that completing a bachelor's degree is challenging, as over one-third of students have not completed their four-year degree within a span of six years. The second reason for interest in degree completion as a measure of student success is its relatively infrequent appearance (compared with GPA) in the research literature as a measure of student success.

For the purpose of this study, Environment was represented by measures of engagement (what Astin would have called "involvement") within the educational environment. Engagement was a measure of student experiences in academic and cocurricular activities while working towards an undergraduate degree. Student engagement data was gathered using the National Survey of Student Engagement survey, which collects information on a wide variety of student behaviors - especially those related to 
student engagement. The NSSE items were tested in groups known as the NSSE

Engagement Indicators. These groupings were identified by the developers of the NSSE.

A review of the literature on student engagement, GPA, and degree completion led to the construction of the conceptual model found on page 13 (Figure 2). Of the ten NSSE Engagement Indicators, five were added to the model as standalone variables (Supportive Environment, Student-Faculty Interaction, Quality of Interaction, Collaborative Learning, and Effective Teaching Practices). One of the ten, Discussions with Diverse Others, was not added as previous studies did not find it to be related to GPA. The remaining four (Higher-Order Learning, Reflective \& Integrative Learning, Learning Strategies, and Quantitative Reasoning) were grouped together within their theme group: Academic Challenge. The Academic Challenge variables were grouped together for two reasons. First, all of these variables represent direct learning behaviors taken by the student to learn new information. Second, a number of studies have found that, Academic Challenge as a whole, predicts for GPA (Carini et al., 2006; Fuller et al., 2011; Fursman, 2012; Gamm, 2011; Gordon et al., 2008; Khaira, 2016; Kuh, 2002; Rugutt \& Chemosit, 2005) and degree completion (Pike, 2013). This relationship is intuitive, and the other Engagement Indicators were expected to play a supporting role by predicting for Academic Challenge, one another, and in some cases, directly predicting GPA and degree completion.

Of the Engagement Indicators besides those within the Academic Challenge theme, Student-Faculty Interaction, and by extension, Quality of Interaction, are likely the most closely related to GPA, while collaborative learning is linked with degree completion. Students may be more likely to recognize and appreciate the varied 
approaches to learning used by faculty if their interactions with them have been positive. Research has consistently shown that frequent interactions with faculty are related to increased academic achievement among students (Anaya \& Cole, 2001; Astin, 1993; Carini et al., 2006; Cole, 2010; Delaney, 2008; Gordon et al., 2008; Hern, 1987; LaNasa et al., 2007; Pascarella \& Terenzini, 2005; Rugutt \& Chemosit, 2005; Sax et al., 2005; Ullah \& Wilson, 2007). Student-Faculty Interaction has also been found to be predictive of student engagement with course information and with educationally purposeful activities (Campbell, 2011; Kuh \& Hu, 2001; Umbach \& Wawrzynski, 2005). Quality of Interaction reports the quality of interaction with faculty as well as peers, academic advisors, student services staff, and other administration. Interactions with faculty have already been shown to predict GPA, but other studies have found that quality relationships with staff and administration are also related to academic performance (Carini et al., 2006; LaNasa et al., 2007). Finally, a study using the previous version of the NSSE found Active and Collaborative Learning (ACL) to significantly predict for degree completion (Hood, 2014).

Supportive Campus assesses the degree to which students feel the commitment of their college or university to their personal success (Fursman, 2012). In this way, Supportive Campus should be linked to varied methods of learning and engaging with academic material (Academic Challenge), as well as to Effecting Teaching practices. In fact, there is evidence that Supportive Environment is most strongly related with the Academic Challenge variables and Effective Teaching Practices as compared to its relationships with other Engagement Indicators (Fursman, 2012; National Survey of Student Engagement, 2017). Supportive Environment should also be closely related to 
the relationship engagement variables, such as Collaborative Learning, Quality of Interaction, and Student-Faculty Interaction. Research has found that Supportive Environment is positively related to each of these variables (Campbell, 2011; Fursman, 2012; Khaira, 2016; Matthews, Andrews, \& Adams, 2011; Nauffal, 2012; Pascarella \& Terenzini, 1991; Zhao \& Kuh, 2004). The correlations with Supportive Environment are strongest with the Engagement Indicators that examine student relationships with faculty and peers (Campbell, 2011; Fursman, 2012). In terms of peer relationships, Supportive Environment has been linked to simple peer interaction and friendships (Pascarella \& Terenzini, 1991), as well as learning groups (Zhao \& Kuh, 2004) and other forms of collaborative learning (Campbell, 2011; Fursman, 2012).

The remaining Engagement Indicators, Collaborative Learning and Effective Teaching Practices, also have additional relationships worth considering in forming a conceptual model. Effective Teaching Practices should be related to varied types of learning in and outside the classroom, including the use of collaborative learning. This has been found to be true, as Effective Teaching Practices has some of its strongest relationships among all the Engagement Indicators with those that comprise the Academic Challenge theme (National Survey of Student Engagement, 2017). Effective Teaching Practices are also closely related to Collaborative Learning (Campbell 2011; Fursman, 2012). As for Collaborative Learning, several studies have found that it is closely linked to other learning and engagement variables, especially to Learning Strategies within the Academic Challenge theme (Campbell, 2011; Khaira, 2016; Matthews, Andrews, \& Adams, 2011; Nauffal, 2012; Zhao \& Kuh, 2004). 
Figure 2

Conceptual Model

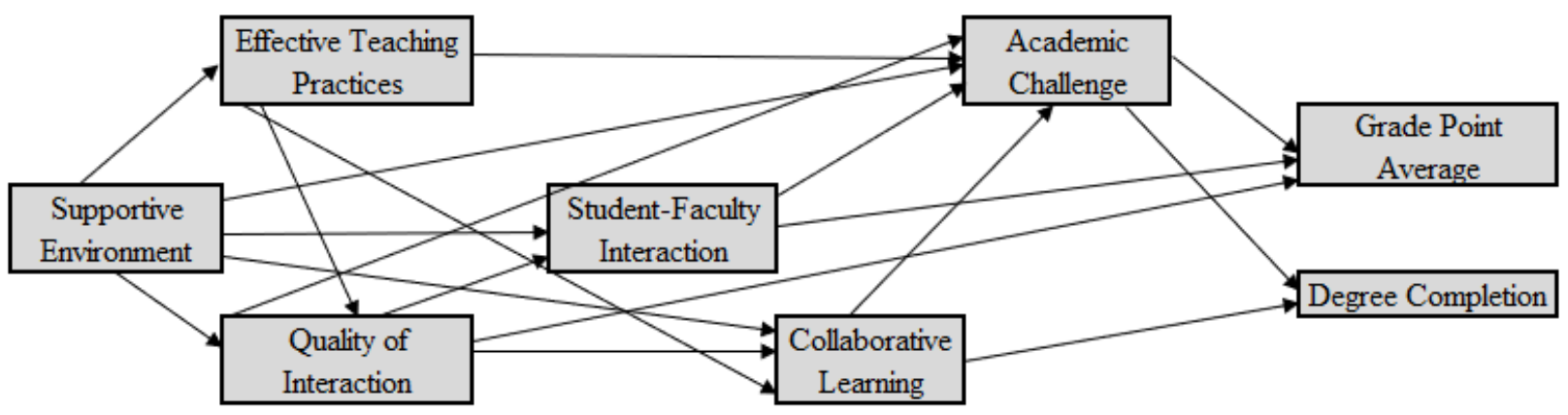

\section{Research Questions}

The current study had two research questions, as follows: 1) "What, if any, relationships exist between student engagement and academic performance of undergraduate students?" This question was divided into two parts: A) "Is student engagement predictive of academic performance?" and B) "Which measures of student engagement best predict academic performance?" The second research question was: 2) "What, if any, relationships exist between student engagement and degree completion of undergraduate students?" This question was also divided into two parts: A) "Does student engagement predict degree completion?" and B) "Which measures of student engagement best predict degree completion?"

\section{Hypotheses}

Based on the research question, sub-problems, and literature review guiding this research, two research hypotheses were tested in this study. 
1. The NSSE Engagement Indicators (excluding Discussions with Diverse Others) will significantly predict for academic performance. Below is the hypothesized model that operationalizes the conceptual model.

Figure 3

Academic Engagment \& GPA Hypothesized Model

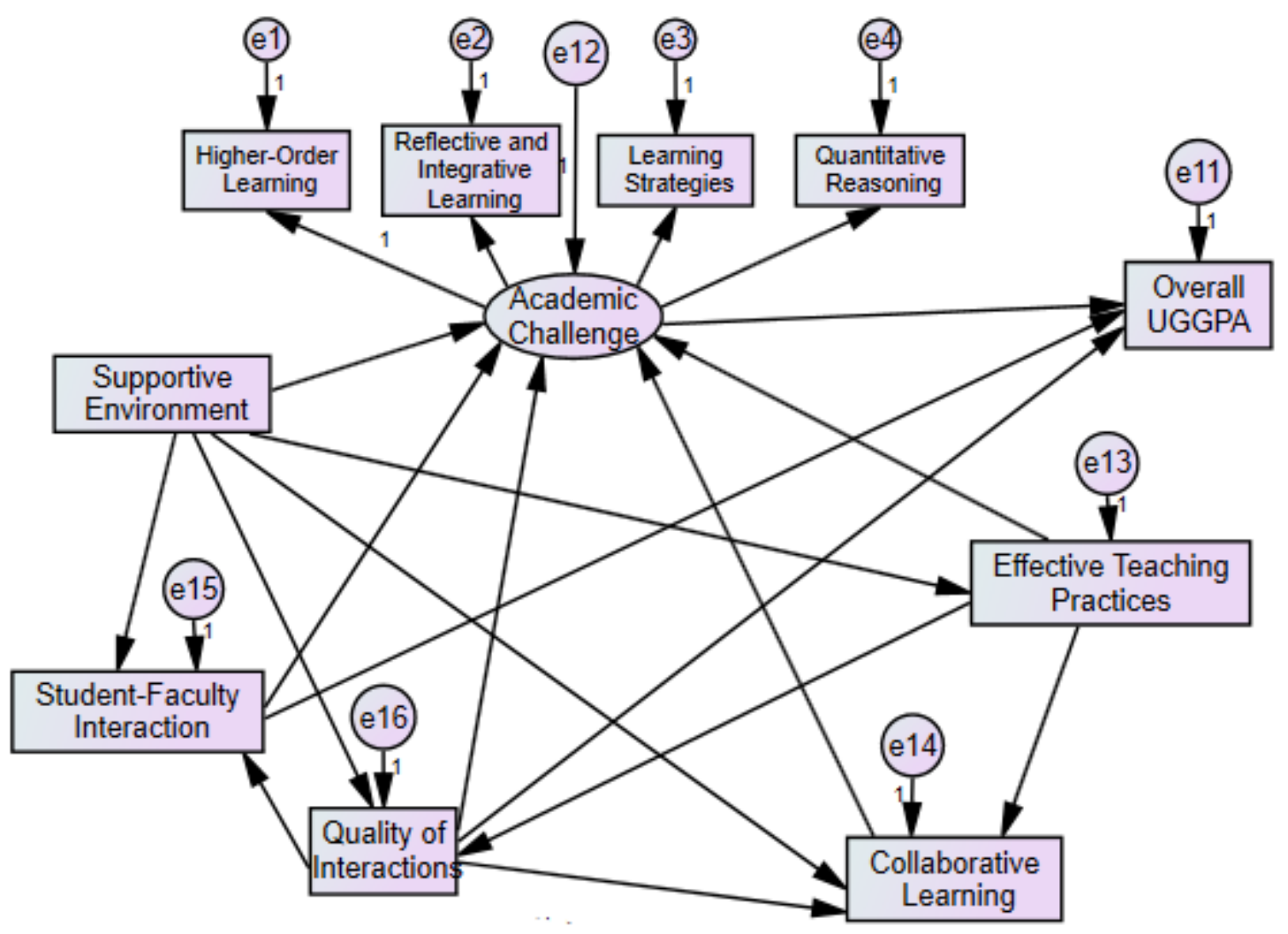

2. NSSE Engagement Indicators Higher-Order Learning, Reflective \& Integrative

Strategies, Learning Strategies, Quantitative Reasoning, and Collaborative Learning will significantly discriminate between those who complete their degree and those who do not.

Each hypothesis was tested in its null form. 


\section{Significance of the Study}

The knowledge generated by this research is beneficial to higher education institutions who are interested in understanding how their students' engagement is related to their overall academic success. This study aims to provide colleges and universities, especially those that are small with diverse student populations, with insight into the most important areas of engagement to target in order to improve student achievement and degree completion rates. Findings on relatively small and racially and ethnically diverse higher education institutions will contribute to the existing literature on larger, less diverse institutions. The present study also improves the current understanding regarding the ability of student engagement to predict actual GPA scores, as most studies use estimated self-report GPA data. Further understanding of the predictive ability of student engagement on degree completion is also added to the existing literature by this study. Audiences that can benefit from this study include educators, higher education administrators, the scientific community, parents, young adults, and anyone considering pursuing an undergraduate degree.

\section{Definition of Terms}

There are a number of terms that occur frequently within this literature review. For the purpose of this study the following terms will be defined as follows.

- Academic achievement / achievement / academic performance - student GPA (unless otherwise specified; Astin, 1977).

- Academic success - the combination of academic achievement and degree completion (Bowden 2014; Cachia, Lynam, \& Stock, 2018; Fursman, 2012; Korobova, 2015). 
- Engagement / student engagement - a variety of ways that students are actively involved with their learning, peers, professors, and school (National Survey of Student Engagement, 2020a).

- Higher learning / institutions of higher education / institutions of higher learning / school / colleges and universities - post-secondary education institutions considered colleges or universities (Merriam-Webster.com, 2021; The Carnegie Classification of Institutions of Higher Education, 2017).

- Grade point average (GPA) - the average obtained by dividing the total number of grade points earned by the total number of credits attempted (MerriamWebster.com, 2021)

- Degree completion / graduation / persistence to graduation / degree conferral student graduation within six years of beginning post-secondary education (National Center for Education Statistics, 2019b).

\section{Limitations of the Study}

The results of this study must be considered in the context of several limitations. The primary limitation is that the items on the NSSE instrument are self-report, and therefore may be subject to inaccuracies related to faulty memory or social desirability (the way that the pressure on respondents to respond to questions in the way that they believe is most acceptable or desired instead of what is most accurate is reflected in their answers). The second limitation is that the NSSE instrument is distributed by email, which may lead to response rate bias; the representativeness of the results depends on the response rate. A third limitation is that this study is not able to examine causal relationships between variables, merely correlations. With correlational relationships, it is 
difficult to determine the directionality, as well as eliminate the possibility that a spurious relationship exists between the correlated variables. A fourth limitation is that the NSSE instrument only gathers data from first-year and senior undergraduate students. Fifth, accurate graduation data is difficult to capture, as one institution's data cannot differentiate between students who drop out, and those that simply transfer and complete their degree elsewhere. As such, only students who completed their degree at Andrews University are indicated as degree completers in the data. Finally, a significant portion of the original dataset had to be removed due to missing data.

\section{Delimitations of the Study}

This study is limited by the scope of data collection. The primary researcher only gathered data from students attending a private university in southern Michigan with an ethnically diverse population. As such, the ability to generalize the findings of this study is limited to undergraduate students and to similar schools in the United States. Second, the sample provided to the researcher was relatively small, with only 136 first-year students and 239 senior students. Finally, the researcher did not use the most recent data. The data used for this study is from 2013 and 2015 because these were the only years collected by the institution that also provided the first-year students in each group enough time to graduate

\section{Organization of the Study}

This research study has been structured into five distinct chapters. Chapter 1 is designed to provide an introduction to the study by providing some background, a rationale for the study, stating the problem the study intends to solve, stating the purpose of the study, providing a conceptual framework of the primary underlying concept, 
stating research questions and hypotheses, indicating the significance of the study, providing a definition of the frequently used terms, and stating the limitations and delimitations of the study. Chapter 2 is composed of the literature review, which provides an in-depth investigation of the previous research on the topic. Chapter 3 consists of the methodology that was utilized for the study, including the research design, research hypotheses, the population and sample, definitions of all the research variables, a detailed description of the instrument used to gather data, the procedures that guided data collection, treatment of the data, and the data analyses used to test the hypotheses. Chapter 4 consists of the results of the data analyses, including tables and graphs that represent those results. The purpose of Chapter 5 is to provide a summary of the research study, provide an interpretation of the results, synthesize the findings of the current study into the existing literature, make conclusions about the study, and make recommendations for both practice and future research. 


\section{CHAPTER 2}

\section{LITERATURE REVIEW}

Chapter 2 provides a detailed description of the relationship between student engagement and academic success, as well as the variables themselves. The student engagement literature is centered on the engagement variables measured by the NSSE. The student success variables selected for this literature search were GPA and degree completion. The search strategy employed in gathering research studies for use in this literature review involved searching online academic databases, Google Scholar, the James White Library at Andrews University, and the Nelson Memorial Library at Pacific Union College. The academic databases searched include: PsycINFO, PsycARTICLES, Sage Premier, Proquest, EBSCO Academic Search Complete, ScienceDirect, Taylor and Francis Online, and ResearchGate. The intention of this literature review is to examine and synthesize the existing research on student engagement and how it impacts their academic achievement and persistence to graduation. The subtopics addressed include early research on engagement, the development of the NSSE instrument, current research on engagement, factors related to engagement, achievement and how it is measured, how engagement is related to GPA, different kinds of engagement and their relationship with GPA, how engagement is related to likelihood of graduation, how student differences interact with the relationship between engagement and student achievement, and an summary of the current literature. 


\section{Student Engagement}

According to the U.S. Department of Education, after adjusting for inflation, the cost of higher education rose $33 \%$ at public institutions and $26 \%$ at private nonprofit institutions between the 2004-2005 and 2014-2015 school years (National Center for Education Statistics, 2019c). With such a rapid increase in costs, governments, parents, and taxpayers have put greater pressure on colleges and universities to provide evidence that they are delivering a high quality education (Zhou, 2010). Although accountability for the quality of education provided has been important for more than 30 years, the rising costs have led to increasing accountability standards (Pascarella, Seifert, \& Blaich, 2010; Zhou, 2010).

Colleges and universities looking for data driven indicators of quality have increasingly turned to measures of student engagement. Besides being measurable, engagement over time has become recognized as a gauge of institutional excellence because good quality teaching and learning are thought to produce high levels of student engagement (Axelson \& Flick, 2011; Chickering \& Gamson, 1987; Coates, 2007; HaguePalmer, 2013; Strayhorn \& DeVita, 2010). The logical progression is simple: students who spend more time and get more deeply involved with their academic studies and at their academic institution should learn better, achieve at a higher level, develop better academic habits, and graduate at a higher rate than their peers who are less engaged (Carini, Kuh, \& Klein, 2006; Kuh, 2003; Shulman, 2002). A better understanding of engagement also allows post-secondary institutions and faculty to make better decisions regarding the efficient allocation of resources and efforts, course offerings, content of courses, and methods of course delivery in order to maximize student learning and 
success (Casuso-Holgado et al., 2013; Coates, 2007; Fuller, Wilson, \& Tobin, 2011). Not only is engagement used to inform decisions, but institutions of higher learning also have a key part to play in the actual engagement of their students by designing and enacting programs that deliberately attempt to better engage students with their academic studies, their peers, their professors, and with the institution itself (Casuso-Holgado et al., 2013; Pascarella \& Terenzini, 2005; Sheard, Carbone, \& Hurst, 2010). As such, student engagement has become a topic of significant academic research (Astin, 1993; Korobova \& Starobin, 2015; Kuh, Kinzie, Schuh, \& Whitt, 2005; Pascarella \& Terenzini, 2005).

Engagement itself is described in a number of different ways and has been given many different definitions. Currently, it is generally understood that student engagement is a complex phenomenon that arises out of a variety of different variables surrounding student involvement in their own learning (Casuso-Holgado et al., 2013; Fredricks, Blumenfeld, \& Paris, 2004). As such, it is difficult to pin down an exact definition as the term itself contains a conglomerate of ideas (Bono, 2011). Attempts to define student engagement include, but are not limited to, describing it as the amount of time and effort exerted on academic activities and social interactions at school, commitment to and involvement in one's own learning, and classroom and other school experiences (Bono, 2011; Casuso-Holgado et al., 2013; Chapman, 2003; Kuh, 2009; Pace, 1980). The National Survey of Student Engagement (NSSE) survey, which was first used in the early 2000s, is the most well-known and widely-used instrument to gather data on student engagement in the United States and Canada (Carini, et al., 2006; Dexter, 2015; Kuh, 2009, Lutz \& Culver, 2010; National Survey of Student Engagement, 2019a). The NSSE includes two parts to its definition of engagement. Part one describes the time and effort 
invested by students into their academic studies, while part two highlights the importance of the college or university's efforts to get their students involved in learning experiences (National Survey of Student Engagement, 2019a). This two-part definition indicates the importance of action from both the student and the institution in the learning environment to maximize student engagement.

In order to understand student engagement, it is important to review its history in academic research, measurement and factors to which it is related. The research history of engagement begins in earnest during the 1970s, and continues throughout the 1980s, 1990s, and into the twenty-first century to the present day. The early research led to the creation of the most widespread attempt to measure engagement, using the NSSE instrument. Since then, researchers have identified a number of variables related to student engagement, besides academic performance and graduation, including gender, race/ethnicity, age, international and native students, transfer status, on- and off-campus residence, parental education, employment, exercise, class preparation, faculty and peer interaction, and institution characteristics and practices.

The History of Student Engagement Research

Although student engagement was studied before the 1990s, the term itself only came into use at this time alongside increasing interest in the topic and how it affects learning (Astin, 1993, 1999; Casuso-Holgado et al., 2013; Courtner, 2014; Kuh, 2009; Pascarella \& Terenzini, 2005). Engagement replaced, or has been used alongside, terms such as involvement and integration throughout the investigation of this topic. Some of the early and most important researchers in this area did not see a difference between the words and used them synonymously. Other researchers disagree, positing that 
engagement indicates a greater depth of interaction between the student and his/her institution, peers, faculty, and academic activities (Wolf-Wendel, Ward, \& Kinzie, 2009).

Some of the earliest research on student engagement was conducted by Ralph Tyler (1969), an educational psychologist that studied, and found significant relationships between, the amount of time students spent on academic work and their learning. Today, time spent on academic activities is central to how student engagement is understood (Courtner, 2014; Merwin, 1984; Tyler, 1969). Since then, continued study of student engagement has led to a continuous evolution of how the term is defined and measured; now it is often considered and measured to include a wider range of activities.

Since Tyler's work, a large number of researchers have contributed to the understanding of student engagement (Dexter, 2015). The following section provides an overview of many of these major contributions to student engagement theory. Some of the major theorists of this time include Astin, Pace, Chickering, Gamson, Tinto, Pascarella, Terenzini, and Kuh. Instead of reviewing the research studies in this area by researcher, research studies and theories are discussed chronologically by decade in order to provide a clear picture of the evolution of these theories over time.

\section{The 1970s}

The foundational research, involving the search for factors that could predict college performance and dropout rates, would later evolve into what is now known as engagement research, which began to gain popularity in the 1970s. Some of the most well-known contributions of this time came from Astin, Pace, Tinto, Pascarella, and Terenzini. Astin $(1973,1975,1977)$, interested in reducing student dropout, found that those living on campus tended to spend more time interacting with professors, staff, and 
their peers than those who lived elsewhere. These studies led him to the concept of involvement, which he found to be related to remaining in college. Through his research at this time, Astin (1977) also found a number of related results. Time spent interacting with faculty outside of class, studying, doing homework, as well as giving presentations in-class, were all related to an increase in GPA. His findings also indicated that students who engaged less frequently in pleasure-seeking behaviors were more likely to maintain self-discipline, to remain and succeed in higher learning environments.

At about this time, Tinto was developing his own model to explain student dropout. Tinto's (1975) model was similar to Astin's, and focused on the importance of student integration into both the academic and social activities of their school. Pascarella and Terenzini (1976) were also studying attrition and interaction, and found that student interactions with faculty could predict both likelihood of dropout as well as student satisfaction with their school. In a later study, Pascarella, Terenzini, and Hibel (1978) found additional support for the importance of student-faculty interaction, linking it to higher SAT scores and better first-year GPAs.

While the contributions of Astin, Tinto, Pascarella, and Terenzini in the 1970s cannot be overlooked, Pace's research might have been the most significant. Pace's (1984) efforts led to his creation of the College Student Experiences Questionnaire (CSEQ) in 1979. The CSEQ was one of the earliest and most popular attempts to measure student engagement, and focused on gathering data on the quality of academic effort, as Pace believed that measuring effort was even more important than time spent. Besides 14 quality-of-effort scales, the CSEQ included items covering overall college experience, demographics, financial support, and educational goals (Courtner, 2014; Fursman, 2012; 
Pace, 1984). The CSEQ remained in use until 2014, when it was discontinued. The instrument is also important in the history of measuring student engagement because the National Survey of Student Engagement (NSSE), which is currently used by institutions of higher learning across North America (and has been adapted for use in other countries), borrows a number of its items from the CSEQ. Pace himself also contributed to the creation of the NSSE instrument (Zhou, 2010).

\section{The 1980s}

The impressive work in the 1970s on student involvement, success, and dropout encouraged the existing researchers in the field to study it further, and interest in the topic to spread. As a result, there is markedly more published research on this area in the 1980s. Researchers looked at new measures of involvement, new variables related to student-faculty interaction, more student background variables, academic performance/achievement/success, academic effort, and good teaching practices. Much of this research continued into the 1990s.

The Early 1980s

In the early 1980s, Pascarella, Walberg, and Pace each made particularly noteworthy contributions to the research on student academic involvement. Focusing on areas such as student-faculty interaction, psychological characteristics, environment, and effort, their research findings and theories help provide the basis for studies and theories published later in the decade.

Providing one of the most important contributions to the date of his paper, Pascarella (1980) synthesized the existing research on student-faculty interaction. Upon review, he found that the frequency and quality of informal student-faculty interaction 
was related to students' academic achievement, intellectual development, attitudes towards college, and educational goals. These associations remained after controlling for students' pre-enrollment traits. Of these relationships, academic achievement was found to be the most statistically significant (Hylton, 2013). Further research by Pascarella and Terenzini (1980) supported these findings. With the current challenges colleges and universities face attracting new students, particularly when ballooning student debt and questions about the value of higher education are at the forefront of the North American collective consciousness, intentionally creating additional opportunities for frequent and quality student-faculty could help to reverse trends towards declining enrollment (Bowden, 2014).

In contrast, Walberg (1982) theorized that students' academic achievement was best predicted by the individual student's psychological traits and his/her psychological environments. Based on his research, Walberg, Fraser, and Welch (1986) later proposed nine factors key to students' success: ability or prior achievement, age, motivation, quantity instruction, quality of the educational experience, home environment, classroom/school environment, peer environment, and media use. This study allowed Walberg and his colleagues to partially support the proposed nine factors, finding relationships between students' achievement on a science test and his/her ability, motivation, attitude, quantity of instruction, quality of instruction, home environment, classroom environment, television viewing, gender, and race.

Alongside his earlier contribution of the CSEQ, Pace (1982) improved upon the existing theory that hypothesized that student success was based on their personal characteristics and environment by noting the importance including measures of effort 
quality. Pace found that by adding measures of effort quality, he was able to improve the predictive ability of the models over those that only included traits and environment by a significant margin. He noted that an understanding of the quality of effort a student exerted was a better predictor of improving one's GPA than previous measures of academic achievement. The quality of effort was also more important than the time spent on task (Pace, 1982). These findings allowed Pace to highlight the importance of student behavior beyond their preexisting characteristics and environments (Dexter, 2015).

Alexander Astin

Of the researchers studying academic involvement and academic outcomes in the 1980s, Astin was one of the most influential. His contributions are arguably some of the most important and are among the most frequently cited in the research literature on student engagement. Although he used the term involvement, what he was referring to is now known as engagement. He defined student involvement as, "the amount of physical and psychological energy that the student devotes to the academic experience" (Astin, 1984/1999, p. 518). This definition remains in use to this day in order to define student engagement (Courtner, 2014).

Bringing together a number of theories at the time, Astin believed that academic outcomes were strongly related to student involvement in their academics (Zacherman \& Foubert, 2014). He theorized that involvement consisted of student characteristics and behaviors, but that outward behaviors such as studying, interaction with faculty, interaction with peers, and taking part in student organizations were easier to measure and indicated internal characteristics (Astin, 1984/1999; Axelson \& Flick, 2011; Courtner, 2014). His theory makes five basic assumptions. First, that involvement is 
considered any energy that the student directs towards both general and specific academic experiences. Second, that the energy invested is measured along a continuum, and differs from activity-to-activity and from student-to-student. Third, involvement is multifaceted, with qualitative and quantitative elements. While the amount of time spent involved in these activities is quantitative, other aspects like the amount of attention or learning occurring during that time are more qualitative in nature. Fourth, the increased knowledge and development that result from a program of education are the direct and proportional result of both the quantitative and qualitative involvement of each student. Fifth, the usefulness of educational policy is measured by its ability to improve student involvement (Astin, 1984/1999). Evident in these basic assumptions is that the student and the institution share the responsibility for the student's involvement. The student is responsible for engaging with peers and faculty, as well as allocating time and energy into academic pursuits. The institution is responsible for shaping the educational experience in a way that facilitates the engagement of the student (Schlinsog, 2010).

\section{Chickering and Gamson}

Important theoretical contributions to the area of involvement and academic success also came from researchers Chickering and Gamson. In 1987, Chickering and Gamson published their Seven Principles for Good Practice in Undergraduate Education, which were based on teaching and learning research of the past 50 years. The researchers note that their principles are good practices or guidelines, and work with students from a wide variety of backgrounds. The seven principles emphasize, among other ideas, student engagement with faculty, peers, and learning material. While engaging with faculty and peers are the first and second of the principles, the next three 
refer to involvement in the learning process. These include active learning, prompt feedback, and time spent on task. The final two guidelines highlight the importance of high expectations and diversity in the classroom. Chickering and Gamson (1987) reason that these will encourage better student outcomes by improving the relevancy and their connection with the learning material by having them incorporate it into their thinking. They also argue that following these principles will improve students' motivation to learn, understanding, critical thinking, ability to interact with and apply information, ability to evaluate their own knowledge, and time management.

One way in which the contributions of Chickering and Gamson (1987) are significant is their hypothesis that student-faculty interaction is the most important factor in student academic success. As noted by Schlossberg (1989) in her theory on mattering versus marginality, students who feel like they matter and are a part of the community will become more invested in it. A strong source for this kind of inclusion is faculty. This follows Pascarella's (1980) research, which recommend that institutions find ways to increase interactions between faculty and their students in order to increase student satisfaction and achievement. In certain ways, each of the principles are related to student-faculty interaction, putting a significant amount of responsibility on faculty members to create opportunities for positive interactions with their students, both inside and outside the classroom. Institutional leaders and government policymakers share some of the responsibility by helping to create environments that contribute to these types of interactions (Zhou, 2010). The importance of quality student-faculty engagement, along with the engagement with their peers, highlights the importance of collaboration on achieving academically. 
Past and present practice has supported the principles of time spent on task and active learning. Time spent on task, for example, is consistent with research from Pace and Walberg, who found important connections between academic success and time spent learning. Active learning, described by Chickering and Gamson (1987) as a student's ability to discuss their learning, relate it to their personal experiences, and apply it to daily life; remains a focus in current teacher training. Another indicator of its relevancy to good educational practices in student engagement, active learning is a benchmark of the NSSE survey.

Chickering and Gamson (1999) later state that their original article was part of a response to the sweeping education reform at the time, which called for good general principles that were practical, easy to understand, and that could be applied in various settings with students from diverse backgrounds. Their guidelines have been supported by research findings that show positive outcomes for students in educational settings that use related practices as compared with settings that do not (Kuh \& Vesper, 1997). The seven guidelines remain the focus of research on education, with some researchers pointing to better outcomes in learning and graduation upon increasing the number of activities that engage students (Kuh et al., 2006; Kuh, 2009). Kuh (2003) also notes the importance of engagement independent of the learning and completion outcomes, by proposing students will cultivate learning habits that will serve them well throughout life. Vincent Tinto

Another theory important in the understanding of student engagement in higher education that builds on the social aspects of the Chickering and Gamson (1987) model was being developed by Tinto during this time. Using Durkheim's (1951) suicide theory 
as a model, Tinto (1987) believed that attrition followed a student's failure to integrate with the academic community of which he/she was a part. The likelihood of integration depends on a number of factors, including commitment to academic goals, commitment to the institution, personal characteristics, and personal values (Tinto, 1987). In order to retain a greater number of students, it was recommended that institutions of higher education make concentrated efforts to engage and involve students socially.

\section{The 1990s}

Interest in engagement continued into the 1990s as researchers continued to build upon the findings and theories established in the prior two decades. Many of the most prominent researchers in this area continued to publish their findings and remained at the forefront of engagement theory. In general, the research findings at this time continued to support earlier stated theories and allow researchers to refine them further. While there was much consensus in the field on the importance of student interaction with others at their college or university, conflicts arose around the importance of student-faculty interactions versus student-peer interactions. Although some researchers found continued support for student-faculty interactions to be most important, there was a general shifting or recognition of the importance of student-peer interactions as well.

\section{Alexander Astin}

Much akin to the previous decade, Astin remained in the middle of engagement research in the 1990s. He decided to study the impact of student participation outside of the classroom setting, focusing on involvement with organizations and clubs. Engaging in these activities led students to develop greater interpersonal and leadership skills, as well as academic and problem-solving skills than those who were not involved (Astin, 1993). 
These findings contributed to the understanding of the importance of student-peer interactions for student development. The importance of student-peer interactions was followed by student-faculty interactions, which were also important for student development in these areas (Astin, 1993).

Based on his work up to this time, Astin developed his I-E-O model. This model attempted to use student inputs (I) and educational environment (E) to predict student outputs (O) (Astin, 1993). This framework was developed as a more comprehensive and accurate model in predicting student outcomes, and had the advantage of controlling for differences in student input. Astin (1993) describes student inputs as everything about the student that may impact his/her ability to succeed; this includes all demographic variables, behaviors, abilities, and education. Similar to Tinto's focus on the need to understand student characteristics in order to predict social integration, Astin believed that the inclusion of these variables was crucial, as they had influence over both the educational environment and the student outcomes. Educational environment was also defined broadly, as all of the experiences a student has during the course of his/her educational program. These include those experiences both inside and outside the classroom; including, but not limited to institutional climate, interactions with faculty and peers, course activities, and extra-curricular involvement. Student outcomes include all variables used to measure student success within the academic program. These contain overall measures such as GPA and degree completion, but also more specific measures such as individual course grades and test scores (Astin, 1993).

Developing his I-E-O model, Astin (1993) recognized the limits on the time and energy that students could dedicate to their education, and that any non-academic 
activities undertaken would subtract from the finite supply of these resources.

Employment, extra-curricular activities, and barriers to the accessibility of classes and class information all limited the amount of time and energy students could employ in academic preparation. With this is mind, Astin encouraged faculty and administration to consider these limited resources when writing and updating campus policies, and planning campus activities. He also noted that getting students involved academically and socially would increase the chances for students to be academically successful. Vincent Tinto

Similar to much of the research and theory at the time, and based on his previous work, Tinto (1993) developed an integration theory that suggested students needed to establish themselves both academically and socially in order to succeed and persist academically. As a student becomes more integrated, he/she will demonstrate a greater loyalty to the academic institution, improve his/her chances to persist academically, and become more committed to his/her academic goals. Social integration included all kinds of social interactions with one's peers, from daily interactions to extra-curricular activities. If these interactions are positive, social integration will increase. If these interactions are negative, social integration will decrease. Academic integration includes attendance, involvement, and completion of any academic activities, whether they be required, like class-related, or optional, like conference attendance. Therefore, increased involvement in these activities will lead to increased integration, while decreased involvement will be related to decreased integration. Overall, students with lower levels of integration would have less commitment to their own academic goals, have less 
institutional loyalty, and would be less likely to persist academically (Pascarella \& Terenzini, 2005; Tinto, 1993).

With further development and research, Tinto's (1997) integration theory becomes his theory of student persistence. The importance of both academic and social integration is maintained from the previous version of the theory, with research indicating the need to subdivide academic integration and social integration into formal and informal systems. Formal academic integration includes academic success as measured by indicators such as GPA and hours studied per week, while informal academic integration consists of factors such as student-faculty interactions and student perceptions of faculty. Formal social integration includes social interaction within the context of school-sponsored extra-curricular activities and student organizations, while informal social integration consists of any peer interactions that are not related to academic pursuits. The highest likelihood of student persistence occurs when both academic and social integration occur. Although it is possible a student will persist with only academic or social integration, these students are more vulnerable to feelings of isolation and academic failure, and therefore less likely to persist (Tinto, 1997). The findings of this study highlight the importance of developing an academic community in which students share in the learning experience. This allows students to integrate both academically and socially, without having to choose between the two. Tinto (1997) noted that this is especially important for commuting students, who do not have the same opportunities for social integration as residential students. 


\section{Other Research}

Much of the other research that occurred at this time highlighted the importance of social interaction with both peers and faculty in increasing the chances of academic success. When asked about the most important factors for their development, college students were most likely to cite peer interaction. The next most important factors included academic activities, faculty interaction, and work, respectively (Kuh et al., 1991). Besides academic development, interaction with peers improves self-esteem, problem-solving, analytical skills, critical thinking, and learning (Johnson, Johnson, \& Smith, 1998; Kuh, 1995; Twale \& Sanders, 1999). Studies further supported the importance of frequent student-faculty interactions, finding that they are related to an increased retention and persistence, improved social integration on campus, improved academic achievement, and increased feelings of institutional support at HBCUs for Black males (Allen, 1992; Kuh, Pace, \& Vesper, 1997; Lamport, 1993; Pascarella \& Terenzini, 1991; Woodside, Wong, \& Weist, 1999).

\section{The National Survey of Student Engagement or NSSE}

The National Survey of Student Engagement (NSSE) was developed in the late 1990s at the Indiana University Center for Postsecondary Research, and was first administered in the year 2000 (after pilot testing in 1999). The Indiana University for Postsecondary Research continues to manage the survey and its distribution to American and Canadian undergraduates each year (National Survey of Student Engagement, 2019a; National Survey of Student Engagement, 2019b; Kuh, 2001). Using a grant from the Pew Charitable Trusts, the NSSE was originally developed as an alternative measure of program quality by a group of experts. Colleges and universities can use this information 
to compare themselves with others, and to identify areas of improvement in their educational practices (National Survey of Student Engagement, 2001). The NSSE was created based on the theories of involvement developed in 1970s, 80s, and 90s, with specific attention to the work of Pace, Astin, Tinto, and Chickering and Gamson (Astin, 1984/1999; Chickering \& Gamson, 1987; Kuh et al., 2001; Tinto, 1993; Zhou, 2010). While the initiative itself is technically the NSSE, and survey itself is called The College Student Report, the survey is usually referred to as the NSSE in the research literature, and is referred to as such here as well. The goal was to measure student engagement in academic activities that were thought to be related to student learning and development in postsecondary education (Kuh et al., 2001). Many of the items were also developed to gather information on behaviors that were related to academic success by previous research (Kuh, 2003).

Current Version

The current version launched in 2013, has 84 questions, as well as a number of demographic questions. All of the questions are self-report Likert-type items, most of which are on a four-point scale (ex., very often, often, sometimes, never). These items are grouped into ten engagement indicators, which are then grouped into four engagement themes: Academic Challenge (theme) - Higher-Order Learning, Reflective \& Integrative Learning, Quantitative Reasoning, and Learning Strategies; Learning with Peers Collaborative Learning, and Discussions with Diverse Others; Experiences with Faculty - Student-Faculty Interaction, and Effective Teaching Practices; Campus Environment Quality of Interactions, and Supportive Environment. Some of the remaining items are grouped into High-Impact Practices, which include: Learning Community, Service- 
Learning, Research with a Faculty Member, Internship or Field Experience, Study Abroad, and Culminating Senior Experience (National Survey of Student Engagement, 2019c). The first section asks participants how frequently they have engaged in various educational practices over the current school year (possible responses: very often, often, sometimes, never). The second section asks how much the participant's coursework has emphasized certain ways of learning over the current school year (possible responses: very much, quite a bit, some, very little). The third section asks participants about how frequently their instructors engaged in certain educational practices over the current school year (possible responses: very much, quite a bit, some, very little). The fourth section asks the participant how frequently he/she has used numerical information in various ways in their learning over the current school year (possible responses: very often, often, sometimes, never). The fifth section asks the student how frequently they have written papers of various lengths over the past year (possible response frequency ranges given). The sixth section asks students to indicate how frequently they have had discussions with people of certain groups over the past year (possible responses: very often, often, sometimes, never). The seventh section asks how frequently the participant has engaged in various preparation activities over the current school year (possible responses: very often, often, sometimes, never). The eighth section asks students if they have engaged in, or plan to engage in, various learning opportunities outside the classroom (possible responses: done or in progress, plan to do, do not plan to do, have not decided). The ninth section asks participants about the quality of their interactions with students, academic advisors, faculty, student services staff, and administrative staff (possible responses are 1 through 7 , with 1 being poor and 7 being excellent). The tenth 
section asks the participant about how much his/her institution emphasizes certain activities, opportunities, and support systems (possible responses: very much, quite a bit, some, very little). The eleventh section asks the student about how many hours he/she spends in a week on various academic and nonacademic activities (possible responses: 0, $1-5,6-10,11-15,16-20,21-25,26-30,30+)$. Section twelve asks the participant how much his/her institution has contributed to his/her knowledge, skills, and development in various areas (possible answers: very much, quite a bit, some, very little). The final section before the demographic section of the survey asks about the participant's educational experience, whether they will return, and whether they would choose this institution if they were to start all over (possible responses vary based on the question; National Survey of Student Engagement, 2019e).

Previous Version

The previous version, and upon which much of the existing research literature is based, had a similar number of questions, 42 of which were grouped into five benchmarks: Level of Academic Challenge (LAC; includes questions about learning practices and expectations), Active and Collaborative Learning (ACL; includes questions about learning with peers and classroom participation), Student-Faculty Interaction (SFI; includes questions about interactions with faculty inside and outside the classroom), Enriching Educational Experiences (EEE; includes questions about interactions with diverse peoples and learning activities outside the classroom), and Supportive Campus Environment (SCE; includes questions about how well the institution supports students in various ways; National Survey of Student Engagement 2010; National Survey of Student Engagement, 2012). These benchmarks serve as tools for comparison, but also for data 
reduction and summarization, providing an understanding of both student engagement and institutional actions towards engaging students (Campbell \& Cabrera, 2011). The changes in groupings of items represent more rigorous statistical testing on the new and updated items of the current version. In the new version, 23\% of the items are new, 27\% have major changes in the way they are written, $28 \%$ have minor wording changes, and $22 \%$ are unchanged (National Survey of Student Engagement, 2019c). The NSSE website lists four goals for the update: 1) Develop new measures related to effective teaching and learning, 2) Refine existing measures and scales, 3) Improve the clarity and applicability of survey language, and 4) Update terminology to reflect current educational contexts (National Survey of Student Engagement, 2019c).

While the NSSE survey provides a global score of engagement for the individual student, it is designed to provide the administering institution an understanding of its areas of strength and weakness on predictors of student success. The survey is not designed to pick out these individuals for additional attention, nor to predict individual success (Pike, 2013; National Survey of Student Engagement, 2019a). The survey is administered to randomly selected freshmen and senior students at participating institutions during the spring. This allows institutions to gather student information on student behavior and experiences after they have already spent some time studying at the college or university, and also to discover how the students may have been changed by the institution during their time as students there (National Survey of Student Engagement, 2019a). Institutional results are then tracked over time, and compared with nationally posted averages (National Survey of Student Engagement, 2019d). This allows 
institutions to check their progress towards their own goals for providing a high-quality education.

Strengths \& Criticisms

Strengths. The NSSE has a number of strengths that make it an attractive tool for institutions eager to improve the experiences and success of their students. One of these is the broad acceptance by the postsecondary education community. Since its inception in 2000, over 1,600 institutions and six million students have participated in the NSSE survey. In 2018, almost 290,000 students from 511 colleges and universities participated (National Survey of Student Engagement, 2019a). There is also evidence that participating institutions have been able to put the findings from their own individual institutions to good use. In one sample of over 200 institutions, Gonyea and colleagues (2013) found that over 40 percent showed improvement in one or more measures of freshmen engagement. Twenty-eight percent showed improvement in senior engagement. The NSSE also provides an external measure of an institution's quality, which is useful for accrediting bodies, government agencies, and all other stakeholders (Courtner, 2014). Another notable strength of the NSSE instrument is the numerous studies that have linked student responses with student outcomes. Research has found relationships between both NSSE item and benchmark scores and GPA (Dexter, 2015; Carini et al., 2006; Gordon, Ludlum, \& Hoey, 2008; Kuh, 2001), freshmen retention (Dexter, 2015; Gordon, et al., 2008; Pike, 2013), graduation rates (Pike, 2013), likelihood to pursue graduate-level education (Gordon et al., 2008), and employment after graduation (Gordon et al., 2008). Scores on NSSE benchmarks are also related to personal well-being, moral reasoning, intercultural effectiveness, and critical thinking (Pascarella et al., 2010). Based 
on their research findings, Pascarella and colleagues (2010) suggest that the NSSE is a better measure of quality undergraduate education than those used by the U.S. News and World Report, which has traditionally been relied upon for college and university rankings. As such, they recommend that institutions focus on making improvements based on the NSSE findings for their particular school, over making changes to the areas measured by the U.S. News and World Report.

Criticisms. The reliability and validity of the NSSE have been questioned by some researchers, whose criticisms generally fall into two main categories: (1) problems with the benchmarks and (2) issues with the questions themselves. Criticisms of the benchmarks are generally with their construct validity, or their inability/limited ability to predict student outcomes. Problems with the questions generally stem from, but are not limited to, the fact that they are self-report.

A number of similar criticisms of the NSSE benchmarks and their construction have been published over time. For example, some research indicates that individual or groups of NSSE items have better predictive strength for student outcomes than the benchmarks themselves (Gordon et al., 2008; Pike, 2004; Zhao \& Kuh, 2004). Bryan, Eagle, Wright, and Icenogle (2012) found that the items may not fit into the benchmarks as well as they appear, with poor SEM fittings for all types of institutions tested. The best results, yet still somewhat poor, were the fittings for liberal arts colleges and public regional universities. These researchers recommended revision to at least two of the benchmarks: Level of Academic Challenge and Supportive Campus Environment (Bryan et al., 2012). Other research also suggest the need to revise the Student-Faculty 
Interaction benchmark, as it has been found to have the weakest predictive ability of the benchmarks (Pascarella et al., 2010).

Critics of the NSSE items have pointed to several characteristics that may bring the reliability and validity of the instrument into question. The most consistent concern is the use of self-report items, to which students may be unwilling or unable to provide accurate responses, due to faulty memory over time or to social desirability (Garcia \& Gustavson, 1997; Shaughnessy, Zechmeister, \& Zechmeister, 2015). The accuracy of self-report data is especially vulnerable when participants are asked to report time spent in an activity (Kuh, 2002). The halo effect may also occur, in that students may overestimate their academic-related behaviors and performance (Kuh, 2002; Pike, 1999). The NSSE has also faced criticism for what some consider vague wording (and therefore varying interpretations), items that are difficult to understand, and use of vague quantifiers as responses (Ex. Very Often, Quite a Bit, Sometimes, etc.; Porter, 2011).

Responses to Criticism. A number of researchers, including those responsible for the maintenance and update of the NSSE, have responded, or have rebutted many of the criticisms brought against the NSSE instrument. In favor of the benchmarks, there is research evidence that indicates that they do measure student experiences in college or university that are related to academic outcomes (Pascarella et al., 2010). Bryan and colleagues (2012), despite criticizing the benchmarks, admit that they have adequate construct validity, and are relatively consistent. While there was some support for continued use of the benchmarks used in the previous version, the major response to the criticism has been to abandon the previous benchmark system in favor of new item combinations. These new combinations, as previously mentioned, are referred to as 
engagement indicators (of which there are ten groupings) and High-Impact Practices (of which there are 6), and have been more rigorously tested (National Survey of Student Engagement, 2019c).

The main response to the criticism of the NSSE items has been to update wording and replace certain items with new ones for the most recent addition of the instrument. For the items themselves, this update was intended to clarify wording, increase the applicability of the items, and to make sure terminology used was current in the field (National Survey of Student Engagement, 2019c). Even during its original construction, the authors recognized the importance of face and content validity, and designed the questions with emphasis on well-defined and clear wording (Kuh, 2002).

There are some criticized item characteristics, however, that have not been changed. One of these unchanged aspects is the self-report nature of the items. According to Kuh $(2002 ; 2004)$, the instrument has been designed to meet the criteria that allow for valid self-report data gathering. These criteria are:

(1) when the information requested is known to the respondents; (2) the questions are phrased clearly and unambiguously; (3) the questions refer to recent activities; (4) the respondents think the questions merit a serious and thoughtful response; and (5) answering the questions does not threaten, embarrass, or violate the privacy of the respondent or encourage the respondent to respond in socially desirable ways. (Kuh, 2002 p. 3-4)

NSSE results have also been shown to be related to outcomes from objective student achievement tests across participating colleges and universities, which is further validation of NSSE findings (Bowden, 2014). Additional support for the self-report items 
on the NSSE is found in the relationship between self-reported GPA and actual GPA scores, which was very strong (Kuh et al., 2007).

In a further step to ensure quality data is gathered, administration of the NSSE occurs in the spring, gathering data on the current year. This is done so that the information gathered is relatively fresh in the mind of the student, reducing the likelihood of memory errors and misreporting (Kuh, 2002). In challenge to the vague quantifiers criticism, one study found that although there were differences between student groups and between institutions, they were generally very small (Laird, Korkmaz, \& Chen, 2008). Despite previously indicated criticisms, NSSE is likely the best alternative to the U.S. News and World Report college ranking system (Bryan et al., 2012).

\section{Factors Related to Engagement}

A study by $\mathrm{Hu}$ and Kuh (2002) of almost 51,000 undergraduate students at 123 institutions indicated that only about $5.4 \%$ of the sample were highly engaged, while $18.2 \%$ were considered to show very low levels of engagement. With relatively few students exhibiting high levels of engagement, a main area of investigation of more recent research has been the search for factors related to engagement. What contributes to engagement and which students are most engaged? What are the characteristics of an engaged student, and how can we improve engagement of all students? Researchers tend to agree that high levels of student engagement manifests as greater amounts of effort or energy and time that is dedicated to academically purposeful activities (Kuh, 2009; Pascarella \& Terenzini, 2005). The greater this investment, the more likely the student is to find his/her environment stimulating (Ethington \& Horn, 2007). Through numerous studies, researchers have identified differences in engagement based on demographic 
variables such as gender, race and ethnicity, and age. Other factors related to engagement that have been identified include class preparation, faculty and peer interaction, and institutional characteristics and practices.

\section{Gender}

A general overview of the research on the interaction between gender and engagement would appear to indicate that being a woman is a predictor for higher engagement (Hu \& Kuh, 2002; Kuh, 2003; Schlinsog, 2010). A more careful examination, however, reveals a somewhat more balanced and nuanced reality. Some of these studies have not found significant differences between male and female engagement, indicating that female engagement had increased to match that of males (Carini et al., 2006; Harper, Carini, Bridges, \& Hayek, 2004). In contrast, Hu and Kuh (2002) found that male engagement scores tended to be clustered at the top and bottom scores, indicating that while most males tended to be less engaged than their female peers, a significant portion were among the most engaged students.

Research has also indicated differences in the ways male and female students engage with their academic institutions. A number of studies suggest that women tend to be more engaged with academic activities and preparation, while men are more likely to be involved with social, fitness, and other non-academic activities; which has explained the greater academic performance enjoyed by women (DeBard \& Sacks, 2011; Hu \& Kuh, 2002; Kinzie, Thomas, Palmer, Umbach, \& Kuh, 2007; Kuh, 2003). A study by Schlinsog (2010) found that while there were no significant differences in engagement across three of five NSSE benchmarks, female students scored significantly higher on both the Academic Challenge (the benchmark that contains academic effort and time 
variables) and Enriching Educational Experiences (the benchmark that contains participation in diverse learning experiences, especially those outside the classroom). This supported an earlier study, which also had found that female students scored significantly higher on the Academic Challenge benchmark (Kinzie et al., 2007).

Differences between male and female students in student-faculty interaction is one area in which research studies do not agree. Kinzie and colleagues (2007), using NSSE data, found that male freshmen students had had more interactions with faculty than their female peers. Also using NSSE data, Schlinsog (2010) found no significant differences between men and women. In contrast, data from the College Student Survey and the Cooperative Institutional Research Program indicated that female students had more interactions with faculty than male students (Sax, Bryant, \& Harper, 2005). A study of Historically Black Colleges and Universities (HBCUs) supported this, finding that female students had higher faculty interaction scores on average. Female students in this study were also more likely to feel supported by the institutional environment and the relationships that they had developed with administration, faculty, and their peers (Gamm, 2011).

\section{Race \& Ethnicity}

Most of the research on race, ethnicity, and engagement has compared the engagement of Black, African American, and Hispanic students to that of White students. Numerous studies have found White students to be less engaged than their peers from minority groups (Bowden, 2014; CCSSE, 2005; Fursman, 2012; Gamm, 2011; Greene, Marti, \& McClenney, 2008; Hu \& Kuh, 2002; Kuh et al., 2006; Schlinsog, 2010). Many of these studies found that African American and Black students were the most engaged 
out of any of the racial and ethnic groups (Bowden, 2014; Fursman, 2012; Gamm, 2011; Schlinsog, 2010). There is some indication that Black and African American students engage in more academically enriching experiences, mental activities, academic preparation, and class assignments than their White peers (Greene et al., 2008; Schlinsog, 2010). In a study of HBCUs, Gamm (2011) found significantly higher engagement scores on all five NSSE benchmarks, when compared with Predominantly White Institutions (PWIs).

Additional research has added a somewhat different and more nuanced understanding of the racial and ethnic differences in engagement. Greene and colleagues (2008) found that both Hispanic and Asian students had greater levels of engagement in mental activities than their White peers, but did not differ from Whites in academic preparation. Asian students were also found to have greater engagement in class assignments than Whites. While Asian and African American students were more likely to be engaged in enriching educational experiences, Whites and Hispanic students were found to enjoy greater engagement with the support of the institution, faculty, and peers (Kuh et al., 2006). White students were also found to engage more in Greek Life activities than their peers (Milem \& Berger, 1997). In contrast to the previous findings, Carini and colleagues (2006) found no significant differences based on student race. Other research studies also indicate that Black male engagement scores may be falling, especially compared with their female counterparts (Harper, 2004, 2009). This was noted in the NSSE benchmark Academic Challenge, and especially at PWIs (Harper, 2004, 2009). These lower levels of engagement appear to be correlated with lower feelings of belongingness (Harper, 2008, 2009; Strayhorn, 2008). 
The higher levels of engagement experienced by minority students seem to have significant positive effects. A number of studies have found that minority students benefit academically more from increases in engagement (Kuh et al., 2006; Kuh, Kinzie, Cruce, Shoup, \& Gonyea, 2007; Kuh, Cruce, Shoup, Kinzie, \& Gonyea, 2008; Pascarella \& Terenzini, 2005). This held true for GPA increases, personal and social improvements, and persistence to graduation (Cruce, Wolniak, Seifert, \& Pascarella, 2006; Kuh et al., 2007; Kuh et al., 2008; Swigart \& Murrell, 2001). These benefits help offset some of the academic under-preparedness and other disadvantages that these students often face (Cruce et al., 2006; Kuh et al., 2007)

Age

Researchers have also found differences in engagement based on student age. In general, older students (24 years of age and older) tend to have higher levels of engagement than younger students. Specifically, these older students tend to have higher active and collaborative learning scores on the NSSE and engage in a greater number of educationally purposeful activities (Conway et al., 2011; Gibson \& Slate, 2010). They have also been found to have better study habits (Jeffreys, 2012). In support of the findings on age, senior students tend to be more engaged than their freshmen counterparts (Fursman, 2012; Hu \& Kuh, 2002). These higher levels of engagement have been suggested as the reason for older students' increased likelihood of academic success and passing rates on licensing exams (Beeson \& Kissling, 2001; Salamonson \& Andrew, 2006). 


\section{Class Preparation}

Preparing for class is a central part of higher education, and according to research in the area, it is also related to student engagement. Students who spend more time in academic preparation tend to have higher engagement scores (Braxton, Milem, \& Sullivan, 2000; Hu \& Kuh, 2002; Khaira, 2016). One theory is that these students develop study habits that are more effective and efficient, allowing them more time to participate in other campus activities (Braxton et al., 2000). Academic preparation has been found to have significant relationships with at least three of the NSSE benchmarks (Khaira, 2016). The relationship between class preparation and the active and collaborative learning benchmarks was the strongest, followed by supportive campus environment, and student-faculty interaction (Khaira, 2016). These results suggest that students who spend more time in academic preparation benefit from more involvement in-class, more collaborative learning with peers, more time discussing what they learned with peers and faculty, had closer relationships with faculty, worked with faculty on projects outside class, had higher quality relationships with peers and institutional employees, and felt greater support from their institution.

\section{Faculty \& Peer Interaction}

Student-faculty interaction is very beneficial to students. While the majority of these benefits are explored in an upcoming section, this interaction is also related to increased student engagement. This is true for both the academic and social aspects of integrating and engaging with one's college or university (Pascarella \& Terenzini, 2005). Interactions with faculty improved student engagement with the course information, and 
in educationally purposeful activities, both inside and outside the classroom (Kuh \& $\mathrm{Hu}$, 2001; Umbach \& Wawrzynski, 2005).

Similar to student-faculty interaction, a student's interaction with his/her peers has a wide range of benefits. While many of these benefits are explored further in a future section, one of them is increased engagement. Interacting with peers generally leads students to develop friendships, increases participation in their institution's activities, and increases feelings of support from one's institution (Pascarella \& Terenzini, 1991). Learning in groups and in small learning communities with peers (living near one another or taking more than one class together) has been found to increase student engagement and integration, with these students also finding their school more supportive of their needs (Zhao \& Kuh, 2004). Having social learning areas has also been found to boost engagement for students who use them (Matthews et al., 2011; Nauffal, 2012).

\section{Institution Characteristics \& Practices}

Although some research has found greater differences within institutions in engagement than between institutions (Kuh, 2003), there are others that have concluded that these differences in institutional characteristics matter when comparing them on student engagement. Some of these characteristics are within a college or university's ability to control, while others are not. For example, there is evidence to suggest that students at private colleges engage better than those at public institutions ( $\mathrm{Hu} \& \mathrm{Kuh}$, 2002). While an institution likely cannot change its public or private status, Gunuc (2014) notes that integrating technology effectively in the classroom is a way that any institution can improve student engagement. Other institution characteristics and practices that 
impact student engagement are institutional size and academic activities available to students.

Institutional Size

Findings on the relationship between institutional size and student engagement generally indicate an inverse relationship between the two, with smaller colleges and universities benefitting from higher engagement scores than their larger counterparts (Conway et al., 2011; Kezar, 2006; Khaira, 2016; Kuh et al., 2006). Despite the general relationship between institution size and engagement, these studies have not always found the relationship to hold true for the same NSSE benchmarks. Kezar (2006) found the smaller schools to have higher engagement scores on four of the five benchmarks. These students had stronger level of academic challenge, active and collaborative learning, student-faculty interaction, and supportive campus environment scores (Kezar, 2006). Conway and colleagues' (2011) results supported three of the relationships originally found in the Kezar study: active and collaborative learning, student-faculty interaction, and supportive campus environment scores. The results of this study also indicated that institution size was more important for predicting engagement than student characteristics (Conway et al., 2011). Later, Khaira's (2016) research also found three inverse relationships between institution size and NSSE benchmarks, only two of which match the previous studies: active and collaborative learning, and student-faculty interaction. The third was enriching educational experiences. Based on the evidence of these studies, smaller institutions have significant advantages in at least two, if not all five, NSSE benchmarks. At minimum, students have greater opportunities for interacting with faculty, and engaging with their peers and community as part of the learning process 
(Conway et al., 2011; Kezar, 2006; Khaira, 2016). It is important to note that there may be exceptions to these findings. As noted by Kuh and colleagues (2007), some smaller institutions having lower overall engagement scores than larger schools.

Several ideas have been proposed to explain the differences in engagement based on institution size. In at least two studies, Kuh (2003) and Kuh and colleagues (2006) note that smaller institutions likely have location and living proximity, student-to-faculty ratio, and class size advantages over larger schools. First, smaller schools may be somewhat geographically isolated, leaving students to live closer to the school and close to one-another. This may promote a greater sense of community and increase the likelihood of students interacting outside class. Second, smaller schools likely have a smaller student-to-faculty ratio, increasing the likelihood that students will have opportunities to interact with faculty inside and outside the classroom. With fewer students, faculty may also have more chances to develop better relationships with their students, and at minimum, learn individual names. Third, smaller class size allows for greater versatility in class format and learning activities. Students may have more opportunities to express and exchange ideas. Each of these may lead to quicker and deeper integration into the academic and social environment on campus (Kuh et al., 2006).

Co-Curricular Activities

Pairing class learning with complementary learning activities outside the classroom is another way that colleges and universities can increase student engagement (Khaira, 2016; Zacherman \& Foubert, 2014). More involvement in co-curricular activities predicted for three of the NSSE benchmarks: level of academic challenge, 
active and collaborative learning, and student-faculty interaction. Co-curricular activity involvement best predicted student-faculty interaction, indicating that a significant portion of these co-curricular activities increase contact with faculty. Active and collaborative learning was next, indicating that these activities facilitated student learning while in contact with peers and the community. Finally, it appears that participation in co-curricular activities is related to academic effort and rigor (Khaira, 2016). These cocurricular activities not only have the potential to increase student engagement, but student learning as well (Hu \& Kuh, 2003; DeNeui, 2003).

\section{The Measurement of Student Achievement}

Throughout a student's time spent in study at the undergraduate level, he/she will undergo numerous examinations of knowledge, skill, and professional preparedness before being granted a diploma in his/her field of study. These measures of achievement come in the form of, but are not limited to, course exams, tests, quizzes, projects, presentations, papers, and demonstrations. Outside the classroom, they may take the form of standardized tests, thesis projects, board exams, licensing exams, and internships. The problem for achievement research, then, is the lack of uniformity in examinations of student achievement between fields of study and between academic institutions. Simply stated, few measures of achievement are common to all fields, and all institutions. Grade point average (GPA) and graduation are two out of this small number, and while they are imperfect measures of comparison between students, they do act as a general guide to understanding a student's level of achievement in his/her field of study. 


\section{GPA}

GPA, or grade point average, has been used synonymously with academic achievement throughout the literature examining student achievement. The use of GPA as a measure of academic achievement has been somewhat controversial, as researchers have questioned its use for such a purpose (Baird, 1985; Porter, 2011). While this criticism is likely valid, grades are an important factor when determining whether or not a student will pass their coursework, graduate, pursue further education, and find employment (Allen, Robbins, Casillas, \& Oh, 2008; Baird, 1985; Cabrera, Burkum, \& LaNasa, 2005; Carini et al., 2006; Pascarella \& Terenzini, 2005; Tinto, 1993). Institutions themselves use GPA as a way to track student success (Fauria \& Fuller, 2015). GPA also provides a simple and accessible way to quantify student achievement across virtually all institutions and fields of study, making it an ideal measure for use in research, without lending itself to the inaccuracies of students' self-perception of achievement (Cabrera et al., 2005; Pascarella \& Terenzini, 2005; Zacherman \& Foubert, 2014). As such, the use of GPA as a measure of academic performance is commonplace within academic research, including the study of student engagement and academic success (Kuh et al., 2008;

Gordon et al., 2008; Carini, et al., 2006; Robbins, Lauver, Le, David, Langley, \& Carlstrom, 2004).

\section{Graduation \& Degree Completion}

Whether it is used as a noun or verb, the word graduate represents the successful completion of some type of training, making it a natural measure of student achievement (Lexico Dictionary, n.d.). In fact, graduation is generally the goal of college, and to do so is to have achieved one's academic goal. Graduation is also related to GPA, the other 
commonplace measure of academic achievement (Cabrera et al., 2005). Graduation can be considered a measure of academic achievement because it is not a foregone conclusion for the students pursuing it. Studies vary somewhat in their findings on graduation rates, but the general range is one-third of first-time degree seekers graduating within four years, and just over half (about 56\%) completing their degree within six years (Berkner \& Choy, 2008; Shapiro, Dundar, Huie, Wakhungu, Bhimdiwala, \& Wilson, 2019; National Center for Education Statistics, 2019b).

\section{Engagement \& Achievement}

Since the 2000-2001 school year (the first-year that the NSSE was used), the average cost (tuition, fees, and room and board) of one year at a 4-year institution in the United States have risen from $\$ 17,909$ to $\$ 26,593$ in the $2016-2017$ school year (National Center for Education Statistics, 2019c). With the cost of tuition rising so rapidly, and the issue of student loan debt increasingly becoming part of societal discourse, the need for indicators of academic program quality has become more important. As has been discussed, student engagement has become one of the key indicators of program quality. These measures of engagement are meant to measure quality by measuring good teaching and institutional practices. If an institution and its faculty use good practices, then this should result in greater rates of student success (Pike, Kuh, \& McCormick, 2011). This assumption raises the question: "Does data support the existence of a relationship between student engagement and student academic achievement?"

Much of the available research provides evidence that supports the relationship between engagement and both GPA and degree attainment (Brown \& Burdsal, 2012; Carini et al., 2006; Conway et al., 2011; Ethington \& Horn, 2007; Fuller et al., 2011; 
Gordon et al., 2008; Hu \& Kuh, 2002; Kuh, 2001; Kuh et al., 2007; Kuh et al., 2008; Pike et al., 2008; Russell, Hancock, \& McCullough, 2007; Svanum \& Bigatti, 2009; Zhou, 2010). The NSSE benchmarks (Carini et al., 2006; Fuller et al., 2011; Gordon et al., 2008; Kuh, 2001; Pike et al., 2008), NSSE total score (Zhou, 2010), individual NSSE items (Kuh, 2009; Kuh et al., 2008; Pascarella \& Terenzini, 2005), as well as other measures of engagement (Brown \& Burdsal, 2012; Svanum \& Bigatti, 2009), have all been found to be related to academic performance. Fewer studies have examined the relationship between engagement and likelihood of graduation. Despite this, a number of studies have found a relationship between the two (Astin, 1993; Brown \& Burdsal, 2012; Hood, 2014; Kuh, 2009; Kuh et al., 2006; Pascarella \& Terenzini; 2005; Russell, et al., 2007; Svanum \& Bigatti, 2009; Tinto, 1987). These relationships are explored in the following section.

There has also been research and researchers that have called into question the relationship between engagement and achievement. Some researchers point to weak predictive values of engagement for academic achievement in studies that have been used as evidence for the existence of the relationship (Carini et al., 2006; Dexter, 2015; Gordon et al., 2008). Other studies did not find relationships between NSSE benchmarks and GPA (Bowden, 2014; Schlinsog, 2010; Zhou, 2010). Some research has even indicated that co-curricular activities may even be inversely related to GPA (Miller \& Kerr, 2002; Furr \& Elling, 2000), or that there is a curvilinear relationship between the variables (Kuh et al., 2008). Despite this, the majority of the research does indicate that increases in engagement, at least as it is measured by the NSSE, is related to increases in GPA and likelihood of graduation. 
The Relationship between Engagement and GPA

The most common variable studied in the research literature on NSSE engagement and academic achievement is GPA. As participants are asked to provide their GPA as part of the NSSE instrument, estimated GPA is readily available for comparison engagement variables, benchmarks, indicators, and other item groupings. The following review is used to examine the relationships between GPA and the following types of engagement: academic challenge and practices, learning with peers, experiences with faculty, enriching experiences, and campus environment.

Each of these types of engagement is a synthesis of a previous NSSE benchmark, a current NSSE engagement indicator, as well as variables that are related, but may not be technically included in the benchmark or indicator. Academic Challenge \& Related Practices includes the Level Academic Challenge benchmark (previous NSSE version), Academic Challenge engagement indicator (current NSSE version), and related variables. Learning with Peers includes the Active and Collaborative Learning benchmark (previous NSSE version), Learning with Peers engagement indicator (current NSSE version), NSSE items related with peer engagement, and other related items. Experiences with Faculty includes the Student-Faculty Interaction benchmark (previous NSSE version), Experiences with Faculty engagement indicator (current NSSE version), and other research examining the student achievement outcome changes as the result of interaction with faculty members. Enriching Experiences includes the Enriching Educational Experiences benchmark (previous NSSE version) and other related variables. Campus Environment includes the Supportive Campus Environment benchmark (previous NSSE version), Campus Environment engagement indicator (current NSSE version), and related 
items. An important note is that there may be some unintentional overlap between the areas listed above. This was unavoidable with the shift from the benchmark to the engagement indicator system, as some subtopics have been rearranged and do not consistently fit into the same categories.

\section{Academic Challenge \& Related Practices}

Academic Challenge and practices encompass the frequency of student experiences with higher-order learning, reflective and integrative learning, quantitative reasoning, various learning strategies, time spent preparing for class, reading assignments, and writing assignments. Much of the existing research provides evidence for a relationship between student GPA and these variables. A positive relationship has been found for both the Level of Academic Challenge benchmark (Carini et al., 2006; Fuller et al., 2011; Fursman, 2012; Gamm, 2011; Gordon et al., 2008; Khaira, 2016; Kuh, 2002; Rugutt \& Chemosit, 2005), as well as a number of the individual variables.

Research indicates that higher scores on the Level of Academic Challenge benchmark (LAC) are more important for first-year than senior student GPA. In fact, several of the studies found a relatively weak positive relationship between LAC and GPA, which was only statistically significant for first-year students; senior students' GPA was not related to their LAC score (Fuller et al., 2011; Fursman, 2012; Gordon et al., 2008). The weak positive relationship between LAC and first-year GPA has held true when controlling for ACT and high school GPA (Fursman, 2012) with Canadian nursing students (Khaira, 2016) and with Georgia Tech students (Gordon et al., 2008). Previous research has typically found general, less specific support for this relationship, although 
the correlations tend to be weak (Carini et al., 2006; Gamm, 2011; Kuh, 2002). While this correlation is generally weak, as LAC scores increase, GPA scores increase also.

Students who spend more time in class preparation activities, such as studying, homework, writing papers tend to have higher GPAs (Astin, 1993; Hyatt, 2011; Kuh, 1995; Kuh et al., 2007; Kuh et al., 2008; Pascarella \& Terenzini, 2005; Salamonson, Andrew, \& Everett, 2009; Tross, Harper, Osher, \& Keidinger, 2000; Webber, Krylow, \& Zhang, 2013). Overall, studying was the most common variable indicated as being important for GPA amongst these studies. In a study by Kuh and colleagues (2008), studying 21 or more hours per week was a stronger predictor of GPA than studying 6 to 20 hours per week. In further support of these findings, students who came to class without completing course requirements were more likely to have a lower GPA (Fiorini, Shepard, Liu, \& Ouimet, 2014). While almost all the above studies agree that studying is important for a good GPA, Salmonson and colleagues (2009) found that studying was not a significant factor for predicting GPA. Instead, homework completion and class attendance were the two significant predictors of academic performance, with homework completion being most important.

Several other variables fit into the group that research has also found to be related to GPA. Students more likely to worker harder than they thought they could to meet the course instructor's expectations were also more likely to have higher GPA scores (Fauria \& Fuller, 2015; Fiorini et al., 2014). LaNasa and colleagues (2007) also found that the frequency of using critical thinking and application skills within coursework was positively related to GPA; as the use of these types of learning increased, so did a student's GPA. In a study of Washington University students using his own measures of 
engagement, Bono (2011) found that student engagement was a significant predictor of GPA for both first-year and upper-class students.

Evidence Against Academic Challenge

At least one study has found evidence that directly contradicts several of the above findings. Students who found their academic work more challenging, had poorer GPA scores. Ways in which these students found their academic work more challenging were that they found exams more challenging, reported more homework that took more than one hour to complete, and spent more time studying. Students who found exams and their academic requirements less challenging tended to have better GPA scores (Fiorini et al., 2014).

\section{Learning with Peers}

As numerous research studies have concluded, the importance of engaging with peers and active involvement in learning practices are key pieces to academic achievement for college and university students (Astin, 1993; Carini et al., 2006; Conard, 2006; DeBard \& Sacks, 2011; Fauria \& Fuller, 2015; Fiorini et al., 2014; Fuller et al., 2011; Gordon et al., 2008; Hawkins, 2010; Kuh, 2002; Kuh et al., 2007; Kuh et al., 2008; Long, 2012; Ullah \& Wilson, 2007; Webber et al., 2013; Yin \& Lei, 2007; Zacherman \& Foubert, 2014). Peer and active learning engagement exist in many forms but has typically been examined in the research literature as general categories of interaction with peers. More specifically, much of the research has focused on the Active and Collaborative Learning benchmark, co-curricular activities, fraternities and sororities, and other social interaction. 
Active and Collaborative Learning

Researchers disagree on whether first-year or senior students' GPA scores were most effected by Active and Collaborative Learning (ACL). Fuller and colleagues (2011) found that higher ACL scores were related to higher GPAs for senior students only. In contrast, Gordon and colleagues (2008) found that ACL scores were not related to senior student GPAs, but instead were positively related to the GPA scores of first-year students. Both studies only found weak relationships, but the difference may lie in that the Fuller study looked at data across many institutions, while the Gordon study looked at many years of data from Georgia Tech. These more recent studies had found conflicting evidence to previous research, which had found links between ACL scores to the GPAs of both first-year and senior students (Carini et al., 2006; Kuh, 2002). Individual active and collaborative items positively related to GPA include tutoring other students, making class presentations, class attendance, and contributing to the class through discussions and questions (Conard, 2006; Fauria \& Fuller, 2015; Fiorini et al., 2014; Ullah \& Wilson, 2007).

Co-Curricular Activities with Peers

The relationship between involvement in co-curricular activities and GPA is likely nonlinear. Several studies have presented evidence that increased time spent engaged in co-curricular activities is harmful to student achievement, distracting them from their academic work (Kuh et al., 2007; Kuh et al., 2008; Yin \& Lei, 2007). Even in these studies, there is evidence of a curvilinear relationship. Kuh and colleagues (2008) found that first-year student GPA was only harmed after engaging in co-curricular activities for more than five hours per week. The results of Zacherman and Foubert's 
(2014) study support this, showing the most benefit from co-curricular involvement is from one to five hours per week. In amounts greater than five hours per week, cocurricular activities had a negative relationship with GPA. It is worth noting, however, that only two time groupings had lower GPA scores than zero hours per week: 21-25 and over 30 hours per week. Therefore, students do benefit from co-curricular involvement, just less so after passing five hours per week. In addition, men seemed to benefit less from participation, and their GPAs were harmed more than those of women as their participation increased (Zacherman \& Foubert, 2014). Other research indicates that one's role in student organizations matters regarding this relationship. GPA scores were highest for those in leadership positions of student organizations, with members having higher GPAs than non-members (Hawkins, 2010).

Other Social Interaction

Students that engaged in study, other academic activities, and social activities tend to have more academic success and higher grades (Astin, 1993; Webber et al., 2013). Specific social activities, such as those simply for relaxation and socialization, appear to have a negative correlation with GPA (Fiorini et al., 2014; Hyatt, 2011; Kuh et al., 2007). First-year students, and students spending more time on social media seem particularly vulnerable to this relationship (Hyatt, 2011; Kuh, et al., 2007).

\section{Experiences with Faculty}

Despite students generally having very few opportunities to interact with faculty (Alderman, 2008; Anaya \& Cole, 2001; Cotton \& Wilson, 2006; Keup, 2007), the interactions that students do have, have a plethora of benefits. Students enjoy better learning (Weaver \& Qi, 2005), have more comfortable class participation (Weaver \& Qi, 
2005), have increased likelihood of advanced study (Gordon et al., 2008), have greater likelihood of employment upon graduation (Gordon et al., 2008), and have greater satisfaction with college or university (Kuh \& Huh, 2001). In addition to these benefits, numerous studies have found that students' academic achievement increases with more frequent interactions with faculty (Anaya \& Cole, 2001; Astin, 1993; Carini et al., 2006; Cole, 2010; Delaney, 2008; Gordon et al., 2008; Hern, 1987; LaNasa et al., 2007; Pascarella \& Terenzini, 2005; Rugutt \& Chemosit, 2005; Sax et al., 2005; Ullah \& Wilson, 2007).

The benefit of frequent faculty interactions to GPA has been found for both firstyear (Hearn, 1987) and senior students (Gordon et al., 2008). In the Gordon and colleagues (2008) study, faculty interaction was only one of two engagement benchmarks that significantly predicted for GPA. In other studies, student-faculty interaction has been one of the best predictors of student GPA (Carini et al., 2006; Rugutt \& Chemositt, 2005). Perceived approachability of faculty, as well as interactions with bilingual faculty have also been found to have positive relationships with academic achievement (Komarraju, Musulkin, \& Bhattacharya, 2010).

\section{Enriching Experiences}

As a whole, the research literature has found little support for a relationship between academic achievement and the Enriching Educational Experiences (EEE) benchmark (Fursman, 2012). However, there is some evidence that GPA is related to EEE. Khaira (2016) found that EEE had the strongest relationship with GPA of any of the NSSE benchmarks. The sample of this study consisted of nursing students, which may explain why it has found a stronger link between EEE and academic performance than 
other research in this area. Most of the support in the literature is for individual practices that fit within the Enriching Experiences benchmark. Participating in volunteer work (Fiorini et al., 2014), integration of diversity into coursework (Carini et al., 2006), participating in community projects as part of a course (Fauria \& Fuller, 2015), and participating in learning communities (Andrade, 2007; Zhao \& Kuh, 2004) have all emerged as significant predictors of academic performance. Beyond the EEE benchmark, participating in spiritual activities and learning communities have also been shown to have a positive relationship with academic performance (Fiorini et al., 2014).

Other findings appear to challenge the positive impact of EEE variables on academic achievement. In one study, lower GPA scores were related to an increased frequency in having discussions with students with diverse backgrounds and incorporating diverse perspectives into class assignments. The same study also found that more frequent use of technology as part of class assignments was related to reduced academic performance (Fiorini et al., 2014).

\section{Campus Environment}

Students benefit academically from a supportive campus environment and from good relationships with administration and staff members at their college or university. Several studies have found significant positive relationships between the Supportive Campus Environment (SCE) benchmark with GPA (Carini et al., 2006; Fursman, 2012; Gordon et al., 2008; Korobova \& Starobin, 2015). In two of these studies, SCE was the best NSSE benchmark predictor of academic performance (Fursman, 2012; Korobova \& Starobin, 2015). Evidence indicates that having a supportive campus is most important for senior students, who in some studies, saw benefits to their GPAs from this support 
while first-year students did not (Fursman, 2012; Gordon et al., 2008). In both of these studies the SCE was the only benchmark that significantly predicted for GPA. According to Korobova and Starobin (2015), SCE is beneficial for both international and American students. Other findings indicate that students who are struggling academically benefit more from a supportive campus than their peers (Carini et al., 2006). Within SCE, the quality of student relationships with people in administrative and staff positions are also related to academic performance (Carini et al., 2006; LaNasa et al., 2007). Findings from a more recent study seem to contradict these earlier studies, indicating that these good relationships were actually related to lower GPA scores (Fiorini et al., 2014).

\section{Engagement Factors Inversely Related to Achievement}

An area of non-student engagement that is measured by the NSSE and appears frequently in the engagement-achievement literature is working for pay. Research has shown that as hours working for pay off campus increase, academic performance decreases (Fiorini et al., 2014; Kuh et al., 2007). Other research has indicated that this relationship may not be linear and may be related to where one works. Pike and colleagues (2008) found that students working up to 20 hours per week on campus had the highest GPA scores, and students who did not work for pay were the second highest GPA group. Other variables related to poor GPA scores included a longer commute to class and managing non-academic responsibilities (Fiorini et al., 2014).

The Relationship between Engagement and Graduation

Compared with GPA, few studies have examined the relationship between student engagement and graduation statistics. Despite this limitation, a survey of the existing research indicates that increased engagement is related to an increased likelihood of 
graduation (Astin, 1993; Brown \& Burdsal, 2012; Hood, 2014; Kuh, 2009; Kuh et al., 2006; Pascarella \& Terenzini; 2005; Russell, et al., 2007; Svanum \& Bigatti, 2009; Tinto, 1987). More engaged students also have a greater probability of graduating earlier (Svanum \& Bigatti, 2009) and on-time (Fiorini et al., 2014) than those with lower engagement scores. In an examination of the NSSE benchmarks on African American students, Hood (2014) found that ACL significantly predicted for whether or not a student would graduate in six years from beginning their degree. SFI and EEE approached significance (<.09). This finding was inconsistent with a previous study, in which LAC (but not ACL) was found to significantly predict for likelihood of graduating with six years (Pike, 2013). This inconsistency may be due to the fact that Pike (2013) did not limit his sample to African American students.

Individual engagement variables have also been linked to graduation. Having higher quality relationships with peers was related to an increased likelihood, and shorter time needed for degree completion (Brown \& Budsal, 2012; Fiorini et al., 2014). Similarly, participation in co-curricular activities was related to four-year graduation (Fiorini et al., 2014). Counter-intuitively, Fiorini and colleagues (2014) found that students with better relationships with faculty were increasingly likely to need additional time to graduate. Fiorini and colleagues (2014) also found that working harder than one thought possible to meet faculty expectations, writing more papers five pages or longer, studying a foreign language, and participating in international study were all related to on-time graduation. Other research has also linked participation in undergraduate research with increased probability of graduation (Russell et al., 2007). Kuh (2009) even suggests that increased engagement can have a disproportionately positive impact on 
students from lower income families, increasing the likelihood that they will complete college at a greater rate than the increase seen for their peers.

Some evidence suggests that engagement is not related to graduation, or that certain types of engagement are actually related to a decreased likelihood of on-time graduation. For example, Schlinsog (2010) did not find a significant relationship between the NSSE measures of engagement and probability of graduation. Student engagement activities such as preparing for class, greater perceived challenge of exams, conversing with people of diverse backgrounds, and discussing course content with others increased the time necessary for graduation (Fiorini et al., 2014). Non-academic behaviors that increased time to graduation included caring for dependents and working for pay on or off campus (Fiorini et al., 2014).

Student Differences, Student Engagement, and Achievement

A portion of the existing research on the relationship between student engagement and both GPA and graduation has been directed towards, or at least interested in, determining if this relationship changes depending on student demographic characteristics. The majority of this research has been interested in racial and ethnic differences, while others have focused on gender, low performing students, low-income students, and first-generation students.

Low performing, first generation, low-income students all appear to benefit disproportionately from student engagement (Carini et al., 2006; Kuh et al., 2008). First generation and low-income first-year students had better grades and were more likely to return for their sophomore year when they were engaged in more educationally purposeful activities (Kuh et al., 2008). Kuh notes that higher levels of engagement seem 
to have helped compensate for lower grades and greater attrition rates generally seen for these groups. Carini and colleagues (2006) found a stronger correlation between engagement and GPA for lower performing students (as measured by SAT performance), indicating that they benefitted more from engagement (supportive campus environment and quality peer relationships) than their higher performing peers did. This difference was even larger for GRE scores, with lower performing students benefitting even more from engagement when taking the GRE (Carini et al., 2006). Further research has supported this, finding that lower performing students that engaged in more educationally purposeful activities saw an increase in their GPA scores relative to their higher performing peers (Kuh et al., 2008).

Male and female students both benefit from greater engagement (Sax et al., 2005). Russell and colleagues (2007) found that both men and women were more likely to graduate after participating in research with faculty. Some research shows that female students interact with faculty members more frequently, and that while both men and women benefit from this interaction, male students' GPA benefits more with increased faculty interaction outside the classroom. Men also had greater GPA increases with general faculty support. Increased faculty interactions were related to higher levels of reported emotional, physical, and academic well-being in women (Sax et al., 2005).

\section{Race \& Ethnicity}

One area of significant attention in student engagement differences is race and ethnicity. This is important because if engagement is related to academic performance and graduation, then minority students, in general, stand the most to gain from greater student engagement. With the exception of Asian students, minority students tend to have 
lower grades and graduation rates (de Brey et al., 2019; Greene et al., 2008). There is little agreement about whether minority students are more or less engaged than white students, with some research indicating minority students are more engaged (Greene et al., 2008), and other research indicating that they tend to be less engaged (Pascarella \& Terenzini, 2005). However, Black, Hispanic, and Asian students tend to earn higher grades when they are engaged in co-curricular activities (Fischer, 2007). Research has also consistently shown that minority students who interact with faculty more frequently have significantly higher GPA scores (Anaya \& Cole, 2001; Kuh \& Hu, 2001; Hylton, 2013). The problem, as Anaya \& Cole (2001) point out, is that student-faculty interaction is generally infrequent. Research conducted more recently shows students experience academic gains as a result of greater engagement, regardless of racial/ethnic group (Fursman, 2012).

\section{Black \& African American Students}

The majority of available research on the relationship between student engagement and achievement for minority students has focused on Black and African American students. Regarding the use of the terms Black and African American, I have remained true to their use in each individual study. I have simply used Black when describing studies that use the term Black, and African American when describing studies that use the term African American. Greene and colleagues (2008) found that African American students were more engaged than their White peers but were not as successful academically. Greene postulates the existence of what he calls an Effort-Outcome Gap (EOG). The EOG may exist because African American students have to overcome a greater number of barriers to access postsecondary education, meaning that they have to 
work harder to persist and succeed academically. Because of the existence of these barriers, engagement then may not translate to the same academic success enjoyed by other groups with fewer barriers to access. Alternatively, it is possible that the most engaged African American students persist long enough to be sampled, or that they have a different understanding of engagement as compared to their peers (Greene et al., 2008). Another issue could be over-involvement. Guiffrida (2004) notes that low achieving African American students are more likely to be over involved in student organizations, to the point their involvement interfered with their academic performance, as compared with high achieving African American students.

HBCUs and PWIs. Another element in understanding this relationship is the type of institution a student is attending. For example, African American students attending Historically Black Colleges and Universities (HBCUs) tend to have higher engagement scores and GPAs than African American students attending Predominately White Institutions (PWIs; Gamm, 2011). One prominent difference is that African American students report a higher frequency of interaction with faculty, more feedback from faculty, greater interest from faculty in their development, and interaction with peers (Gamm, 2011). Minority students attending PWIs also tend to enjoy greater academic success when they have a greater frequency of interaction with faculty (Hylton, 2013). Despite the increased frequency and quality of faculty interactions at HBCUs, some research indicates no difference in African American graduation rates after six years between HBCUs and PWIs (Gamm, 2011). This may be the result of HBCUs accepting a greater number of first generation and lower income students (Nichols \& Evans-Bell, 2017; Richards \& Awokoya, 2012). Interestingly, for Black men attending PWIs, no 
relationship was found between engagement scores and GPA (Bowden, 2014). Also noteworthy, however, is that Bowden (2014) did not find a relationship between engagement and academic performance for any racial or ethnic group.

Male students. Of particular concern is the academic achievement of Black male students. The graduation rate for Black men is currently $34 \%$, as compared to $44 \%$ for Black women, and a $57 \%$ overall graduation rate for men (National Center for Education Statistics, 2019d). Similar to the general population, increased engagement is related to greater likelihood of academic success for African American men (Harper 2012;

Strayhorn, 2008). Involvement in student organizations and supportive relationships with faculty and their peers have both been linked to greater levels of academic achievement (Strayhorn, 2008). The lack of supportive relationships may leave Black men without a sense of belonging, which further harms their opportunities for academic success (Strayhorn \& DeVita, 2010). According to Harper (2012), academic institutions have a responsibility to promote the student engagement and success of African American men. When such initiatives and systems exist, the achievement of these students improves as a result (Bush \& Bush, 2010).

Support for Conceptual Framework and Statistical Model Analyses

Since its introduction, the general concepts and relationships included in the I-EO Model have been tested by numerous researchers and have been supported. There is an abundance of evidence that a student's student engagement is related to his/her GPA and degree completion. There is also evidence of mostly weak and moderate relationships between the engagement indicators. While much of this was discussed throughout the 
literature review, it is summarized here as support for the conceptual framework and the data analysis proposed for this study.

\section{Engagement, GPA, \& Degree Completion}

Many studies have linked educational outcomes with the inputs and educational environment. Two of these outcomes are GPA and degree completion. While more studies have been completed and found evidence supporting the relationship between GPA and engagement, a number of studies have also supported the relationship between degree attainment and engagement (Brown \& Burdsal, 2012; Carini et al., 2006; Conway et al., 2011; Ethington \& Horn, 2007; Fuller et al., 2011; Gordon et al., 2008; Hu \& Kuh, 2002; Kuh, 2001; Kuh et al., 2007; Kuh et al., 2008; Pike et al., 2008; Russell, Hancock, \& McCullough, 2007; Svanum \& Bigatti, 2009; Zhou, 2010).

A large number of engagement variables have been positively related to GPA. Preparing for class, such as completing homework, papers, and studying, is related to higher GPA scores (Astin, 1993; Hyatt, 2011; Kuh, 1995; Kuh et al., 2007; Kuh et al., 2008; Pascarella \& Terenzini, 2005; Salamonson, Andrew, \& Everett, 2009; Tross, Harper, Osher, \& Keidinger, 2000; Webber, Krylow, \& Zhang, 2013). Engaging in learning experiences with peers has been related to higher academic achievement (Carini et al., 2006; Conard, 2006; Fauria \& Fuller, 2015; Fiorini et al., 2014; Fuller et al., 2011; Gordon et al., 2008; Kuh, 2002; Ullah \& Wilson, 2007). Peer involvement is not all positive, however, as research generally suggests that engaging in co-curricular activities is related to lower levels of achievement (Astin, 1993; Grubb, 2006; Kuh et al., 2007; Kuh et al., 2008; Pascarella \& Terenzini, 2005; Yin \& Lei, 2007). Similar to engaging in learning with peers, interacting with faculty has been found to be related to academic 
achievement (Anaya \& Cole, 2001; Astin, 1993; Carini et al., 2006; Cole, 2010; Delaney, 2008; Gordon et al., 2008; Hern, 1987; LaNasa et al., 2007; Pascarella \& Terenzini, 2005; Rugutt \& Chemosit, 2005; Sax et al., 2005; Ullah \& Wilson, 2007). Students who find their college or university to have a supportive campus atmosphere also tend to have higher GPA scores (Carini et al., 2006; Fursman, 2012; Gordon et al., 2008; Korobova \& Starobin, 2015).

In general, the research evidence indicates that the most important areas of engagement in predicting student achievement are those in the NSSE area of Academic Challenge as well as Experiences with Faculty. Academic Challenge could be considered a core of student engagement as it attempts to directly measure students' engagement with their course material. Within Academic Challenge, Learning Strategies is likely one of the best predictors, as it requires engagement with course material outside of class that is initiated by the student themselves. Higher-Order Learning as well as Reflective and Integrative Learning appear to be good predictors as well. These indicators provide information on students' mental engagement with their course material, and therefore are predicted to be an important part of the model predicting GPA. Experiences with Faculty is also important, with evidence that specifically points to Student-Faculty Interaction as a good predictor of student achievement. Based on this relationship, it is predicted that Student-Faculty interaction will predict for student GPA directly and indirectly through the Academic Challenge Engagement Indicators. Similarly, other similar social engagement and teacher interaction indicators such as Supportive Environment, Quality of Interaction, Effective Teaching Practices, and Collaborative Learning are also hypothesized to indirectly predict student GPA as they provide the needed environment 
to better engage academically. The nonspecific nature of the Supportive Environment Engagement Indicator suggests that it will be predictive of all the other social engagement and teacher interaction variables.

Degree completion is related to a number of engagement variables. Students who are more engaged than their peers are also more likely to graduate (Astin, 1993; Brown \& Burdsal, 2012; Hood, 2014; Kuh, 2009; Kuh et al., 2006; Pascarella \& Terenzini; 2005; Russell, et al., 2007; Svanum \& Bigatti, 2009; Tinto, 1987). Better relationships with peers, writing more papers, and working on research as an undergraduate are just some of the variables that are related to degree completion (Fiorini et al., 2014; Russell et al., 2007).

\section{Engagement Indicator Intercorrelations}

There appears to be very little current available research on predicting student success using a SEM to determine the interrelationships between engagement indicators. As such, any model would have to rely on several factors: (1) the existing research on predictors of student academic achievement and degree completion, (2) the conceptual model for predicting student achievement and degree completion, (3) the engagement indicator theme groupings that have been set out by the NSSE, and (4) the correlations between the engagement indicators reported by the NSSE and the existing literature on the predictive value of these indicators for predicting student success.

The existing research discussed within the literature review provides at least some indication that all but one of the Engagement Indicators significantly predicts for student GPA. The exception is Discussions with Diverse Others, which is therefore the only indicator excluded from the model to predict for GPA. Fewer studies and less evidence 
are available on the value of the indicators in predicting for degree completion. As such, the indicators that have shown some promise in predicting degree completion have been included in the degree completion model. The nine included indicators are: Learning Strategies, Higher-Order Learning, Reflective \& Integrative Learning, Quantitative Learning, Collaborative Learning, Student-Faculty Interaction, Effective Teaching Practices, Quality of Interactions, and Supportive Environment.

The conceptual model for this study has been discussed previously and is based on Astin's I-E-O Model. The focus of the current study is on the Environment and Output elements of the model. GPA and degree completion are used to represent the Output in the model, while Environment is represented by the Engagement Indicators. Although Inputs is not a focus of this study, the lack of racial and ethnic diversity in other studies on this topic is an important reason to complete this research with a more diverse sample. Inputs can also be represented by the size and type of the institution, and while most studies on this topic use samples from Carnegie R1 and R2 classifications, this study will not.

The Engagement Indicator themes developed by the NSSE that group the indicators were also considered when developing the hypothesized SEM. These four themes provided recommendations on how the indicators should be grouped. The first theme is Academic Challenge and includes the indicators: Higher-Order Learning, Reflective \& Integrative Learning, Learning Strategies, and Quantitative Learning. The second theme is Learning with Peers and includes Collaborative Learning and Discussions with Diverse Others. The third theme is Experiences with Faculty and includes Student-Faculty Interaction and Effective Teaching Practices indicators. The 
fourth theme is Campus Environment which includes Quality of Interactions and Supportive Environment.

The latest available report on the internal consistency of the NSSE's Engagement Indicators reveals that most of the correlations between the Indicators are weak to moderate. These correlations are also split into groups based on first-year and senior students. In both groups, the strongest correlation exists between Higher-Order Learning (HO) and Reflective \& Integrative (RI) as both are greater than 0.53 . The weakest for first-year students is between Collaborative Learning (CL) and Effective Teaching Practices (ET), and equals 0.148. The weakest for senior students is between CL and Quality of Interactions (QI) and equals 0.080 . Forty of the first-year and forty-one of the senior student engagement indicator intercorrelations were greater than 0.2 (National Survey of Student Engagement, 2017).

\section{Brief Analysis of the Literature}

There is a paucity of current research on the relationship between NSSE outcomes and student academic achievement among small, diverse colleges and universities. Most of the existing research has been done with data from large public institutions that have predominantly White student populations and tend to have Carnegie classifications of R1 or R2, or with data from a large number of schools combined. Also, it is uncommon for researchers to examine the relationship between NSSE outcomes and degree completion. Many of the existing articles are ten or more years old, and as such, examine the previous NSSE benchmarks. New research is needed on the more recently developed NSSE Engagement Indicators. Some of the existing studies have found no relationship between engagement and achievement. Some of the studies that have found a relationship, have 
only found a weak one. Studies also tend to find different areas of engagement as most important for academic performance. Finally, a number of regression models exist for using engagement factors to predict academic achievement; however, there is need for statistical models that examine the interrelationship between engagement factors as they predict for academic achievement. Further research is needed to better understand these relationships, as well as their strengths. 


\section{CHAPTER 3}

\section{METHODOLOGY}

The present study is designed to investigate the ability of measures of student engagement to predict for student GPA and degree completion in a small sample of diverse undergraduate students attending a private university in the United States. The predictor, or independent variables are the measures of student engagement as measured by the NSSE. The criterion, or dependent variables, are GPA and degree completion. Demographic variables gathered for this study include major, highest level of expected education, parents' education, gender, age, international student status, race/ethnicity, housing arrangements, student athlete status, and disability status. The purpose of this chapter is to present information on the study's research design, hypotheses, population and sample, definition of variables, instrumentation, procedures, treatment of data, and data analyses. The researcher is attempting to answer the following research questions: 1) "What, if any, relationships exist between student engagement and academic performance of undergraduate students?" and 2) "What, if any, relationships exist between student engagement and degree completion of undergraduate students?"

\section{Research Hypotheses}

Based on the research question, sub-problems, and literature review guiding this research, two research hypotheses are tested in this study. 
1. The NSSE Engagement Indicators (excluding Discussions with Diverse Others) will significantly predict for academic performance. Below is the hypothesized model that operationalizes the conceptual model. This model depicts the predicted primary and secondary predictors for GPA and their interrelationships as hypothesized by the researcher based on the review of the literature. The model allows the researcher to test the specific ways in which student engagement predicts or does not predict GPA scores. This includes which are the best direct and indirect predictors of GPA.

Figure 4

Academic Engagment \& GPA Hypothesized Model

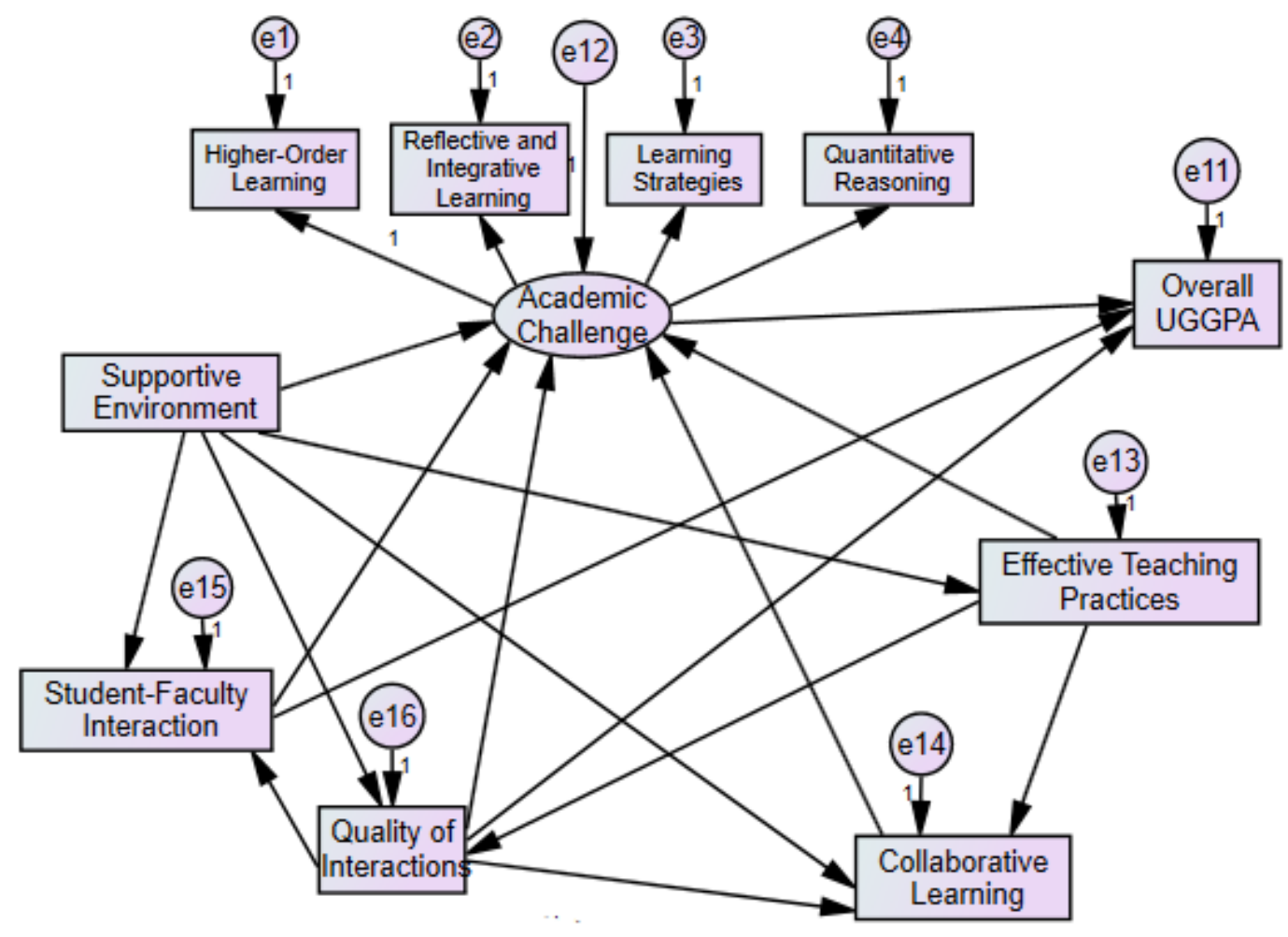

2. NSSE Engagement Indicators Higher-Order Learning, Reflective \& Integrative Strategies, Learning Strategies, Quantitative Reasoning, and Collaborative Learning 
will significantly discriminate between those who complete their degree and those who do not.

Each hypothesis was tested in its null form.

\section{Research Design}

The design of this study is a secondary quantitative analysis of non-experimental descriptive data collected using survey methodology. Secondary analysis occurs when existing data, collected earlier or for a different purpose, is used to answer new questions and analyzed in a new way. The design is ideal for this topic as the required quantitative data has already been collected by Andrews University using the National Survey of Student Engagement (NSSE). The data gathered by the NSSE allows for predictive analysis, which is used in this study.

\section{Population and Sample}

This research study drew its sample from the population of students attending Andrews University. Andrews University is a small private university in southwest Michigan with about three and a half thousand students. The sample for this study consisted of the students who participated in the 2013 and 2015 iterations of the NSSE at Andrews University. The 2013 and 2015 datasets were selected because they can be used in determining the relationship between engagement and degree completion, as these are the only groups of freshmen data available that will have had the opportunity to graduate. In 2013, 103 first-year and 124 senior students completed the NSSE. In 2015, 101 firstyear and 160 senior students completed the NSSE. This provided a total sample of 488 students, or 204 first-year students and 284 senior students. 
The NSSE is only administered every other year at Andrews University (but was not administered in 2017), and the 2013 and 2015 iterations will be used to increase the sample size, as they are the only years with collected data that would have allowed for the first-year students to complete their degree. Cases with missing data on the Engagement Factors were removed. First-year education majors were also removed from the 2015 sample because they require five years to complete their undergraduate degree and therefore would not have had the chance to graduate when this dataset was compiled. After removing both the missing and 2015 first-year education major data, this left 136 total first-year students and 239 total senior students. Removal of cases with missing data did not result in significant changes in demographic, engagement, or GPA data.

Statistical testing indicated that there were no statistically significant differences ( $\mathrm{p} \geq$ $\left..119 ; \eta p^{2}<.019\right)$ between the 2013 and 2015 first-year students on engagement and GPA. This, combined with the relatively small sample of 136 , led the researcher to decide to combine the 2013 and 2015 first-year data. Statistical testing indicated that there were a couple statistically significant differences between the 2013 and 2015 senior students on engagement but had very small effect sizes $\left(\eta p^{2}<.023\right)$. Therefore, the researcher decided to combine the 2013 and 2015 senior student data as well.

\section{Definition of Variables}

The following terms are operationally defined for this study:

1. Academic Performance is measured by participants' actual overall GPA scores as recorded by Andrews University. Overall GPA scores were used because they include all the student's grades (both those earned at Andrews and those transferred in) and because 
of the correlation between Overall GPA and Andrews GPA (first-year students $r=.99, p$ $<.001$; senior students $r=.97, p<.001)$.

2. Degree completion was added to the NSSE dataset by institutional research staff and is assessed by the indication of whether or not each student has completed their degree at Andrews University. For the 2015 first-year student data, education majors were excluded as it takes five years to complete a bachelor's degree in education at Andrews. This data was compiled before the 2015 first-year students would have had a chance to graduate.

3. Higher-Order Learning is defined as the NSSE Engagement Indicator Higher-Order Learning and is measured by [designated] item numbers $22-25$. Items $22-25$ ask about how frequently in the past year the participant's coursework has emphasized applying, analyzing, evaluating, and synthesizing information.

4. Reflective \& Integrative Strategies is defined as the NSSE Engagement Indicator Reflective \& Integrative Strategies and is measured by [designated] item numbers $10-$ 16. Items $10-16$ ask about how frequently in the past year the participant's coursework has emphasized personally connecting course materials to other course, societal issues, and prior knowledge and experience. These items also ask about how frequently the participant's coursework has emphasized considering diverse perspectives, understanding someone else's views, analyzed the strengths and weaknesses of one's own views, and learned something that changed the participant's understanding of an issue/concept.

5. Learning Strategies is defined as the NSSE Engagement Indicator Learning Strategies and is measured by [designated] item numbers $41-43$. Items $41-43$ ask about how frequently in the past year the participant has identified key information from reading 
assignments, reviewed notes after class, and summarized what he/she learned from class or course materials.

6. Quantitative Reasoning is defined as the NSSE Engagement Indicator Quantitative Reasoning and is measured by [designated] item numbers $31-33$. Items $31-33$ ask about how frequently in the past year the participant has used numerical information to reach conclusions, used numerical information to examine a real-world problem, and evaluated others' conclusions on numerical information.

7. Collaborative Learning is defined as the NSSE Engagement Indicator Collaborative Learning and is measured by [designated] item numbers $5-8$. Items $5-8$ ask about how frequently in the past year the participant has asked another student for help in understanding course material, explained course material to another student(s), studied for exams with other students, and worked on group projects.

8. Discussions with Diverse Others is defined as the NSSE Engagement Indicator Discussions with Diverse Others and is measured by [designated] item numbers $37-40$. Items $37-40$ ask about how frequently in the past year the participant has had discussions with people from a different race or ethnicity, economic background, religious beliefs, and political views to one's own.

9. Student-Faculty Interaction is defined as the NSSE Engagement Indicator StudentFaculty Interaction and is measured by [designated] item numbers 17 - 20. Items $17-20$ ask about how frequently in the past year the participant has talked about career plans with faculty, worked with faculty on activities other than coursework, discussed course topics/ideas/concepts with faculty, and discussed one's academic performance with faculty. 
10. Effective Teaching Practices is defined as the NSSE Engagement Indicator Effective Teaching Practices and is measured by [designated] item numbers $26-30$. Items $26-30$ ask about how frequently in the past year the participant's instructors have clearly explained course goals and requirements, taught in an organized way, used examples or illustrations to explain difficult points, provided feedback on a draft/work in progress, and provided prompt and detailed feedback on tests or completed assignments.

11. Quality of Interactions is defined as the NSSE Engagement Indicator Quality of Interactions and is measured by [designated] item numbers $52-56$. Items $52-56$ ask about the quality of the participant's interactions with students, academic advisors, faculty, student services staff, and other administrative staff and offices at his/her institution.

12. Supportive Environment is defined as the NSSE Engagement Indicator Supportive Environment and is measured by [designated] item numbers $58-65$. Items $58-65$ ask about how much the participant's institution emphasizes providing support to help students succeed academically, using learning support services, encouraging contact among students from different backgrounds, providing opportunities to be involved socially, providing support for the participant's overall well-being, helping the participant manage non-academic responsibilities, attending campus activities and events, and attending events that address important social, economic or political issues.

\section{Instrumentation}

The instrument used is The College Student Report (The Report), which is administered as part of the National Survey of Student Engagement (NSSE). This instrument was originally developed in the late 1990s and was first administered in 2000. 
The instrument was developed by a panel of experts as an alternative measure of program quality. The current version launched in 2013, has 84 questions, as well as a number of demographic questions.

All of the questions are self-report Likert-type items, most of which are on a fourpoint scale (ex., very often, often, sometimes, never). Many of these items are grouped into ten engagement indicators, which are then grouped into four engagement themes: Academic Challenge (theme) - Higher-Order Learning, Reflective \& Integrative Learning, Quantitative Reasoning, and Learning Strategies; Learning with Peers Collaborative Learning, and Discussions with Diverse Others; Experiences with Faculty - Student-Faculty Interaction, and Effective Teaching Practices; Campus Environment Quality of Interactions, and Supportive Environment. Some of the remaining items are designated as High-Impact Practices, which include: Learning Community, ServiceLearning, Research with a Faculty Member, Internship or Field Experience, Study Abroad, and Culminating Senior Experience (National Survey of Student Engagement, 2019c). The first section asks participants how frequently they have engaged in various educational practices over the current school year (possible responses: very often, often, sometimes, never). The second section asks how much the participant's coursework has emphasized certain ways of learning over the current school year (possible responses: very much, quite a bit, some, very little). The third section asks participants about how frequently their instructors engaged in certain educational practices over the current school year (possible responses: very much, quite a bit, some, very little). The fourth section asks the participant how frequently he/she has used numerical information in various ways in their learning over the current school year (possible responses: very 
often, often, sometimes, never). The fifth section asks the student how frequently they have written papers of various lengths over the past year (possible response frequency ranges given). The sixth section asks students to indicate how frequently they have had discussions with people of certain groups over the past year (possible responses: very often, often, sometimes, never). The seventh section asks how frequently the participant has engaged in various preparation activities over the current school year (possible responses: very often, often, sometimes, never). The eighth section asks students if they have engaged in, or plan to engage in, various learning opportunities outside the classroom (possible responses: done or in progress, plan to do, do not plan to do, have not decided). The ninth section asks participants about the quality of their interactions with students, academic advisors, faculty, student services staff, and administrative staff (possible responses are 1 through 7 , with 1 being poor and 7 being excellent). The tenth section asks the participant about how much his/her institution emphasizes certain activities, opportunities, and support systems (possible responses: very much, quite a bit, some, very little). The eleventh section asks the student about how many hours he/she spends in a week on various academic and nonacademic activities (possible responses: 0 , 1-5, 6-10, 11-15, 16-20, 21-25, 26-30, 30+). Section twelve asks the participant how much his/her institution has contributed to his/her knowledge, skills, and development in various areas (possible answers: very much, quite a bit, some, very little). The final section before the demographic section of the survey asks about the participant's educational experience, whether they will return, and whether they would choose this institution if they were to start all over (possible responses vary based on the question; National Survey of Student Engagement, 2019f). 
Reliability and validity data on The Report, as well as the report itself, is available on the NSSE website (https://nsse.indiana.edu/nsse/psychometric-portfolio/index.html). The 2013 and 2015 versions of The Report are also available in Appendix A and B of this report. Cronbach's alpha scores by class (first-year \& senior) are reported for both 2013 and 2015 versions, by Engagement Indicator. Cronbach's alpha scores for Higher-Order Learning range from .85-.87, Reflective \& Integrative Learning ranges from .87-.89, Learning Strategies range from .77-.79, Quantitative Reasoning ranges from .85-.87, Collaborative Learning ranges from .80-.82, Discussions with Diverse Others range from .89-.91, Student-Faculty Interaction ranges from .83-.86, Effective Teaching Practices range from .85-.87, Quality of Interactions range from .81-.85, and Supportive Environment is .89 for both years and classes (National Survey of Student Engagement, $2019 \mathrm{~g})$.

Three main areas of evidence for the validity of the 2013 version of The Report instrument include content evidence, response process evidence, and predictive evidence. For the content evidence, a brief review of the literature is provided to support all ten Engagement Indicators. Numerous studies, including analysis of their own data, led the NSSE researchers to make major changes to The Report, which included the development of the ten Engagement Indicators. These changes made the NSSE items and Engagement Indicators to better reflect the content evidence (National Survey of Student Engagement, 2020b).

Response process and predictive evidence are also provided. NSSE researchers conducted cognitive interviews and used focus groups to gather information on the survey items. In cognitive interviews, participants were asked to vocalize their thought 
process while completing the survey. They were later asked to provide examples of the behaviors that they were asked about in the survey. This process helped the researchers understand how participants processed and understood the items, allowing them to adjust the items to best gather the information they were seeking with each item (National Survey of Student Engagement, 2020c). Predictive evidence was provided through research demonstrating the NSSE's ability to predict retention of first-year students. Researchers found a positive relationship between various measures within the NSSE and retention of first-year students (National Survey of Student Engagement, 2020d). Additional and more in-depth information on the validity of The Report can be found on the NSSE website (National Survey of Student Engagement, 2020e).

\section{Procedures}

As a secondary analysis of quantitative data, the sample for this study consisted of the students who participated in the 2013 and 2015 iterations of the NSSE at Andrews University. When the data was collected, the institution collecting the data was responsible for providing participants with informed consent and treating them in an ethical manner. Access to the participants' data was gained by going through the IRB procedures, and requesting that the institutional research department share the data with the primary investigator of this study. Upon completion of the IRB procedures, the IRB approval form was submitted to the institutional research department, along with specific requests for student GPA scores and degree completion to be added to the data. Further confirmation of the need for this data was provided to the institutional research department by members of the dissertation committee. Upon receiving each of these pieces of information, the institutional research department added the GPA and degree 
completion data to the 2013 and 2015 NSSE data sets. They also removed all identifying data from the datasets before it was sent to the primary investigator of this study, in order to maintain confidentiality between the participants and the institution. The data was held on the primary researcher's personal password-protected computer, which only he has access to.

\section{Treatment of the Data}

As the data had already been collected and stored, it was transferred to the primary researcher using a Statistical Package for Social Sciences (SPSS) file in order to minimize the possibility of introducing errors into the dataset. While the data was already reviewed and cleaned by the providing institution, the primary researcher also checked for missing data and outliers using descriptive statistics. Cases with missing data on the Engagement Factors were removed, which resulted in a much smaller sample than had originally existed within the dataset. After removing both the missing and 2015 first-year education major data, this left 136 total first-year students and 239 total senior students. Removal of cases with missing data did not result in significant changes in demographic, engagement, or GPA data. While the format of the instrument does not allow for extreme outliers, and graphing the data confirmed this. There was no need for the primary researcher to do any scoring of the instrument, as the institution providing the data already completed data scoring.

\section{Data Analysis}

The data was analyzed using Structural Equation Modeling (SEM) and discriminant analyses. 
1. In order to test hypothesis 1, a SEM was computed. Academic performance (GPA) served as the endogenous variable, and all of the NSSE Engagement Indicators (excluding Discussions with Diverse Others) served as exogenous variables. This analysis was computed once for the first-year students and once for the seniors $(2013 \&$ 2015 freshman combined, and $2013 \& 2015$ seniors combined).

2. In order to test hypothesis 2, discriminant analyses were computed. Degree completion (whether or not the participant has graduated) served as the dependent variable, and the NSSE Engagement Indicators Higher-Order Learning, Reflective \& Integrative Strategies, Learning Strategies, Quantitative Reasoning, and Collaborative Learning served as independent variables. This analysis was computed two times: once for the first-year students and once for the seniors (2013 \& 2015 freshman combined, and 2013 \& 2015 seniors combined).

\section{Summary}

This chapter described the methodology utilized by this research study. This study investigated the predictive relationship of student engagement with GPA and degree completion. Student engagement and demographic variables were measured by The Report instrument, which is part of the NSSE. GPA and degree completion information were then matched to individual student NSSE scores by the higher education institution and provided to the primary researcher.

The data had already been collected by Andrews University. GPA and degree completion data will be matched by the institution to individual engagement scores and provided to the primary researcher. After receiving the data, statistical analysis was conducted using SPSS Version 25 \& SPSS Amos Version 25 for Windows. 


\section{CHAPTER 4}

\section{DATA ANALYSIS \& RESULTS}

\section{Descriptive Statistics}

After analyzing demographic data on the participants, descriptive statistics for the engagement, graduation, and GPA variables were compiled. Scales for the NSSE Engagement Indicators had a maximum score of 60, and a minimum score of zero. GPA was based on the typical 4-point scale. Degree completion was either zero (did not graduate) or one (graduated).

\section{First-Year Students}

The demographic variables for first-year students are found in Table 1. Within the first-year student group of 136, 23.5\% (32) identified themselves as Asian, $22.1 \%$ (30) as Black or African American, 8.8\% (12) as Hispanic or Latino, 2.9\% (4) as Native Hawaiian or Other Pacific Islander, 33.1\% (45) as White, 7.4\% (10) as two or more races/ethnicities, and 2.2\% (3) did not respond. There were 91 (66.9\%) women and 45 $(33.1 \%)$ men. The largest academic major groupings were $25.7 \%$ (35) in health professions, $20.6 \%$ (28) in biological sciences/agriculture/natural resources, $19.1 \%$ (26) in arts and humanities, $8.1 \%$ (11) in business, and 7.4\% (10) in social sciences. Twenty $(14.7 \%)$ indicated that they had a second major as well. Most of the respondents indicated that they were full-time students $(94.9 \% ; 129)$, were not first-generation students $(75.7 \%$; 103), were not international students $(80.9 \% ; 110)$, were not student athletes $(91.2 \%$; 
124), were not current or former members of the Armed Forces/Reserves/National Guard (97.8\%; 133), did not have a disability or impairment $(87.5 \%$; 119), started school at Andrews University $(83.8 \% ; 114)$, and lived in a dormitory or other campus housing (77.9\%; 106). As for the highest level of education that either one of their parents completed, the largest portion indicated a doctoral or professional degree $(27.9 \% ; 38)$, followed by a Master's degree $(25.0 \%$; 34), Bachelor's degree $(22.8 \% ; 31)$, attended college but did not complete a degree $(8.8 \% ; 12)$, Associate's degree $(8.1 \% ; 11)$, high school diploma $(3.7 \% ; 5)$, did not finish high school $(2.2 \% ; 3)$, and two did not respond. They had an average age of 19.51 years. At the time of this study, they had a current average GPA of 3.47 and $91(66.9 \%)$ had completed their degree. 
Table 1

First-year Student Demographics $(\mathrm{N}=136)$

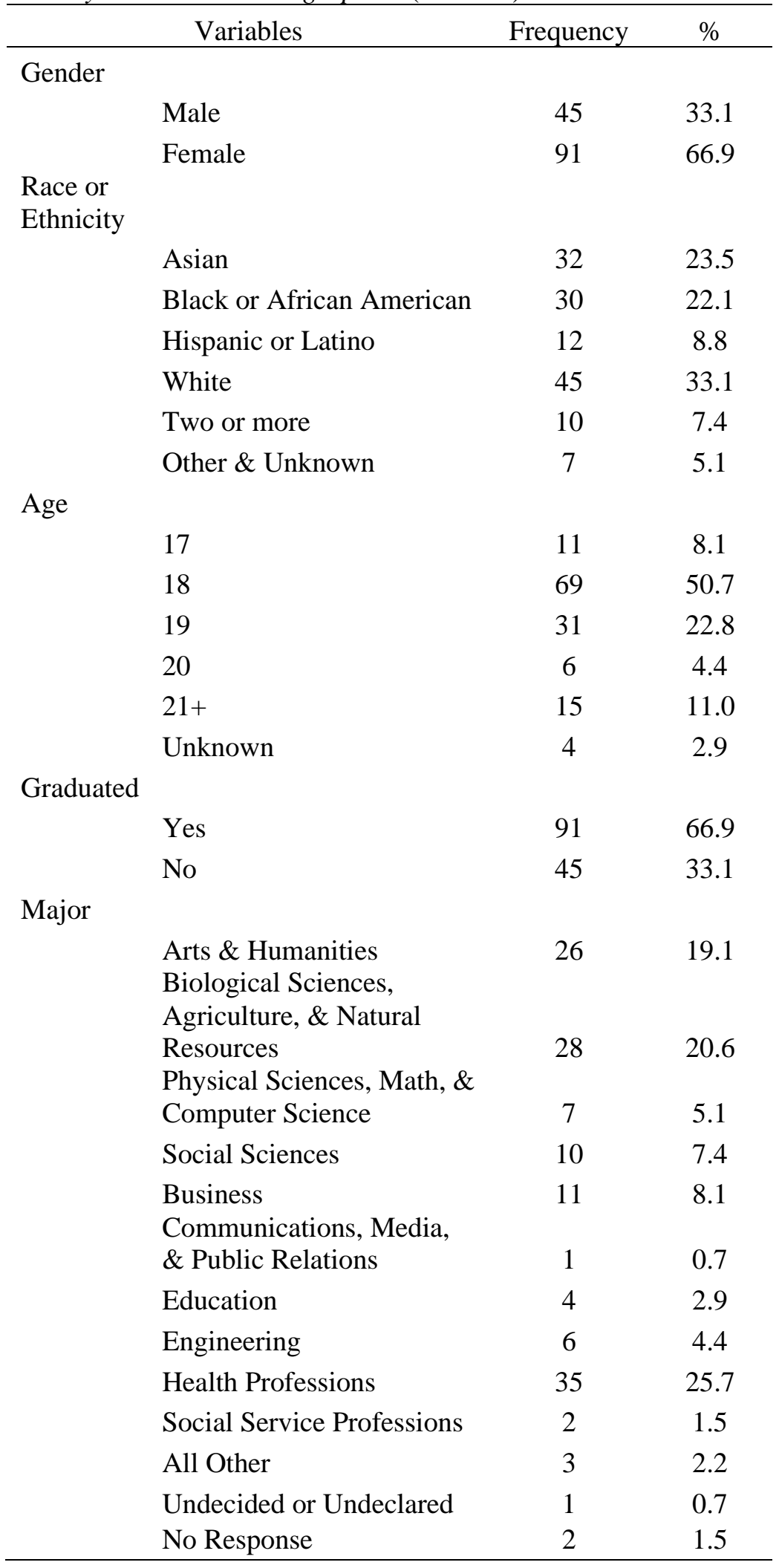




\section{Senior Students}

The senior student demographics are somewhat different those of the first-year students. Within the senior student group of 239, 0.4\% (1) identified as American Indian or Alaska Native, 14.6\% (35) as Asian, 22.6\% (54) as Black or African American, 7.5\% (18) as Hispanic or Latino, $47.3 \%$ (113) as White, 3.8\% (9) as two or more races/ethnicities, and 3.8\% (9) did not respond. There were 148 (61.9\%) women and 91 $(38.1 \%)$ men. The largest academic major groups were $23.8 \%$ (57) in arts and humanities, $21.3 \%$ (51) in health professions, $11.7 \%$ (28) in biological sciences/agriculture/natural resources, $7.5 \%$ (18) in education, $7.5 \%$ (18) in social sciences, $7.1 \%$ (17) in business, and 5.4\% (13) in physical sciences/math/computer science. Forty (16.7\%) indicated that they had a second major. Most of the respondents indicated that they were full-time students $(89.1 \% ; 213)$, were not first-generation students $(67.8 \% ; 162)$, were not international students $(84.9 \% ; 203)$, were not student athletes $(95.0 \% ; 227)$, were not current or former members of the Armed Forces/Reserves/National Guard $(97.5 \% ; 233)$, did not have a disability or impairment $(89.5 \% ; 214)$, started school at Andrews University $(62.8 \% ; 150)$, and lived in a dormitory or other campus housing $(54.8 \% ; 131)$. As for the highest level of education that either one of their parents completed, the largest portion indicated a Bachelor's degree $(27.2 \% ; 65)$, followed by a Master's degree $(20.5 \% ; 49)$, a doctoral or professional degree $(20.1 \%$; 48), high school diploma (12.6\%; 30), Associate's degree $(8.4 \% ; 20)$, attended college but did not complete a degree $(7.1 \% ; 17)$, did not finish high school $(2.9 \% ; 7)$, and three did not respond. They had an average age of 23.44 years. At 
the time of this study, they had a current average GPA of 3.48 and 221 (92.5\%) had completed their degree.

Table 2

Senior Student Demographics $(\mathrm{N}=239)$ Variables

Frequency $\%$

Gender

Male

91

38.1

Female

148

61.9

Race or

Ethnicity

American Indian or Alaska

Native

$1 \quad 0.4$

Asian

35

14.6

Black or African American

22.6

Hispanic or Latino

54

7.5

White

18

47.3

Two or more

113

3.8

Unknown

9

$\begin{array}{ll}9 & 3.8\end{array}$

Age

$$
19
$$

20

3

1.3

21

12

5.0

22

66

27.6

23

63

26.4

24

38

15.9

25

18

7.5

26

5

2.1

$27+$

$\begin{array}{ll}6 & 2.5\end{array}$

Unknown

25

10.5

3

1.3

Graduated

Yes

No

Major

Arts \& Humanities

$221 \quad 92.5$

$18 \quad 7.5$

Biological Sciences, Agriculture, \& Natural

Physical Sciences, Math, \&

Computer Science

$13 \quad 5.4$




\begin{tabular}{lcc} 
Social Sciences & 18 & 7.5 \\
Business & 17 & 7.1 \\
Communications, Media, & 7 & 2.9 \\
\& Public Relations & 18 & 7.5 \\
Education & 9 & 3.8 \\
Engineering & 51 & 21.3 \\
Health Professions & 7 & 2.9 \\
Social Service Professions & 11 & 4.6 \\
All Other & 3 & 1.3 \\
No Response & \\
\hline
\end{tabular}

\section{Engagement Indicators}

Engagement Indicator statistics for first-year students can be found in Table 3 below. Each of these indicator scales range from 0 (lowest possible score) to 60 (highest possible score). Those indicators with scores in the mid and upper thirties indicate somewhat greater student engagement, while those in the upper teens and early twenties indicate somewhat lower student engagement than the middle score of thirty. First-year students highest reported score was Quality of Interactions $(M=39.98, S D=12.72$, skewness $=-.55$, kurtosis $=-.24$, Cronbach's Alpha $=.82)$, which was followed closely by Higher Order Learning $(M=38.75, S D=13.97$, skewness $=-.23$, kurtosis $=-.28$, Cronbach's Alpha $=.84)$ and Learning Strategies $(M=38.52, S D=15.31$, skewness = .18$, kurtosis $=-.79$, Cronbach's Alpha $=.80)$. Following these was Effective Teaching Practices $(M=37.52, S D=12.67$, skewness $=-.48$, kurtosis $=.25$, Cronbach's Alpha $=$ .79), Supportive Environment $(M=36.76, S D=13.17$, skewness $=-.04$, kurtosis $=-.74$, Cronbach's Alpha $=.88)$, Reflective and Integrative Learning $(M=33.90, S D=11.42$, skewness $=.33$, kurtosis $=-.24$, Cronbach's Alpha $=.84)$, Collaborative Learning $(M=$ 31.03, $S D=13.95$, skewness $=.37$, kurtosis $=-.35$, Cronbach's Alpha $=.79)$, 
Quantitative Reasoning $(M=22.41, S D=15.69$, skewness $=-.36$, kurtosis $=-.53$,

Cronbach's Alpha $=.83)$, and Student-Faculty Interaction $(M=19.37, S D=12.61$, skewness $=.67$, kurtosis $=.33$, Cronbach's Alpha $=.78)$. Each of these fell within the normal range on the skewness and kurtosis statistics. GPA $(M=3.47, S D=.58$, skewness $=-2.05$, kurtosis $=6.25$ ) fell outside the normal range for skewness and kurtosis, indicating a negatively skewed and platykurtic distribution. While GPA scores for all students were not available for comparison, the distribution of these scores indicates that this sample was skewed towards higher achieving students. Of these first-year students, $66.9 \%$ (91) had completed their degree by the time this data was collected.

Table 3

Engagement Indicators for First-Year Students

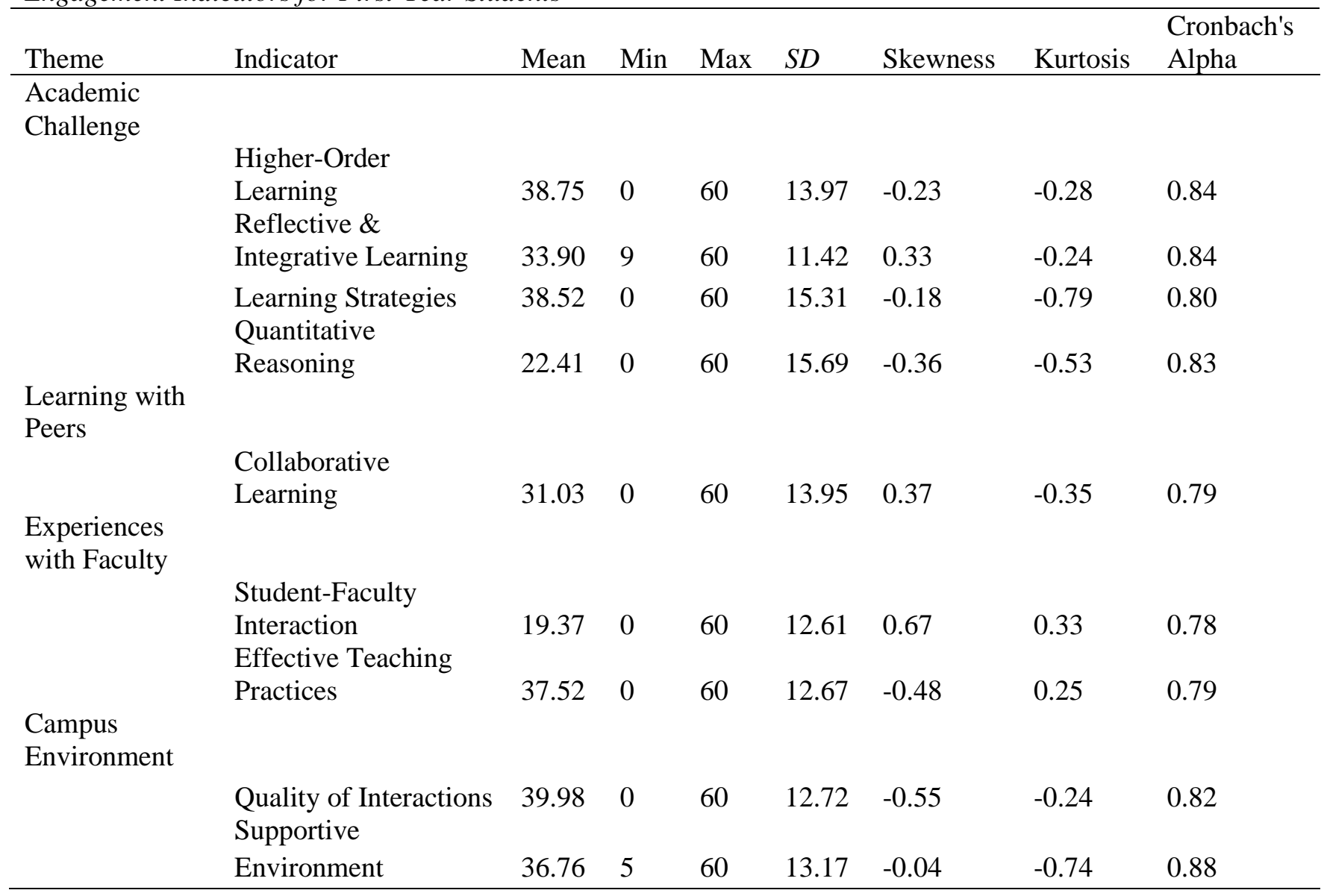


Senior students exhibited a similar pattern in their reporting of engagement, but with generally slightly higher scores, especially in Student-Faculty Interaction (Table 4). Again, each of these indicator scales range from 0 (lowest possible score) to 60 (highest possible score). Those indicators with scores in the mid-thirties and low forties indicate somewhat greater student engagement, while those in the early and mid-twenties indicate somewhat lower student engagement than the middle score of thirty. Quality of Interactions $(M=40.75, S D=11.05$, skewness $=-.51$, kurtosis $=.25$, Cronbach's Alpha $=.73)$ had the highest score, which was followed Higher Order Learning $(M=39.75, S D$ $=14.39$, skewness $=-.25$, kurtosis $=-.86$, Cronbach's Alpha $=.85)$, Effective Teaching Practices $(M=38.29, S D=13.22$, skewness $=-.08$, kurtosis $=-.70$, Cronbach's Alpha $=$ $.85)$, Reflective and Integrative Learning $(M=37.08, S D=12.84$, skewness $=-.03$, kurtosis $=-.37$, Cronbach's Alpha $=.88)$, Learning Strategies $(M=36.94, S D=15.13$, skewness $=-.23$, kurtosis $=-.56$, Cronbach's Alpha $=.76)$, Supportive Environment $(M=$ 33.53, $S D=13.38$, skewness $=.09$, kurtosis $=-.48$, Cronbach's Alpha $=.87$, Collaborative Learning $(M=31.76, S D=13.02$, skewness $=.27$, kurtosis $=-.17$, Cronbach's Alpha $=.76)$, Student-Faculty Interaction $(M=25.15, S D=13.61$, skewness $=.43$, kurtosis $=-.27$, Cronbach's Alpha $=.74)$, and Quantitative Reasoning $(M=23.36$, $S D=16.76$, skewness $=.32$, kurtosis $=-.70$, Cronbach's Alpha $=.86)$. Each of these fell within the normal range on the skewness and kurtosis statistics. GPA $(M=3.46, S D=$ .39 , skewness $=-.57$, kurtosis $=.25)$ fell outside the normal range for kurtosis, indicating a slightly negatively skewed and platykurtic distribution. Similar to the first-year students, the distribution of these GPA scores indicate that this sample was skewed 
towards higher achieving students. Of these senior students, 92.5\% (221) had completed their degree by the time this data was collected.

Table 4

Engagement Indicators for Senior Students

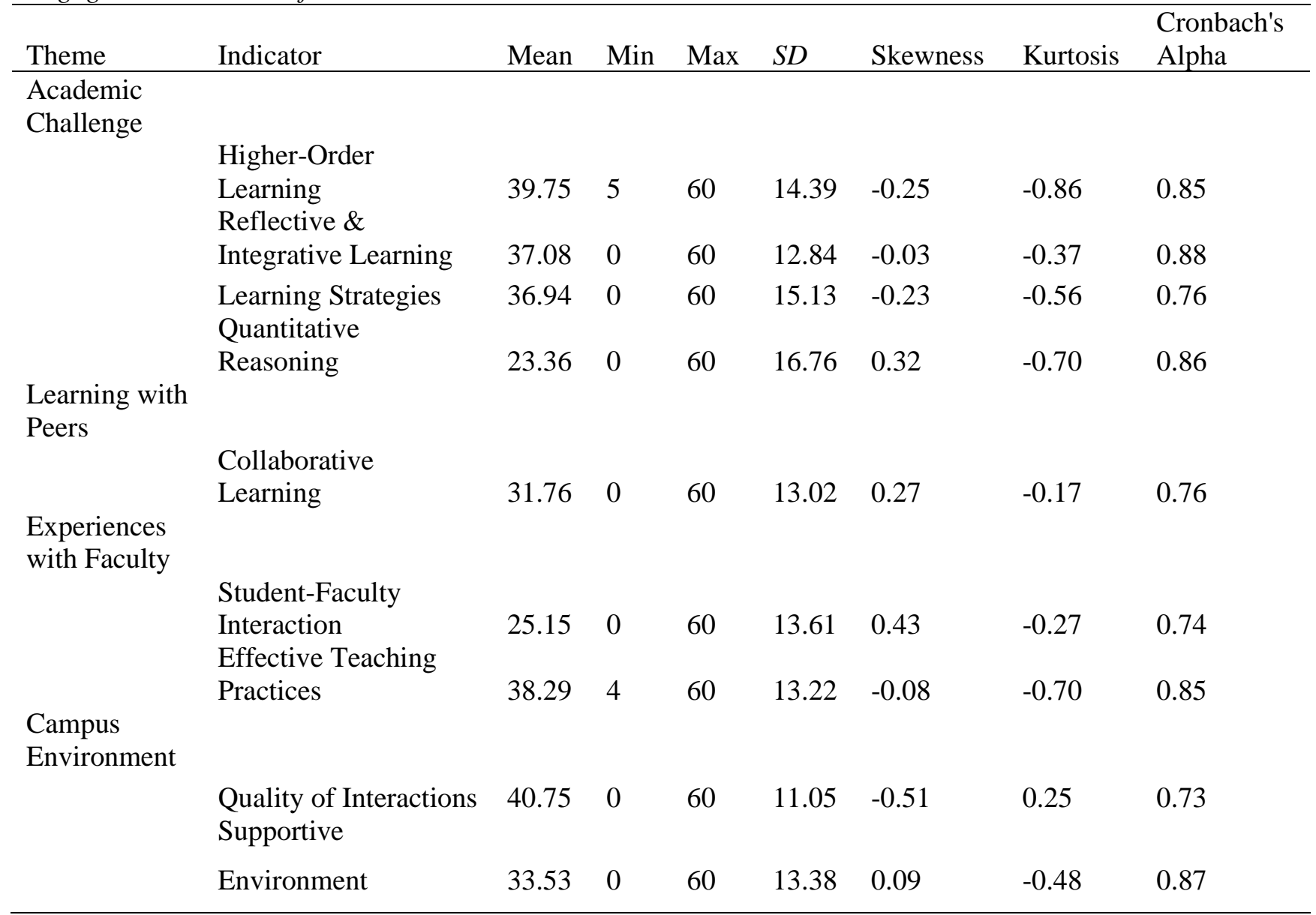

\section{Engagement Indicator Questions}

As previously mentioned, the Engagement Indicators are each comprised of multiple measured items. While the means scores on these items is generally similar between the first-year and senior students, there are some interesting differences as well. All items were measured on a Likert-type scale, with one being the lowest possible score 
and four being the highest possible. The exception to this is the items that are a part of the Quality of Interactions engagement indicator, which uses a seven-point Likert-type scale (one being the lowest and seven being the highest). These measured items are discussed below within each Engagement Indicator.

Higher-Order Learning

The first-year and senior students reported very similar scores on the HigherOrder Learning items (Table 5). On coursework that emphasized applying facts, theories, or methods to practical problems or new situations, first-year students had a mean score of $2.94(S D=.85)$ and seniors had a mean score of $3.10(S D=.83)$, meaning that students in both groups responded with 'often' (reflected by a score of 3) on average. This was the largest difference between the groups and indicated that both groups are somewhat more engaged on this item than the middle score of 2.5. This pattern is also seen with the other Higher-Order Learning items, with a slight drop on the last two. Coursework that emphasized analyzing an idea, experience or line of reasoning in depth by examining its parts first-year students reported a slightly higher mean score $(M=3.05, S D=.83)$ compared with seniors $(M=2.99, S D=.88)$. For coursework emphasizing evaluating a point of view, decision, or information source, seniors $(M=2.94, S D=.87)$ scored slightly higher than first-year students $(M=2.90, S D=.84)$. Finally, senior students $(M=$ $2.92, S D=.87)$ scored slightly higher than first-year students $(M=2.86, S D=.88)$ on coursework emphasizing forming a new idea or understanding from various pieces of information. 
Table 5

Higher-Order Learning Item Comparison: First-Year \& Senior Students

\begin{tabular}{llll}
\hline Item & Standing & Mean & $S D$ \\
\hline Applying facts, theories, or methods & & & \\
& First-Year & 2.94 & 0.85 \\
& Senior & 3.10 & 0.83 \\
Analyzing an idea, experience, or line of reasoning & & & \\
& First-Year & 3.05 & 0.83 \\
& Senior & 2.99 & 0.88 \\
Evaluating a point of view, decision, or information & & & \\
source & & & \\
& First-Year & 2.90 & 0.84 \\
& Senior & 2.94 & 0.87 \\
Forming a new idea or understanding & & & \\
& First-Year & 2.86 & 0.88 \\
& Senior & 2.92 & 0.87 \\
\hline
\end{tabular}

Reflective \& Integrative Learning

Some larger differences in learning between first-year and senior students become apparent within the Reflective \& Integrative Learning items (Table 6). On each item, senior students report higher mean scores, indicating that more of this type of learning is done towards the end of one's undergraduate studies. Senior students $(M=2.79, S D=$ $.86)$ are more likely than first-year students $(M=2.49, S D=.84)$ to combine ideas from different courses when completing assignments. First-year students fall directly between never engaged (represented by a score of 1) and very often engaged (represented by a score of 4) in these activities, while seniors scored somewhat more towards often engaged (represented by a score of 3). This pattern repeats for the following two items. Senior students also score higher in connecting their learning to societal problems $(M=$ 2.67, $S D=.90$; first-years $M=2.48, S D=.86$ ) and in including diverse perspectives in 
course discussions or assignments (seniors $M=2.73, S D=.91$; first-years $M=2.53, S D$ $=.85)$. The highest scores, but smaller differences between the groups, existed in connecting ideas from your courses to your prior experiences and knowledge (seniors $M$ $=3.16, S D=.76$; first-years $M=3.06, S D=.73$ ), trying to better understand someone else's views by imagining how an issue looks from his or her perspective (seniors $M=$ 2.94, $S D=.83$; first-years $M=2.81, S D=.78$ ), learning something that changed the way you understood an issue or concept (seniors $M=2.86, S D=.81$; first-years $M=2.81, S D$ $=.81$ ), and examining the strengths and weaknesses of your own views on a topic or issue (seniors $M=2.84, S D=.83$; first-years $M=2.67, S D=.84$ ). Most of these higher scoring items indicated that both seniors and first-year students were often engaged in these activities. 
Table 6

Reflective \& Integrative Learning Item Comparison: First-Year \& Senior Students

Item assignments Standing

Mean $S D$

First-Year $\quad 2.49 \quad 0.84$

Senior $\quad 2.79 \quad 0.86$

Connected your learning to societal problems or issues

First-Year $\quad 2.48 \quad 0.86$

Senior $\quad 2.67 \quad 0.90$

Included diverse perspectives in course discussions or assignments

Examined the strengths and weaknesses of your own views on a

First-Year $\quad 2.53 \quad 0.85$

Senior

$2.73 \quad 0.91$

topic or issue

$\begin{array}{lll}\text { First-Year } & 2.67 & 0.84 \\ \text { Senior } & 2.84 & 0.83\end{array}$

Tried to better understand someone else's views by imagining how an issue looks from his or her perspective

$\begin{array}{lll}\text { First-Year } & 2.81 & 0.78 \\ \text { Senior } & 2.94 & 0.83\end{array}$

Learned something that changed the way you understand an issue or concept

First-Year $\quad 2.81 \quad 0.81$

Senior $\quad 2.86 \quad 0.81$

Connected ideas from your course to you prior experience and knowledge

First-Year $\quad 3.06 \quad 0.73$

Senior $\quad 3.16 \quad 0.76$

\section{Learning Strategies}

With only three measured items, first-year and senior students had similar scores on two of the Learning Strategies items (Table 7). First-year and senior students reported the greatest likelihood of identifying key information from reading assignments (seniors $M=3.19, S D=.84$; first-years $M=3.16, S D=.80$ ). These groups also are equally likely to summarize what they learned in class or from course materials (seniors $M=2.76, S D=$ 
.95 ; first-years $M=2.77, S D=.96)$. A surprising difference was reported between these groups on their likelihood to review their notes after class, with first-year students reporting reviewing their notes more frequently (first-years $M=2.85, S D=.96$; seniors $M=2.59, S D=.97)$. In almost all cases, students, on average as indicated by the mean score, indicated that they engaged in these learning strategies often.

Table 7

Learning Strategies Item Comparison: First-Year \& Senior Students

\begin{tabular}{llll}
\hline Item & Standing & Mean & $S D$ \\
\hline Identified key information from reading assignments & & & \\
& First- & & \\
& Year & 3.16 & 0.80 \\
& Senior & 3.19 & 0.84 \\
& & & \\
Reviewed your notes after class & First- & & \\
& Year & 2.85 & 0.96 \\
& Senior & 2.59 & 0.97 \\
Summarized what you learned in class or from course & & & \\
materials & & & \\
& First- & & \\
& Year & 2.77 & 0.96 \\
& Senior & 2.76 & 0.95 \\
\hline
\end{tabular}

Quantitative Reasoning

First-year and senior students report similar engagement in Quantitative Reasoning (Table 8). Both groups were most likely to reach conclusions based on their own analysis of numerical information (seniors $M=2.36, S D=1.00$; first-years $M=$ $2.32, S D=.97)$. While scores on this item are almost directly between never and very often engaged, the remaining items indicate that students are generally only 'sometimes' 
(as indicated by a score of 2) engaged in them. Evaluating what others had concluded from numerical information was next most frequently learning activity students engaged in within this area (seniors $M=2.11, S D=.90$; first-years $M=2.08, S D=.90$ ). Using numerical information to examine a real-world problem or issue (seniors $M=2.03, S D=$ .94 ; first-years $M=1.95, S D=.86$ ) was least common.

Table 8 Quantitative Reasoning Item Comparison: First-Year \& Senior Students

\begin{tabular}{llll}
\hline Item & Standing & Mean & $S D$ \\
\hline $\begin{array}{l}\text { Reached conclusions based on you own analysis of numerical } \\
\text { information }\end{array}$ & & & \\
& First- & & \\
& Year & 2.32 & 0.97 \\
& Senior & 2.36 & 1.00 \\
Used numerical information to exam a real-world problem or & & & \\
issue & & & \\
& First- & & \\
& Year & 1.95 & 0.86 \\
& Senior & 2.03 & 0.94 \\
Evaluated what others have concluded from numerical & & & \\
information & & & \\
& First- & & \\
& Year & 2.08 & 0.90 \\
& Senior & 2.11 & 0.90
\end{tabular}

Collaborative Learning

First-year and senior students have comparable Collaborative Learning experiences (Table 9), all which fall in the middle of the engagement range between 'sometimes' and 'often'. Within Collaborative Learning, both groups are most likely to have explained course material to one or more students (seniors $M=2.75, S D=.82$; firstyears $M=2.68, S D=.82$ ) and worked with other students on course projects or 
assignments (seniors $M=2.74, S D=.87$; first-years $M=2.62, S D=.86$ ). Asking another student to help you understand the course material (seniors $M=2.41, S D=.77$; firstyears $M=2.49, S D=.85$ ) and preparing for exams by discussing or working through course material with other students (seniors $M=2.44 S D=.96$; first-years $M=2.42, S D$ $=1.01$ ) was reported less frequently by both groups.

Table 9

Collaborative Learning Item Comparison: First-Year \& Senior Students

\begin{tabular}{llrr}
\hline Item & Standing & Mean & $S D$ \\
\hline Asked another student to help you understand course material & & & \\
& First- & & \\
& Year & 2.49 & 0.85 \\
& Senior & 2.41 & 0.77 \\
Explained course material to one or more students & & & \\
& First- & & \\
& Year & 2.68 & 0.82 \\
& Senior & 2.75 & 0.82 \\
Prepared for exams by discussing or working through course & & & \\
material with other students & & & \\
& First- & & \\
& Year & 2.42 & 1.01 \\
& Senior & 2.44 & 0.96 \\
Worked with other students on course projects or assignments & & & \\
& First- & & \\
& Year & 2.62 & 0.86 \\
& Senior & 2.74 & 0.87 \\
\hline
\end{tabular}

Student-Faculty Interaction

Interaction with faculty is another engagement indicator that senior students report occurring at a higher rate than first-year students (Table 10), with first-year students generally indicating 'sometimes' and seniors generally indicating almost directly between 'sometimes' and 'often'. Talking about career plans with a faculty member was 
rated as most likely type of faculty contact (seniors $M=2.48, S D=.89$; first-years $M=$ $2.23, S D=.83$ ). This was followed by discussing course topics, ideas, or concepts with a faculty member outside of class (seniors $M=2.31, S D=.90$; first-years $M=2.03, S D=$ .85 ) and discussing the student's academic performance with a faculty member (seniors $M=2.13, S D=.86$; first-years $M=2.01, S D=.78)$. The least likely for both first-year and senior students, but also with the largest difference between them in this area, is working with a faculty member on activities other than coursework (seniors $M=2.10, S D$ $=.98$; first-years $M=1.61, S D=.79)$.

Table 10

Student-Faculty Interaction Item Comparison: First-Year \& Senior Students

\begin{tabular}{lll}
\hline Item & Standing Mean $S D$ \\
\hline
\end{tabular}

Talked about career plans with a faculty member

Worked with a faculty member on activities other than

First-

$\begin{array}{lll}\text { Year } & 2.23 \quad 0.83\end{array}$

Senior $\quad 2.48 \quad 0.89$ coursework

First-

$\begin{array}{lll}\text { Year } & 1.61 & 0.79\end{array}$

Discussed course topics, ideas, or concepts with a faculty

Senior

$2.10 \quad 0.98$
member outside of class

First-

Year $\quad 2.03 \quad 0.85$

Discussed your academic performance with a faculty

Senior $\quad 2.31 \quad 0.90$
member

First-

$\begin{array}{lll}\text { Year } & 2.01 & 0.78\end{array}$

Senior $\quad 2.13 \quad 0.86$ 


\section{Effective Teaching Practices}

First-year and senior students rate their instructors as using comparable Effective Teaching Practices (Table 11), ranking these practices as occurring 'often' or between 'sometimes' and 'often' on average. The largest difference existed on instructors providing prompt and detailed feedback on test or completed assignments (seniors $M=$ $2.73, S D=.87$; first-years $M=2.56, S D=.90)$. Instructors clearly explaining course goals and requirements (seniors $M=3.12, S D=.75$; first-years $M=3.08, S D=.79$ ), instructors teaching course sessions in an organized way (seniors $M=2.98, S D=.78$; first-years $M=3.07, S D=.80$ ), instructors used examples or illustrations to explain difficult points (seniors $M=3.08, S D=.81$; first-years $M=3.04, S D=.80$ ), and instructors provided feedback on a draft or work in progress (seniors $M=2.66, S D=.97$; first-years $M=2.65, S D=.96$ ) followed. The lack of difference in reported feedback provided on drafts or works in progress is somewhat surprising, as it might be expected that senior students are completing capstone and/or other detailed projects that would require instructor feedback. 
Table 11

Effective Teaching Practices Item Comparison: First-Year \& Senior Students

Item $\quad$ Standing Mean SD

Clearly explained course goals and requirements

First-

$\begin{array}{lll}\text { Year } & 3.08 & 0.79\end{array}$

Senior $\quad 3.12 \quad 0.75$

Taught course sessions in an organized way

First-

Year $\quad 3.07 \quad 0.80$

Senior $\quad 2.98 \quad 0.78$

Used examples or illustrations to explain difficult points

First-

$\begin{array}{lll}\text { Year } \quad 3.04 & 0.80\end{array}$

Provided feedback on a draft or work in progress

Senior $\quad 3.08 \quad 0.81$

First-

Year $\quad 2.65 \quad 0.96$

Senior $\quad 2.66 \quad 0.97$

Provided prompt and detailed feedback on tests or completed assignments

First-

Year $\quad 2.56 \quad 0.90$

Senior $\quad 2.73 \quad 0.87$

Quality of Interactions

This is the only engagement indicator in which the items that comprise it are on a seven-point Likert-type scale, which ranges from one ('poor') to seven ('excellent'; Table 12). Both first-year and senior students rated the quality of interactions with other students highest (seniors $M=5.58, S D=1.34$; first-years $M=5.53, S D=1.48$ ). The second highest quality interactions were with academic advisors (seniors $M=5.49, S D=$ 1.68; first-years $M=5.19, S D=1.78$ ), followed by the quality of interactions with faculty (seniors $M=5.42, S D=1.48$; first-years $M=5.13, S D=1.44$ ). Students rate these 
notably better than the middle score of four, enjoying their interactions with peers, academic advisors, and faculty most. The quality of interactions with student services staff (seniors $M=4.54, S D=1.68$; first-years $M=4.69, S D=1.72$ ) and with other administrative staff and offices (seniors $M=4.30, S D=1.72$; first-years $M=4.47, S D=$ 1.81) were rated lower; just above the middle score and indicating a somewhat moderate quality of interactions with these staff.

Table 12

Quality of Interactions Item Comparison: First-Year \& Senior Students

\begin{tabular}{llll}
\hline Item & Standing & Mean & $S D$ \\
\hline Students & & & \\
& First- & & \\
& Year & 5.53 & 1.48 \\
& Senior & 5.58 & 1.34 \\
Academic advisors & & & \\
& First- & & \\
& Year & 5.19 & 1.78 \\
& Senior & 5.49 & 1.68 \\
Faculty & & & \\
& First- & & \\
& Year & 5.13 & 1.44 \\
Student services staff & Senior & 5.42 & 1.48 \\
& & & \\
& First- & & \\
& Year & 4.69 & 1.72 \\
Other administrative staff and offices & Senior & 4.54 & 1.68 \\
& & & \\
& First- & & \\
\hline
\end{tabular}




\section{Supportive Environment}

Although many of the mean scores were similar, the first-year students found their institution more supportive than did senior students (Table 13). The areas that students felt their institution emphasized the most were in using learning support services (first-years $M=3.10, S D=.82$; seniors $M=2.80, S D=.90$ ), providing support to help students succeed academically (first-years $M=3.04, S D=.86$; seniors $M=2.90, S D=$ .89 ), providing support for student overall wellbeing (first-years $M=3.02, S D=.86$; seniors $M=2.78, S D=.95$ ), providing opportunities to be involved socially (first-years $M=2.90, S D=.84 ;$ seniors $M=2.85, S D=.91)$, encouraging contact among students from different backgrounds (first-years $M=2.90, S D=.95$; seniors $M=2.77, S D=1.01$ ), and attending campus activities and events (first-years $M=2.89, S D=.90$; seniors $M=$ $2.73, S D=.89)$. All of these areas were ranked 'often' on average by both first-year and senior students. Areas of support that were rated lowest included attending events that address important social, economic, or political issues (first-years $M=2.47, S D=.93$; seniors $M=2.45, S D=.94$ ) and helping students manage their non-academic responsibilities (first-years $M=2.30, S D=1.04$; seniors $M=2.02, S D=.95$ ). 
Table 13

Supportive Environment Item Comparison: First-Year \& Senior Students

Item Standing Mean SD

Providing support to help students succeed academically

First-

Year $\quad 3.04 \quad 0.86$

Senior $\quad 2.90 \quad 0.89$

Using learning support services

First-

Year $\quad 3.10 \quad 0.82$

Encouraging contact among students from different

Senior $\quad 2.80 \quad 0.90$
backgrounds

First-

Year $\quad 2.90 \quad 0.95$

Senior $\quad 2.77 \quad 1.01$

Providing opportunities to be involved socially

First-

$\begin{array}{lll}\text { Year } & 2.90 & 0.84\end{array}$

Senior $\quad 2.85 \quad 0.91$

Providing support for your overall well-being

Helping you manage your non-academic responsibilities

First-

$\begin{array}{lll}\text { Year } \quad 3.02 & 0.86\end{array}$

Senior $\quad 2.78 \quad 0.95$

First-

Year $\quad 2.30 \quad 1.04$

Senior $\quad 2.02 \quad 0.95$

Attending campus activities and events

First-

$\begin{array}{lll}\text { Year } & 2.89 & 0.90\end{array}$

Senior $\quad 2.73 \quad 0.89$

Attending events that address important social, economic, or political issues

\begin{tabular}{lll} 
First- & & \\
Year & 2.47 & 0.93 \\
Senior & 2.45 & 0.94 \\
\hline
\end{tabular}




\section{Hypothesis Testing}

There were four research questions divided into two hypotheses that guided this study. The first hypothesis was tested using Structural Equation Modeling (SEM) and the second was tested with a discriminant function analysis.

\section{Engagement \& Academic Achievement}

These SEMs were conducted to determine what relationships existed, as well as the direction of the relationships between GPA, Higher-Order Learning, Reflective \& Integrative Learning, Learning Strategies, Quantitative Reasoning, Collaborative Learning, Student-Faculty Interaction, Effective Teaching Practices, Quality of Interactions, and Supportive Environment for first-year and for senior students. The goal was to develop a statistical model for each group using the Engagement Indicators to predict for GPA in order to answer the two research questions regarding engagement and academic achievement: 1) "Is student engagement predictive of academic performance?" and 2) "Which measures of student engagement best predict academic performance?"

One issue worth noting before discussing the data analysis is sample size. As discussed in Tabachnick \& Fidell (2019), larger samples are required in order to reliably estimate correlations. As the hypothesized model in the current study has a number of factors with generally weak to moderate correlations, a large sample is suggested $(\geq 300)$. However, the current study uses well-determined factors in the analysis, which may reduce sample size needed (Tabachnick \& Fidell, 2019). Other researchers recommend five to ten participants per estimated parameter, which would suggest the need for a sample of approximately 80 to $160\left(16^{*} 5\right.$ or $\left.16^{*} 10\right)$ for this study (Bentler \& Chou, 1987 ; 
Schreiber, Nora, Stage, Barlow, \& King, 2006). The present study roughly meets these smaller sample size recommendations, with 139 first-year and 239 senior students.

A second issue worth mentioning prior to the discussion of the data analysis are the criteria for improving model fit. Meyers, Gamst, and Guarino (2013) have several recommendations for respecifying a model to improve its fit with the data. First is adding or removing correlations from the model. Viewing the parameter change column within the output, approximate correlations that could be added to the model can be viewed. Greater values here may indicate that if the correlation is added to the model, the fit of the model will improve. This includes covarying error terms. However, any correlations must make theoretical sense in order to be added. Also, any existing correlations in the model that are nonsignificant can be removed (there were no correlations within the hypothesized model). Paths may also be added or removed from the model in order to improve the model fit. Existing paths may be removed if they are nonsignificant, or if they have very little practical value. Regression weights may indicate new paths that could be added to improve the model as long as they make theoretical sense. The removal of nonsignificant paths was used frequently to adjust the models.

\section{First-Year Students}

The variables were tested based on the assumptions of normal distribution, homogeneity of variance, linearity, and collinearity. The Kolmogorov-Smirnov test of normality indicated that none of the variables were normally distributed $(p<.03)$; however, it is worth noting that these tests are very sensitive to deviation from normality. A follow-up review of the Q-Q plots for each variable, excluding GPA, determined that the variables were relatively normally distributed. Additional evidence of normal 
distribution of the variables was provided by a Cook's distance of less than one, indicating outliers did not have a significant influence on the data. With the exception of GPA, the variables' skewness and kurtosis scores indicated that they were relatively normal (within the -1 to 1 range), providing further evidence for the relative normality of the predictor variables. To test linearity and collinearity, Pearson's $r$ values found most of the correlations to be statistically significant ( $p \leq .03$ ), with the exceptions of Quantitative Reasoning and Student-Faculty Interaction. The $r$ values of the statistically significant predictors ranged from .16 to .37 , indicating little likelihood of collinearity and some possibility of nonlinear relationships (Table 14). A review of the scatterplot graphs indicated somewhat linear relationships between the dependent and independent variables. Collinearity tolerance scores and VIF scores were all with satisfactory ranges (tolerance .61 to $.74 ; \mathrm{VIF}=1.31$ to 1.62 ). Finally, the homogeneity of variance assumption was tested using a Levene's test. The test was statistically significant for Higher-Order Learning $(p<.01)$, Collaborative Learning $(p<.02)$, Student-Faculty Interaction $(p=.01)$, Effective Teaching Practices $(p<.01)$, Quality of Interactions $(p<$ $.01)$, and Supportive Environment $(p<.01)$, indicating equal variance cannot be assumed for these variables. Equal variances can be assumed $(p>.05)$ for Reflective \& Integrative Strategies, Learning Strategies, and Quantitative Reasoning. 





Table 15

SEM Fit Indices: First-Year Students

\begin{tabular}{|c|c|c|c|c|}
\hline Fit Indices & $\begin{array}{l}\text { Target } \\
\text { Value }\end{array}$ & Model 1 & Model 2 & Model 3 \\
\hline Chi-Square & $p>.05$ & .002 & .005 & .215 \\
\hline Chi-Square/df & $\leq 2$ & $<.01$ & $<.01$ & $<.01$ \\
\hline Goodness of Fit Index (GFI) & $\geq .95$ & .932 & .933 & .963 \\
\hline Comparative Fit Index (CFI) & $\geq .95$ & .901 & .905 & .979 \\
\hline Normed Fit Index (NFI) & $\geq .95$ & .834 & .828 & .907 \\
\hline $\begin{array}{l}\text { Root Mean Square Error of } \\
\text { Approximation (RMSEA) } \\
\text { Standardized Root Mean }\end{array}$ & $\leq .06$ & .087 & .082 & .043 \\
\hline Square Residual (SRMSR) & $\leq .10$ & .068 & .068 & .049 \\
\hline
\end{tabular}

Model 1 \& Model 2

The hypothesized model, or Model 1, somewhat fit the data $\left(\chi^{2}=50.68, d f=25, p\right.$ $=.002, \mathrm{GFI}=.932, \mathrm{CFI}=.901, \mathrm{RMSEA}=.087 ;$ Figure 4$).$ A review of the regression weights found a number of relationships that were nonsignificant $(p>.10)$ and removed. Collaborative Learning was not predicted by Supportive Environment $(\beta=.12, p=.19)$, Effective Teaching Practices $(\beta=-.15, p=.11)$, or Quality of Interactions $(\beta=.14, p=$ $.12)$, and therefore these relationships were removed from the model. Quality of Interactions was not predictive of Student-Faculty Interactions $(\beta=-.004, p=.97)$, Academic Challenge $(\beta=.02, p=.85)$, or GPA $(\beta=.09, p=.32)$, and therefore these relationships were removed from the model. With the removal of these relationships, the Quality of Interactions variable was also removed, as it no longer contributed to the model. After these changes, the remaining model was referred to as Model 2. The Model 2 fit indices were slightly improved over Model $1\left(\chi^{2}=45.64, d f=24, p=.005\right.$, GFI $=$ $.933, \mathrm{CFI}=.905, \mathrm{RMSEA}=.082 ;$ Figure 5). 
Figure 5

Model 1 - First-year Students



Fit Indices

Chi-Square $=50.681 \mathrm{df}=25 \mathrm{p}=.002$

$\mathrm{NFI}=.834 \mathrm{GFI}=.932 \mathrm{CFI}=.901$

RMSEA $=.087$ Cl90 $=.052, .122$

SRMR $=.068$ 
Figure 6

Model 2 - First-year Students

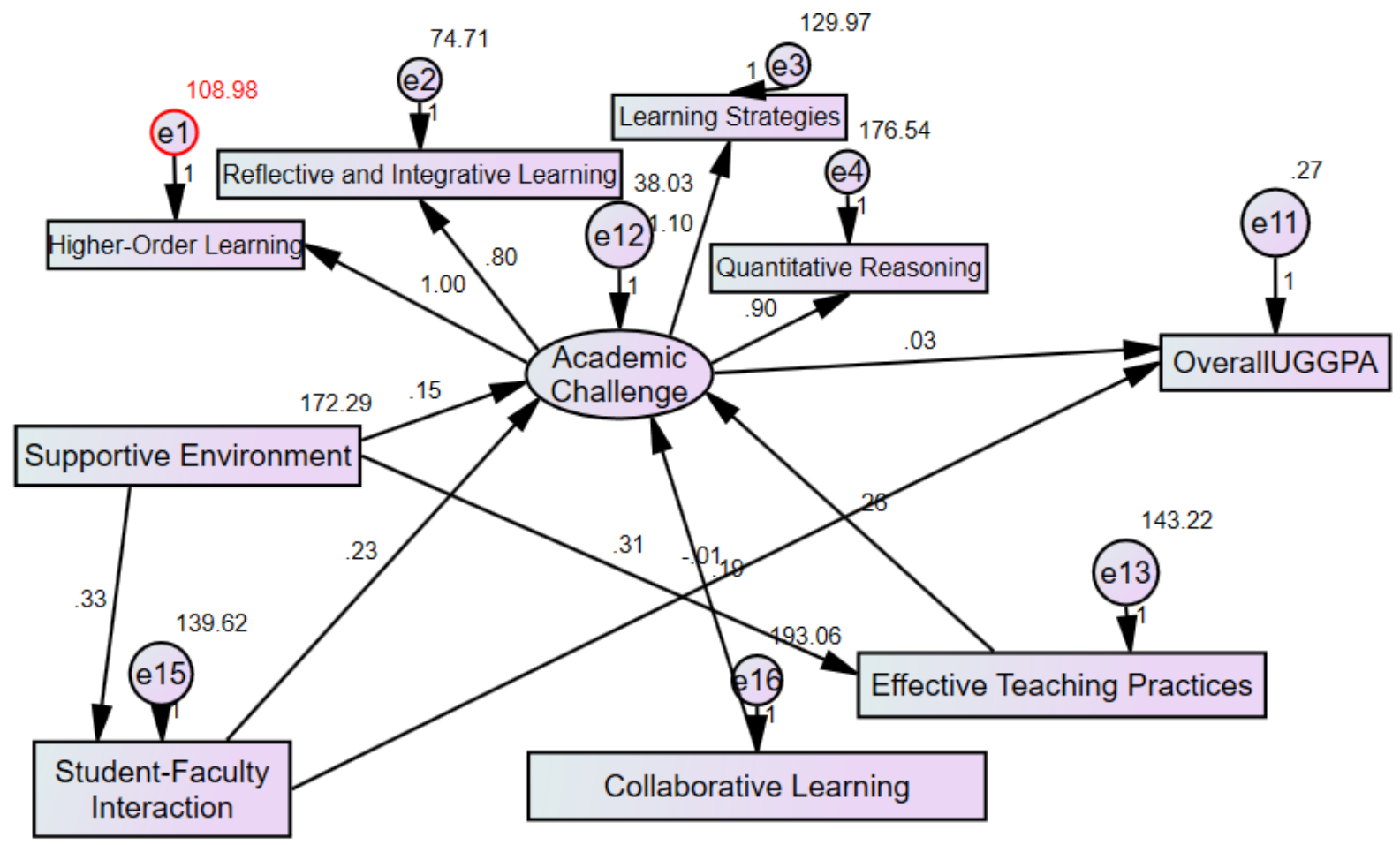

Fit Indices

Chi-Square $=45.639 \mathrm{df}=24 \mathrm{p}=.005$

$\mathrm{NFI}=.828 \mathrm{GFI}=.933 \mathrm{CFI}=.905$

RMSEA $=.082$ Cl90 $=.044, .117$

SRMR $=.068$

Model 3

Further adjustments of the model were made in order to improve model fit. Of these adjustments, it was found that the removal of Collaborative Learning, which was only predictive of Academic Challenge $(\beta=.19, p<.001)$ and was not predicted by any of the other variables in the model, significantly improved the model fit. The removal of Collaborative Learning did not have a significant impact on the model's ability to predict 
for GPA. There were no further nonsignificant relationships, and no other changes were made. In the third and final model, all fit indices were within acceptable ranges and indicated a good fit with the data $\left(\chi^{2}=21.25, d f=24, p=.22\right.$, GFI $=.963$, CFI $=.979$, RMSEA $=.043$; Figure 6; Table 15). The model predicts 19\% of student GPA and indicates the importance of the Academic Challenge $(\beta=.51)$ variables, as well as Student-Faculty Interaction $(\beta=-.21)$ as direct predictors of first-year student grades, suggesting that higher GPA scores are associated with higher Academic Challenge but lower Student-Faculty Interaction. Academic Challenge can be explained by StudentFaculty Interactions ( $\beta=.41)$, Effective Teaching Practices $(\beta=.32)$, and Supportive Environment $(\beta=.23)$. Supportive Environment $(\beta=.34)$ explains about $12 \%$ of the variance in Student-Faculty Interaction, and about $(\beta=.32) 10 \%$ of the variance in Effective Teaching Strategies. 
Figure 7

Model 3 - First-Year Students

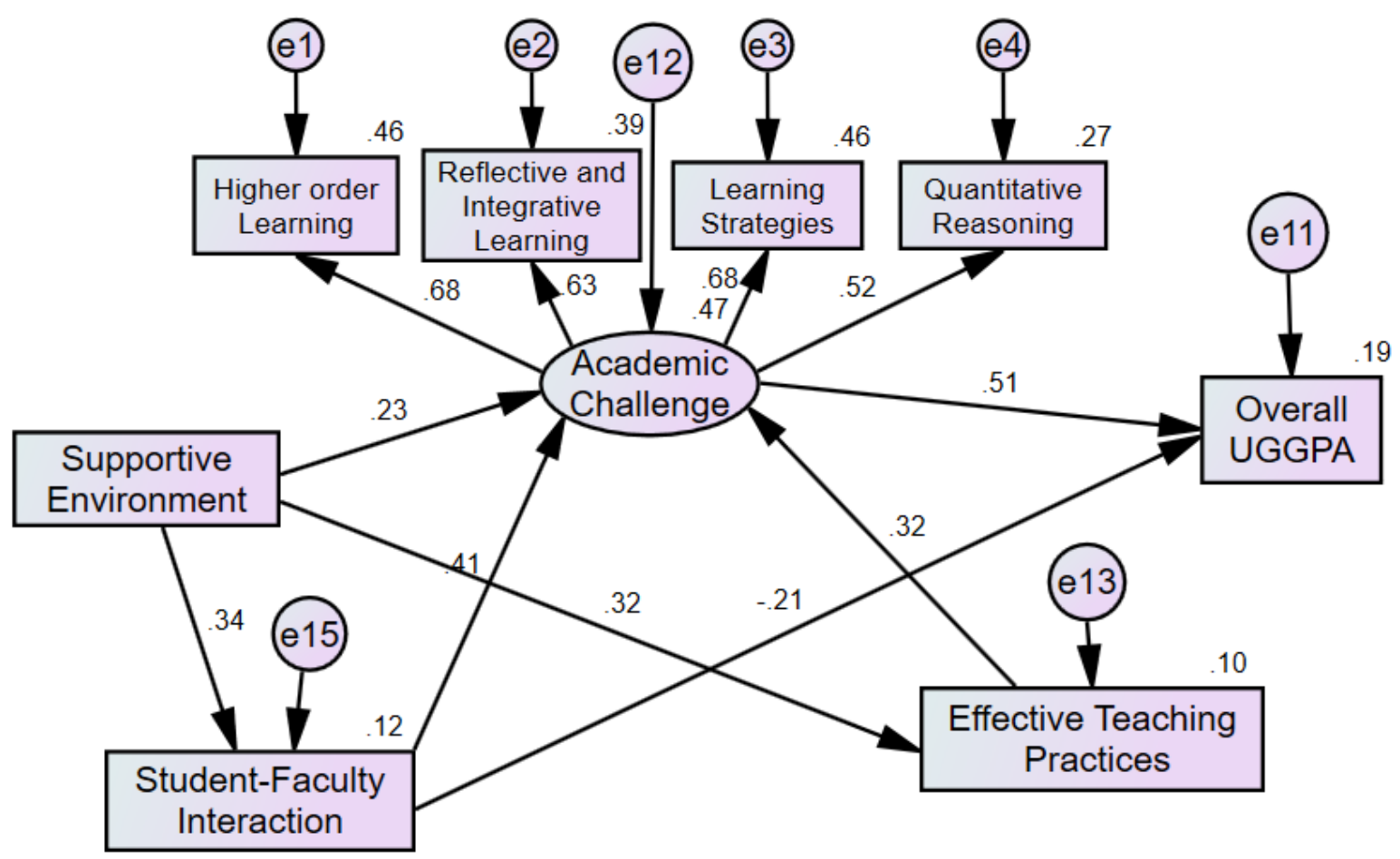

Fit Indices

Chi-Square $=21.249 \mathrm{df}=17 \quad \mathrm{p}=.215$

$\mathrm{NFI}=.907 \mathrm{GFI}=.963 \mathrm{CFI}=.979$

RMSEA $=.043 \mathrm{Cl} 190=.000, .094$

SRMR $=.049$ 
Table 16

Path Coefficients: First-Year Students Model 3

\begin{tabular}{|c|c|c|c|c|c|}
\hline Paths & & & $\mathrm{b}$ & S.E. & $\beta$ \\
\hline $\begin{array}{l}\text { Student-Faculty } \\
\text { Interaction }\end{array}$ & $<---$ & $\begin{array}{l}\text { Supportive } \\
\text { Environment }\end{array}$ & .326 & .077 & $.340 * *$ \\
\hline $\begin{array}{l}\text { Effective Teaching } \\
\text { Practices }\end{array}$ & $<---$ & $\begin{array}{l}\text { Supportive } \\
\text { Environment }\end{array}$ & .305 & .078 & $.317 * *$ \\
\hline Academic Challenge & $<---$ & $\begin{array}{l}\text { Supportive } \\
\text { Environment }\end{array}$ & .116 & .066 & $.233^{*}$ \\
\hline Academic Challenge & $<---$ & $\begin{array}{l}\text { Effective Teaching } \\
\text { Practices }\end{array}$ & .239 & .067 & $.322 * *$ \\
\hline Academic Challenge & $<---$ & $\begin{array}{l}\text { Student-Faculty } \\
\text { Interaction }\end{array}$ & .305 & .071 & $.409 * *$ \\
\hline Higher-Order Learning & $<---$ & Academic Challenge & 1 & & $.676^{* *}$ \\
\hline $\begin{array}{l}\text { Reflective \& Integrative } \\
\text { Learning }\end{array}$ & $<---$ & Academic Challenge & .761 & .128 & $.628 * *$ \\
\hline Learning Strategies & $<---$ & Academic Challenge & 1.101 & .176 & $.679 * *$ \\
\hline Quantitative Reasoning & $<---$ & Academic Challenge & .859 & .171 & $.516^{* *}$ \\
\hline $\begin{array}{l}\text { Overall Undergraduate } \\
\text { GPA }\end{array}$ & $<---$ & Academic Challenge & .032 & .008 & $.512 * *$ \\
\hline $\begin{array}{l}\text { Overall Undergraduate } \\
\text { GPA }\end{array}$ & $<---$ & $\begin{array}{l}\text { Student-Faculty } \\
\text { Interaction }\end{array}$ & -.010 & .005 & $-.212 *$ \\
\hline
\end{tabular}


Table 17

Standardized Direct and Indirect Effects: First-Year Students Model 3

\begin{tabular}{|c|c|c|c|}
\hline \multirow[b]{2}{*}{ Outcome } & \multirow[b]{2}{*}{ Predictors } & \multicolumn{2}{|c|}{ Effects } \\
\hline & & Direct & Indirect \\
\hline $\begin{array}{l}\text { Student-Faculty Interaction } \\
R^{2}=.116\end{array}$ & Supportive Environment & $.340 * *$ & \\
\hline $\begin{array}{l}\text { Effective Teaching Practices } \\
R^{2}=.100\end{array}$ & Supportive Environment & $.317 * *$ & \\
\hline $\begin{array}{l}\text { Academic Challenge } \\
R^{2}=.465\end{array}$ & $\begin{array}{l}\text { Supportive Environment } \\
\text { Effective Teaching } \\
\text { Practices } \\
\text { Student-Faculty Interaction }\end{array}$ & $\begin{array}{l}.233 * \\
.322 * * \\
.409 * *\end{array}$ & $.172 *$ \\
\hline $\begin{array}{l}\text { Overall Undergraduate GPA } \\
R^{2}=.194\end{array}$ & $\begin{array}{l}\text { Student-Faculty Interaction } \\
\text { Academic Challenge } \\
\text { Supportive Environment } \\
\text { Effective Teaching } \\
\text { Practices }\end{array}$ & $\begin{array}{l}-.212 * \\
.512 * *\end{array}$ & $\begin{array}{l}.171^{*} \\
.165^{*}\end{array}$ \\
\hline Higher Order Learning & Academic Challenge & $.676 * *$ & \\
\hline$R^{2}=.456$ & $\begin{array}{l}\text { Supportive Environment } \\
\text { Student-Faculty Interaction } \\
\text { Effective Teaching } \\
\text { Practices }\end{array}$ & & $\begin{array}{l}.320^{* *} \\
.276^{*} \\
.217^{*}\end{array}$ \\
\hline $\begin{array}{l}\text { Reflective \& Integrative } \\
\text { Learning }\end{array}$ & Academic Challenge & $.628 * *$ & \\
\hline$R^{2}=.395$ & $\begin{array}{l}\text { Supportive Environment } \\
\text { Student-Faculty Interaction } \\
\text { Effective Teaching } \\
\text { Practices }\end{array}$ & & $\begin{array}{l}.298 * * \\
.257 * \\
.202 *\end{array}$ \\
\hline Learning Strategies & Academic Challenge & $.679 * *$ & \\
\hline$R^{2}=.460$ & $\begin{array}{l}\text { Supportive Environment } \\
\text { Student-Faculty Interaction } \\
\text { Effective Teaching } \\
\text { Practices }\end{array}$ & & $\begin{array}{l}.321 * * \\
.278 * \\
.218 *\end{array}$ \\
\hline Quantitative Reasoning & Academic Challenge & $.516^{* *}$ & \\
\hline$R^{2}=.266$ & $\begin{array}{l}\text { Supportive Environment } \\
\text { Student-Faculty Interaction } \\
\text { Effective Teaching } \\
\text { Practices }\end{array}$ & & $\begin{array}{l}.244^{*} \\
.211^{*} \\
.166^{*}\end{array}$ \\
\hline
\end{tabular}

Note ${ }^{* *} p<.001, * p<.05$ 


\section{Senior Students}

For the senior student dataset, the variables were also tested based on the assumptions of normal distribution, homogeneity of variance, linearity, and collinearity. The Kolmogorov-Smirnov test of normality indicated that none of the variables were normally distributed $(p<.01)$; however, it is again worth noting that these tests are very sensitive to deviation from normality. A follow-up review of the Q-Q plots for each variable, excluding GPA, determined that the variables were relatively normally distributed. Additional evidence of normal distribution of the variables was provided by a Cook's distance of less than one, indicating outliers did not have a significant influence on the data. Except GPA, the variables' skewness and kurtosis scores indicated that they were relatively normal (within the -1 to 1 range), providing further evidence for the relative normality of the predictor variables. To test linearity and collinearity, Pearson's $r$ values found the correlations between GPA and Reflective \& Integrative Learning, Collaborative Learning, Quality of Interactions, and Supportive Environment to be statistically significant $(p<.05)$. The relationship between GPA and Higher-Order Learning, Learning Strategies, Quantitative Reasoning, Student-Faculty Interaction, and Effective Teaching Practices were all nonsignificant $(p>.05)$. The $r$ values of the statistically significant predictors ranged from .11 to .29 , indicating little likelihood of collinearity and the possibility of nonlinear relationships (Table 18). A review of the scatterplot graphs indicated somewhat linear relationships between the dependent and independent variables. Collinearity tolerance scores and VIF scores were all with satisfactory ranges (tolerance .59 to $.79 ; \mathrm{VIF}=1.26$ to 1.68 ). Finally, the homogeneity of variance assumption was tested using a Levene's test. The test was statistically 
significant $(p \leq .02)$, indicating equal variance cannot be assumed for any of the variables. 


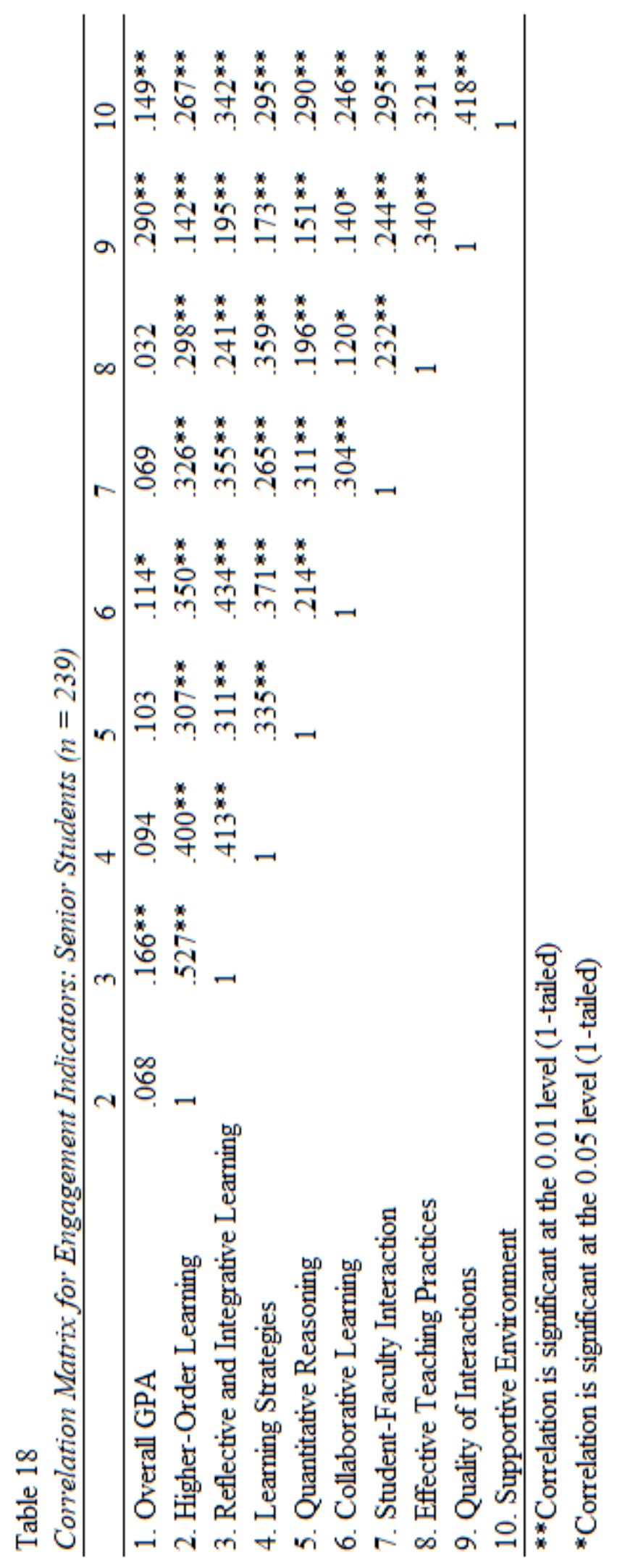


Table 19

SEM Fit Indices: Senior Students

\begin{tabular}{|c|c|c|c|c|c|}
\hline Fit Indices & $\begin{array}{l}\text { Target } \\
\text { Value }\end{array}$ & $\begin{array}{l}\text { Model } \\
1 \\
\end{array}$ & $\begin{array}{l}\text { Model } \\
2\end{array}$ & $\begin{array}{l}\text { Model } \\
3\end{array}$ & Model 4 \\
\hline Chi-Square & $p>.05$ & .009 & .021 & .289 & .176 \\
\hline $\begin{array}{l}\text { Chi-Square df } \\
\text { Goodness of Fit Index }\end{array}$ & $\leq 2$ & $<.01$ & $<.01$ & .01 & $<.01$ \\
\hline $\begin{array}{l}\text { (GFI) } \\
\text { Comparative Fit Index }\end{array}$ & $\geq .95$ & .966 & .964 & .975 & .971 \\
\hline$(\mathrm{CFI})$ & $\geq .95$ & .956 & .961 & .992 & .985 \\
\hline Normed Fit Index (NFI) & $\geq .95$ & .909 & .906 & .936 & .928 \\
\hline $\begin{array}{l}\text { Root Mean Square Error of } \\
\text { Approximation (RMSEA) } \\
\text { Standardized Root Mean }\end{array}$ & $\leq .06$ & .058 & .050 & .023 & .032 \\
\hline Square Residual (SRMSR) & $\leq .10$ & .047 & .047 & .047 & .039 \\
\hline
\end{tabular}

Model 1, 2, \& 3

The hypothesized model, or Model 1 , fit the data relatively well $\left(\chi^{2}=44.92, d f=\right.$ $25 p=.009, \mathrm{GFI}=.966, \mathrm{CFI}=.956, \mathrm{RMSEA}=.058$; Figure 7$).$ A review of the regression weights found a number of relationships that were nonsignificant $(p>.10)$ and were removed. Collaborative Learning was not predicted by Effective Teaching Practices $(\beta=.04, p=.58)$ or Quality of Interactions $(\beta=.04, p=.62)$, and therefore these relationships were removed from the model. Quality of Interactions was not predictive of Academic Challenge $(\beta=-.04, p=.54)$ and therefore this relationship was removed from the model. Student-Faculty Interactions were not predictive of GPA $(\beta=-.06, p=.42)$ and was removed from the model. Academic Challenge was not significantly predictive of GPA $(\beta=.11, p=.15)$, but this relationship was retained in order to maintain the integrity of the model. After these changes, the remaining model was referred to as Model 2. The Model 2 fit indices were slightly improved over Model $1\left(\chi^{2}=46.58, d f=\right.$ 
$29 p=.021, \mathrm{GFI}=.964, \mathrm{CFI}=.961, \mathrm{RMSEA}=.050 ;$ Figure 8$).$ Finally, a correlation

was added between the error term for Student-Faculty Interaction and the error term for

Collaborative Learning, further improving the model which was then referred to as

Model $3\left(\chi^{2}=31.66, d f=28, p=.289, \mathrm{GFI}=.975, \mathrm{CFI}=.992, \mathrm{RMSEA}=.023\right.$; Figure

9).

Figure 8

Model 1 - Senior Students

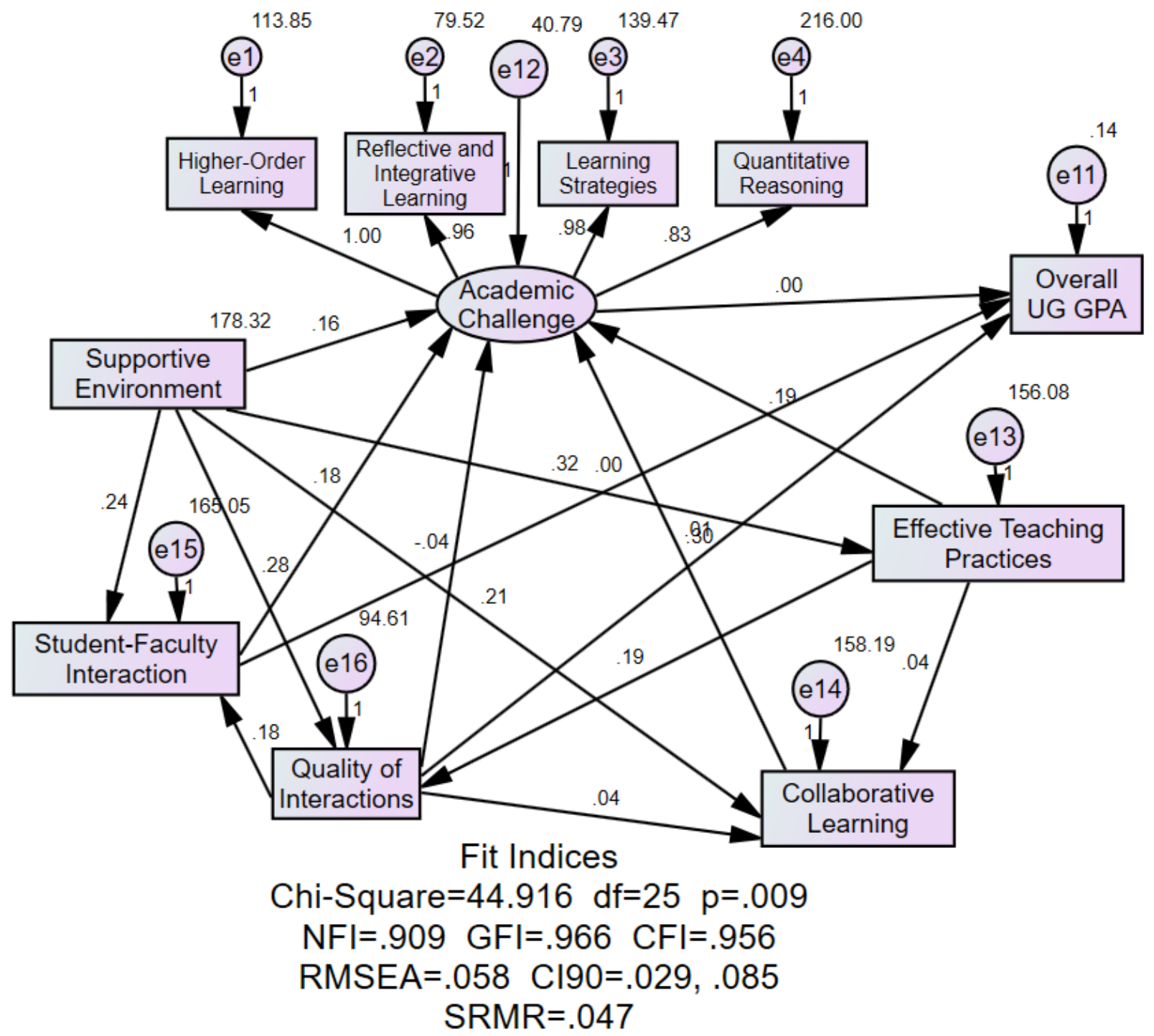


Figure 9

Model 2 - Senior Students

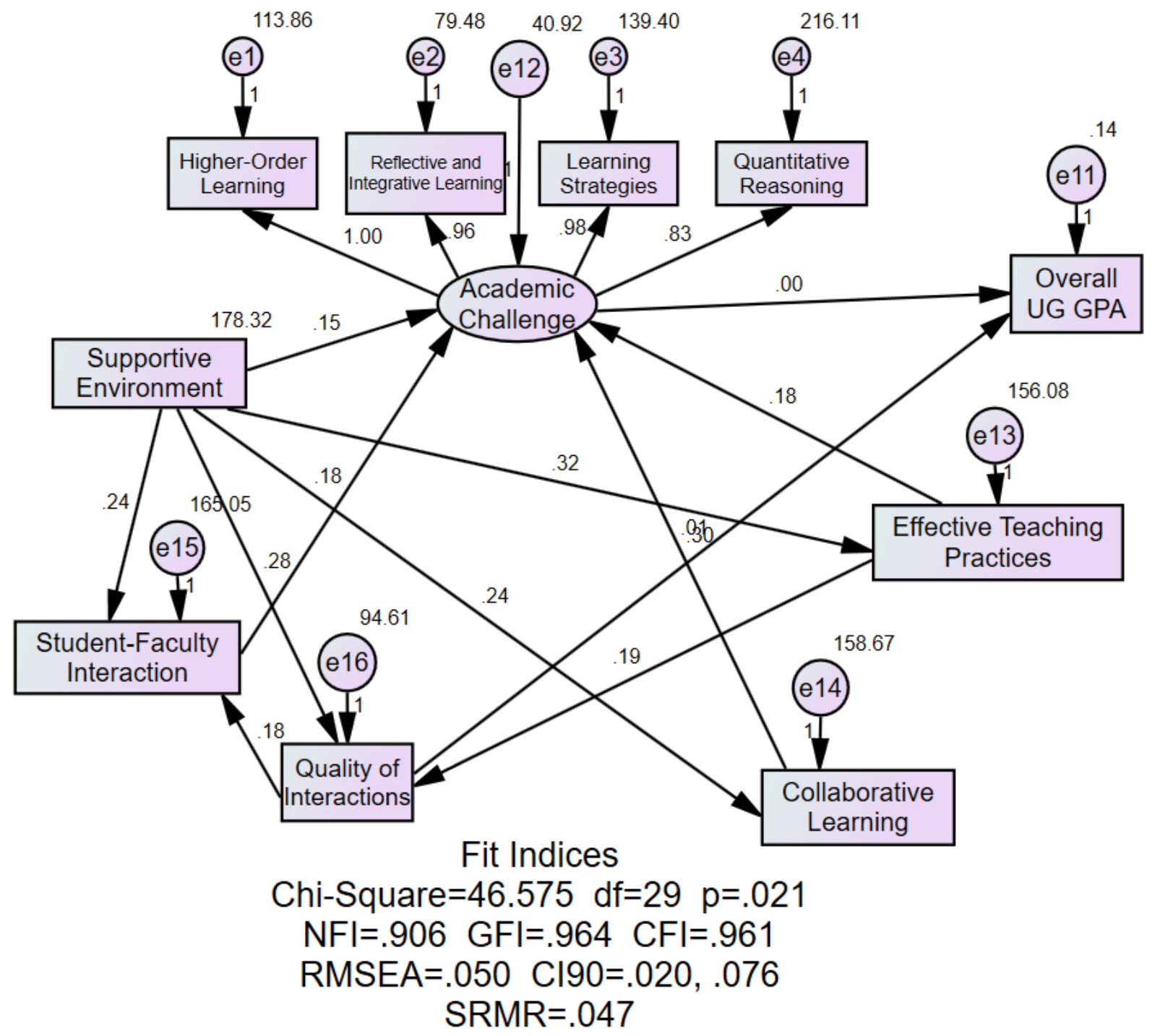


Figure 10

Model 3 - Senior Students



Model 4

At this point, the strength of the predictive value of Quality of Interactions to Student-Faculty Interaction fell below .2 and was removed $(\beta=.14, p=.04)$, resulting in the final model (Model 4). Model 4 fit indices all fell within acceptable ranges and 
indicated a good fit with the data $\left(\chi^{2}=35.93, d f=29, p=.176, \mathrm{GFI}=.971, \mathrm{CFI}=.985\right.$, RMSEA $=.032$; Figure 10). Despite fitting the data, the model only predicts $9 \%$ of senior student GPA, which is far less than the model for first-year students. Model 4 indicates that Quality of Interactions $(\beta=.27)$ is the most important direct predictor of seniors' GPA, indicating that higher quality interactions predict a higher GPA score. Academic Challenge remains a weak and nonsignificant $(\beta=.09, p=.24)$ predictor of senior GPA. The model also indicates the importance of a Supportive Environment $(\beta=.34 ; 12 \%)$ and Effective Teaching Practices $(\beta=.23 ; 5 \%)$ in predicting Quality of Interactions. A more Supportive Environment was important for predicting more Effective Teaching Practices $(\beta=.32)$, greater Student-Faculty Interaction $(\beta=.30)$, and more Collaborative Learning ( $\beta=.25)$. Academic Challenge was predicted by more Collaborative Learning ( $\beta=.41)$, great use of Effective Teaching Practices $(\beta=.26)$, greater Student-Faculty Interaction ( $\beta=.25)$, and a more Supportive Environment $(\beta=.22)$. 
Figure 11

Model 4 - Senior Students

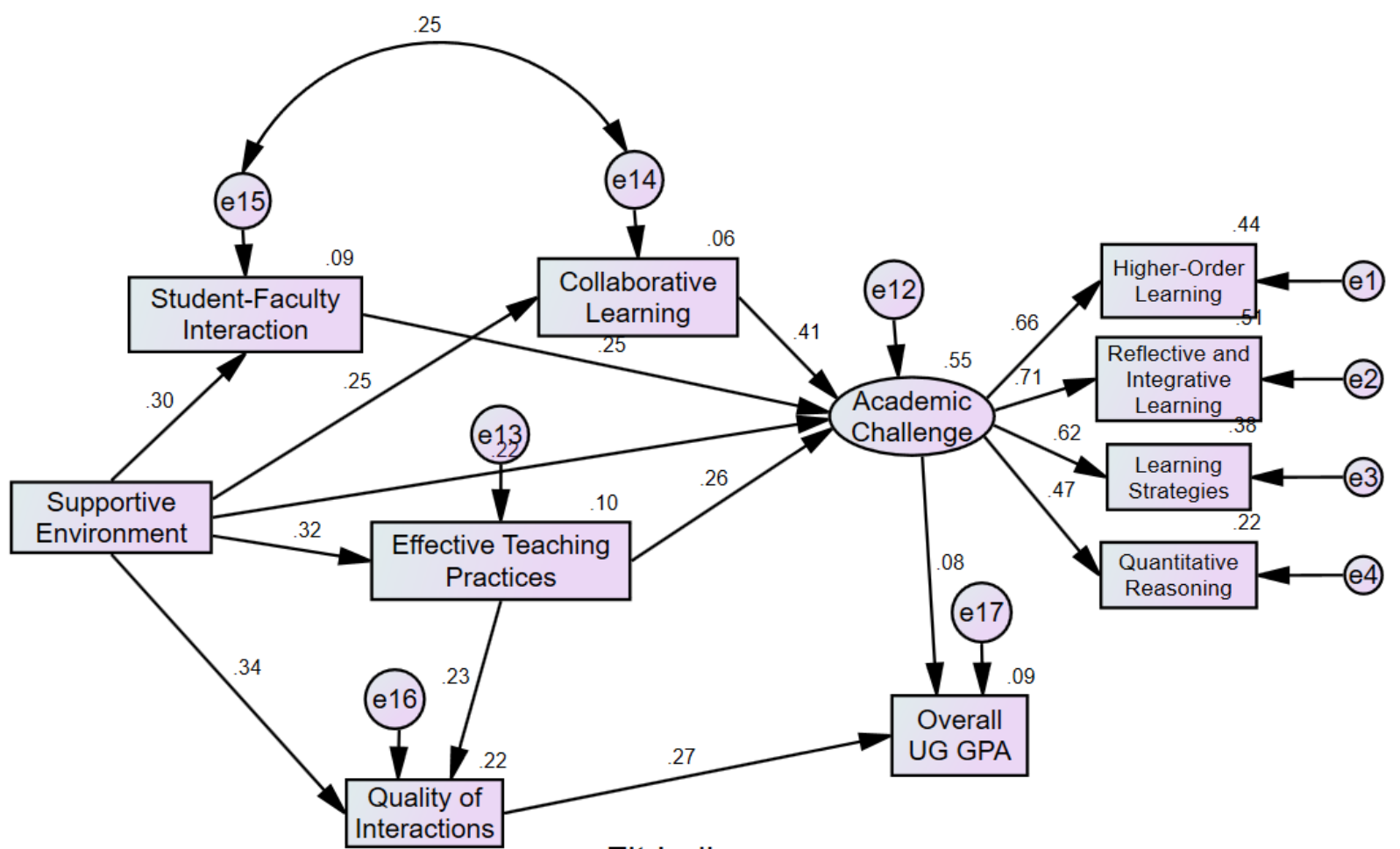

Fit Indices

Chi-Square $=35.933 \mathrm{df}=29 \mathrm{p}=.176$

$\mathrm{NFI}=.928 \mathrm{GFI}=.971 \mathrm{CFI}=.985$

RMSEA $=.032 \mathrm{Cl} 90=.000, .062$

SRMR $=.039$ 
Table 20

Path Coefficients: Senior Students Model 4

\begin{tabular}{|c|c|c|c|c|c|}
\hline Paths & & & $\mathrm{b}$ & S.E. & $\beta$ \\
\hline $\begin{array}{l}\text { Student-Faculty } \\
\text { Interaction }\end{array}$ & $<--$ & Supportive Environment & .300 & .063 & $.295 * *$ \\
\hline Collaborative Learning & $<---$ & Supportive Environment & .239 & .061 & $.246 * *$ \\
\hline $\begin{array}{l}\text { Effective Teaching } \\
\text { Practices }\end{array}$ & $<--$ & Supportive Environment & .317 & .061 & $.321 * *$ \\
\hline Academic Challenge & $<---$ & Supportive Environment & .153 & .048 & $.216 * *$ \\
\hline Quality of Interaction & $<---$ & Supportive Environment & .284 & .050 & $.344 * *$ \\
\hline Academic Challenge & $<--$ & $\begin{array}{l}\text { Student-Faculty } \\
\text { Interaction }\end{array}$ & .175 & .046 & $.251 * *$ \\
\hline Academic Challenge & $<---$ & Collaborative Learning & .300 & .051 & $.410 * *$ \\
\hline Academic Challenge & $<---$ & $\begin{array}{l}\text { Effective Teaching } \\
\text { Practices }\end{array}$ & .183 & .047 & $.255^{* *}$ \\
\hline Quality of Interactions & $<---$ & $\begin{array}{l}\text { Effective Teaching } \\
\text { Practices }\end{array}$ & .192 & .050 & $.230 * *$ \\
\hline Higher-Order Learning & $<---$ & Academic Challenge & 1 & & $.664 * *$ \\
\hline $\begin{array}{l}\text { Reflective \& Integrative } \\
\text { Learning }\end{array}$ & $<---$ & Academic Challenge & .958 & .112 & $.714 * *$ \\
\hline Learning Strategies & $<---$ & Academic Challenge & .979 & .127 & $.618 * *$ \\
\hline Quantitative Reasoning & $<---$ & Academic Challenge & .830 & .135 & $.472 * *$ \\
\hline $\begin{array}{l}\text { Overall Undergraduate } \\
\text { GPA }\end{array}$ & $<--$ & Quality of Interactions & .009 & .002 & $.267 * *$ \\
\hline $\begin{array}{l}\text { Overall Undergraduate } \\
\text { GPA }\end{array}$ & $<---$ & Academic Challenge & .003 & .003 & .085 \\
\hline
\end{tabular}

Table 21

Standardized Direct and Indirect Effects: Senior Students Model 4

\begin{tabular}{|c|c|c|c|}
\hline \multirow[b]{2}{*}{ Outcome } & \multirow[b]{2}{*}{ Predictors } & \multicolumn{2}{|c|}{ Effects } \\
\hline & & Direct & Indirect \\
\hline $\begin{array}{l}\text { Effective Teaching Practices } \\
R^{2}=.103\end{array}$ & Supportive Environment & $.321 * *$ & \\
\hline $\begin{array}{l}\text { Collaborative Learning } \\
R^{2}=.060\end{array}$ & Supportive Environment & $.246 * *$ & \\
\hline $\begin{array}{l}\text { Student-Faculty Interaction } \\
R^{2}=.087\end{array}$ & Supportive Environment & $.295 * *$ & \\
\hline Quality of Interactions & Supportive Environment & $.344 * *$ & .074 \\
\hline
\end{tabular}




\begin{tabular}{|c|c|c|c|}
\hline$R^{2}=.222$ & $\begin{array}{l}\text { Effective Teaching } \\
\text { Practices }\end{array}$ & $.230 * *$ & \\
\hline Academic Challenge & Supportive Environment & $.216^{* *}$ & $.257 * *$ \\
\hline \multirow[t]{3}{*}{$R^{2}=.545$} & $\begin{array}{l}\text { Effective Teaching } \\
\text { Practices }\end{array}$ & $.255^{* *}$ & \\
\hline & Collaborative Learning & $.410 * *$ & \\
\hline & Student-Faculty Interaction & $.251 * *$ & \\
\hline Overall Undergraduate GPA & Quality of Interactions & $.267 * *$ & \\
\hline \multirow[t]{5}{*}{$R^{2}=.090$} & Academic Challenges & .085 & \\
\hline & Supportive Environment & & $.152 *$ \\
\hline & $\begin{array}{l}\text { Effective Teaching } \\
\text { Practices }\end{array}$ & & .083 \\
\hline & Collaborative Learning & & .035 \\
\hline & Student-Faculty Interaction & & .021 \\
\hline Higher Order Learning & Academic Challenges & $.664 * *$ & \\
\hline \multirow[t]{4}{*}{$R^{2}=.441$} & Supportive Environment & & $.314 * *$ \\
\hline & $\begin{array}{l}\text { Effective Teaching } \\
\text { Practices }\end{array}$ & & $.170^{*}$ \\
\hline & Collaborative Learning & & $.273 * *$ \\
\hline & Student-Faculty Interaction & & $.167 *$ \\
\hline $\begin{array}{l}\text { Reflective \& Integrative } \\
\text { Learning }\end{array}$ & Academic Challenges & $.714 * *$ & \\
\hline \multirow[t]{4}{*}{$R^{2}=.510$} & Supportive Environment & & $.338 * *$ \\
\hline & $\begin{array}{l}\text { Effective Teaching } \\
\text { Practices }\end{array}$ & & $.182 *$ \\
\hline & Collaborative Learning & & $.293 * *$ \\
\hline & Student-Faculty Interaction & & $.179^{*}$ \\
\hline Learning Strategies & Academic Challenges & $.618 * *$ & \\
\hline \multirow[t]{4}{*}{$R^{2}=.382$} & Supportive Environment & & $.292 * *$ \\
\hline & $\begin{array}{l}\text { Effective Teaching } \\
\text { Practices }\end{array}$ & & $.158^{*}$ \\
\hline & Collaborative Learning & & $.254 * *$ \\
\hline & Student-Faculty Interaction & & $.155^{*}$ \\
\hline Quantitative Reasoning & Academic Challenges & $.472 * *$ & \\
\hline \multirow[t]{4}{*}{$R^{2}=.223$} & Supportive Environment & & $.223^{*}$ \\
\hline & $\begin{array}{l}\text { Effective Teaching } \\
\text { Practices }\end{array}$ & & .121 \\
\hline & Collaborative Learning & & $.194 *$ \\
\hline & Student-Faculty Interaction & & .118 \\
\hline
\end{tabular}

Note ${ }^{* *} p<.001, * p<.05$ 


\section{Engagement \& Degree Completion}

These discriminant function analyses were conducted to determine whether the student engagement variables Higher-Order Learning, Reflective \& Integrative Learning, Learning Strategies, Quantitative Reasoning, Collaborative Learning, Student-Faculty Interaction, Effective Teaching Practices, Quality of Interactions, and Supportive Environment could significantly predict the likelihood of degree completion for first-year and for senior students. The goal was to answer the two research questions regarding this section: 1) "Does student engagement predict degree completion?" and 2) "Which measures of student engagement best predict for degree completion?"

Before discussing the discriminant analyses, a brief explanation of the criteria for inclusion of variables when interpreting a discriminant function should be given. Tabachnick \& Fidell (2019) recommend the use of correlation scores for interpreting the discriminant function while the standardized coefficients should be used when computing discriminant scores. They also recommend that correlation coefficients only be interpreted if they reach .33 (10\% of the variance), which is considered poor. Loadings reaching .45 (20\%) are considered fair, .55 (30\%) are considered good, .63 (40\%) are considered very good, and .71 (50\%) are considered excellent.

\section{First-Year Students}

The assumptions for discriminant analysis for the first-year dataset have already been tested above, with good evidence for normal distribution, a lack of collinearity, and only three of the nine engagement variables meeting the homogeneity of variancecovariance assumption. A Box's $M$ test also indicated a failure to meet the homogeneity of variance-covariance assumption $(M=82.17, p<.01)$. Wilks's lambda for the overall 
test was statistically significant, $\Lambda=.87, \chi^{2}(9, N=136)=17.84, p<.04$, indicating that the engagement variables differentiated between whether or not the student graduated. Since there were only two groups, graduated and did not graduate, only one discriminant function was possible. The analysis indicated an eigenvalue of .15 and canonical correlation of $.36\left(\eta^{2}=.13\right)$.

Based on the correlation coefficients with discriminant functions and standardized coefficients for discriminant functions, Learning Strategies (.60) and Reflective \& Integrative Learning (.54) were the best variables for predicting degree completion. These were followed by Collaborative Learning (.40), Higher-Order Learning (.34), Quality of Interactions (.33), Supportive Environment (.32), Quantitative Reasoning (.12), Effective Teaching Practices (-.04), and Student-Faculty Interaction (-.01). Three of the best variables for predicting degree completion, including Higher-Order Learning, Reflective \& Integrative Learning, and Learning Strategies, along with Quantitative Reasoning, which is not strong predictor, comprise the latent variable Academic Challenge. Another way to look at the outcome is to combine the three best variables which are Learning Strategies, Reflective \& Integrative Learning, and Cooperative Learning, which may for a latent variable that could be referred to as General Learning Strategies. This indicates that Academic Challenge and/or General Learning Strategies discriminates between those who completed their degree (group centroid $=-.542$ ) and those who did not (group centroid $=.268$ ). These results suggest that students are more likely to complete their degree if they experience greater levels of Academic Challenge.

The function was much better at predicting that students had completed their degree $($ group centroid $=.268)$ than it was student failure to complete a degree (group 
centroid $=-.542$ ). The function was able to correctly classify $66.9 \%$ of the original cases ( $86.8 \%$ graduated, $26.7 \%$ did not graduate). In order to account for chance agreement, a kappa coefficient was computed resulting in a value .34 , a fair value.

Table 22

Discriminant Function Summary: First-Year Students

\begin{tabular}{lcc}
\hline Variable & Correlation & $\begin{array}{c}\text { Standardized } \\
\text { Coefficient }\end{array}$ \\
\hline Higher-Order Learning & .335 & .000 \\
Reflective and Integrative Learning & .535 & .470 \\
Learning Strategies & .598 & .582 \\
Quantitative Reasoning & -.121 & -.433 \\
Collaborative Learning & .404 & .281 \\
Student-Faculty Interaction & -.010 & -.33 \\
Effective Teaching Practices & -.040 & -.397 \\
Quality of Interactions & .333 & .405 \\
Supportive Environment & .322 & .250 \\
Canonical Correlation $=.359$ & & \\
Wilk's Lambda = .871 & & \\
Chi-Square $=17.835$ & & \\
$d f=9$ & & \\
$p=.037$ & & \\
\hline
\end{tabular}

\section{Senior Students}

The assumptions for discriminant analysis for the senior data set have also already been tested above, with good evidence for normal distribution, a lack of collinearity, and failure to meet the homogeneity of variance assumption. A Box's $M$ test also indicated a failure to meet the homogeneity of variance-covariance assumption $(M=77.90, p=.05)$. The Wilks's lambda for the overall test was not statistically significant, $\Lambda=.98, \chi^{2}(9, N=$ $239)=5.23, p>.05$, indicating that the engagement variables did not differentiate 
between whether or not the student graduated. Since there were only two groups, graduated and did not graduate, only one discriminant function was possible. The analysis indicated an eigenvalue of .02 and canonical correlation of $.15\left(\eta^{2}=.02\right)$.

Based on the correlation coefficients with discriminant functions and standardized coefficients for discriminant functions, Effective Teaching Practices (.43) and Collaborative Learning (.38) were the best variables for predicting degree completion. These were followed by Supportive Environment (.33), Higher-Order Learning (.30), Student-Faculty Interaction (.25), Reflective \& Integrative Learning (-.24), Quantitative Reasoning (.13), Quality of Interactions (-.12), and Learning Strategies (-.01). These results suggest that students with professors who use more Effective Teaching Practices and students engaging in more frequent Collaborative Learning are more likely to complete their degree. The function predicted that all the students had completed their degree (group centroid $=.043)$ and that none had failed to complete their degree $(-.526)$. The function was able to correctly classify $92.5 \%$ of the original cases (100\% degree completed, $0 \%$ did not complete degree). 
Table 23

Discriminant Function Summary: Senior Students

\begin{tabular}{lcc}
\hline & & Standardized \\
Variable & Correlation & Coefficient \\
\hline Higher-Order Learning & .297 & .393 \\
Reflective and Integrative Learning & -.243 & -.825 \\
Learning Strategies & -.008 & -.333 \\
Quantitative Reasoning & .128 & .041 \\
Collaborative Learning & .378 & .557 \\
Student-Faculty Interaction & .253 & .191 \\
Effective Teaching Practices & .425 & .532 \\
Quality of Interactions & -.119 & -.446 \\
Supportive Environment & .327 & .418 \\
Canonical Correlation $=.149$ & & \\
Wilk's Lambda $=.978$ & & \\
Chi-Square $=5.232$ & & \\
$d f=9$ & & \\
$p=.814$ & & \\
\hline
\end{tabular}

\section{Summary of Major Findings}

- Senior students had a greater amount of interaction with faculty while first-year students reported feeling a higher level of support from their institution.

- SEM indicated that the best direct predictor of first-year student GPA was Academic Challenge (Higher-Order Learning, Reflective \& Integrative Learning, Learning Strategies, and Quantitative Reasoning). Higher levels of Academic Challenge predicted for higher GPA scores.

○ The only other significant direct predictor of first-year student GPA was Student-Faculty Interaction. Of note, this relationship was inverse. Fewer interactions with faculty predicted a better GPA. 
- Supportive Environment, Student-Faculty Interaction, and Effective Teaching Practices were important indirect predictors of first-year student GPA by predicting $46.5 \%$ of Academic Challenge.

- Collaborative Learning and Quality of Interactions were not important direct or indirect contributors to first-year student GPA.

- The final first-year SEM fit the data well and explained 19\% of first-year student GPA.

- SEM indicated that the best direct predictor of senior student GPA was Quality of Interactions. Better Quality of Interactions was related to higher GPA scores.

- The only other direct predictor that remained in the model was Academic Challenge (Higher-Order Learning, Reflective \& Integrative Learning, Learning Strategies, and Quantitative Reasoning), which contributed very little in explaining GPA scores (nonsignificant).

- Supportive Environment, Student-Faculty Interaction, and Effective Teaching Practices, and Collaborative Learning were indirect predictors of senior student GPA by predicting for Academic Challenge.

- Supportive Environment and Effective Teaching Practices were important indirect predictors of senior student GPA by predicting 22.2\% of Quality of Interactions.

- The final senior SEM fit the data well but only explained $9 \%$ of senior student GPA.

- A discriminant analysis was able to correctly classify $66.9 \%$ of first-year student cases on whether or not they eventually graduated based on the student engagement variables. 
- The best variables for predicting degree completion were Learning Strategies and Reflective \& Integrative Learning.

- A discriminant analysis based on the student engagement variables was not able to significantly predict for senior student graduation.

- The best variables for predicting degree completion were Effective Teaching Practices and Collaborative Learning. 


\section{CHAPTER 5}

\section{SUMMARY, DISCUSSION, CONCLUSION, \& RECOMMENDATIONS}

\section{Statement of the Problem}

As the tuition and student loan debt has risen, the pressure on colleges and universities to provide stakeholders with accountability and student success data has increased. This social climate demands that institutions of higher education leverage the data they collect from their students to improve the learning environment. While other researchers have investigated this topic, there are important samples that needed further examination. Small private and highly racially and ethnically diverse college and university populations have largely been overlooked as research has focused on large, predominantly white, research institutions. Research is needed to determine if the relationships found between academic engagement and success found in these larger, less diverse schools is similar or different for those that are smaller and more diverse. There is also a need for researchers to examine this relationship based on the newest version of the NSSE, and whether it can predict degree completion rates of first-year students, requiring four to five years to elapse after its release. Finally, research in this area tends to employ regression analysis to examine the relationship between academic engagement and success, but very few have attempted to use Structural Equation Modeling (SEM) to help understand the complex relationships between engagement and achievement. As higher education institutions attempt to apply existing findings on the relationship between 
academic engagement and success to their practices, they need a more clear and nuanced understanding which SEM provides.

\section{Purpose of the Study}

The purpose of this study was to investigate the relationship between student engagement and both academic performance and degree completion. The primary researcher was interested in determining the nature of this relationship. The goal was to identify areas of engagement that are most important to student achievement and degree completion. Findings from this study may provide institutions and faculty with a better understanding of how to engage students to maximize the students' opportunities for academic success.

\section{Summary of the Literature}

The increasing costs of higher education has led to a greater demand for accountability standards, and academic engagement as become one of those standards (Pascarella, Seifert, \& Blaich, 2010; Zhou, 2010). Besides being measurable, engagement over time has become recognized as a gauge of institutional excellence because good quality teaching and learning are thought to produce high levels of student engagement (Axelson \& Flick, 2011; Chickering \& Gamson, 1987; Coates, 2007; Hague-Palmer, 2013; Strayhorn \& DeVita, 2010). Not only is engagement used to inform decisions, but colleges and universities design programs in order to better engage students with their academic studies, their peers, their professors, and with the institution itself (CasusoHolgado et al., 2013; Pascarella \& Terenzini, 2005; Sheard, Carbone, \& Hurst, 2010). The NSSE survey, which was developed from research from the 1970s through 2000, has been used to measure engagement over the past twenty years, and includes both student 
time and effort invested in academic studies as well as the effort of the higher education institution to get their students involved in learning experiences (National Survey of Student Engagement, 2019a).

\section{Engagement}

Over time, researchers have found differences in academic engagement based on numerous demographic and other variables, including gender, race and ethnicity, age, class preparation, faculty and peer interaction, and institutional characteristics and practices. In general, women tend to be more engaged than men (Hu \& Kuh, 2002), racial and ethnic minorities indicate higher levels of engagement than White students (Bowden, 2014; CCSSE, 2005; Fursman, 2012; Gamm, 2011; Greene, Marti, \& McClenney, 2008; Hu \& Kuh, 2002; Kuh et al., 2006; Schlinsog, 2010), older students are more engaged than their younger peers (Conway et al., 2011; Fursman, 2012; Gibson \& Slate, 2010; Hu \& Kuh, 2002), more class preparation is related to higher overall engagement (Braxton, Milem, \& Sullivan, 2000; Hu \& Kuh, 2002; Khaira, 2016), increased interaction with faculty and peers is related to greater engagement (Kuh \& Hu, 2001; Pascarella \& Terenzini, 1991; Umbach \& Wawrzynski, 2005), and smaller institutions tend to have greater engagement (Conway et al., 2011; Kezar, 2006; Khaira, 2016; Kuh et al., 2006).

\section{Measures of Student Achievement}

Although students engage in many activities that are designed to demonstrate and quantify their learning, most lack uniformity between fields of study and academic institutions. This leads researchers to rely on the comparable measures, such as GPA, standardized tests, and graduation rates. While imperfect and controversial, these are still important measures of academic success and their use, especially GPA, is commonplace 
within academic research (Kuh et al., 2008; Gordon et al., 2008; Carini, et al., 2006;

Robbins, Lauver, Le, David, Langley, \& Carlstrom, 2004).

Engagement \& Achievement

Academic Challenge, or Level of Academic Challenge (LAC) as it was known in the previous version of the NSSE, gathers information on the types of learning and time spent in learning activities that a student engages in. Research in this area has indicated a positive relationship between these activities and academic achievement (Carini et al., 2006; Fuller et al., 2011; Fursman, 2012; Gamm, 2011; Gordon et al., 2008; Khaira, 2016; Kuh, 2002; Rugutt \& Chemosit, 2005). A number of these studies only found that this relationship held true for first-year students, but not seniors (Fuller et al., 2011; Fursman, 2012; Gordon et al., 2008). Most studies also agree that class preparation, specifically, is what is positively related to higher GPA scores (Astin, 1993; Hyatt, 2011; Kuh, 1995; Kuh et al., 2007; Kuh et al., 2008; Pascarella \& Terenzini, 2005; Salamonson, Andrew, \& Everett, 2009; Tross, Harper, Osher, \& Keidinger, 2000; Webber, Krylow, \& Zhang, 2013).

Learning with Peers roughly corresponds to Active and Collaborative Learning (ACL) in the previous version of the NSSE. While numerous studies have found links between engaging with peers, active involvement in learning practices, and academic achievement, there is some disagreement on whether first-year or senior students benefit (Fuller et al., 2011; Gordon et al., 2008). Other research indicates that both groups benefit (Carini et al., 2006; Kuh, 2002). Other research findings, specifically related to the relationship between involvement in co-curricular activities and GPA, indicate a likely non-linear relationship (Kuh et al., 2008; Zacherman \& Foubert, 2014). This indicates 
that some involvement in co-curricular activities is related to increases in GPA, but that too much involvement is harmful.

Students benefit from interactions with faculty, despite having few opportunities to do so (Alderman, 2008; Anaya \& Cole, 2001; Cotton \& Wilson, 2006; Keup, 2007). There is evidence that interacting with faculty provides students with numerous benefits, including an increase in GPA (Carini et al., 2006; Gordon et al., 2008; Hearn, 1987; Rugutt \& Chemositt, 2005). Certain studies find this to be true for first-year students (Hearn, 1987) or seniors (Gordan et al., 2008), while others have found this interaction to be a better predictor of GPA than other forms of academic engagement (Carini et al., 2006; Rugutt \& Chemositt, 2005).

Students' academic achievement also benefits from good relationships with administration and staff (Carini et al., 2006; LaNasa et al., 2007). These relationships, along with other factors, contribute to a positive campus environment. There have also been studies that found student ratings of the supportiveness of their campus as the best predictors of their academic performance (Fursman, 2012; Korobova \& Starobin, 2015). Research indicates that senior students see the most benefit to their GPAs from a supportive campus when compared with first-year students (Fursman, 2012; Gordon et al., 2008).

Although fewer studies have attempted to examine the relationship between academic engagement and degree completion, there is still good evidence that the two tend to be positively related (Astin, 1993; Brown \& Burdsal, 2012; Hood, 2014; Kuh, 2009; Kuh et al., 2006; Pascarella \& Terenzini; 2005; Russell, et al., 2007; Svanum \& Bigatti, 2009; Tinto, 1987). Students who are more engaged are more likely to graduate 
earlier (Svanum \& Bigatti, 2009) and on-time (Fiorini et al., 2014) than their less engaged peers. Participation in co-curricular activities has been linked to on-time graduation (Fiorini et al., 2014), participation in undergraduate research has been linked to increased likelihood of degree completion (Russell et al., 2007), and better relationships with peers has been found to be related to both on-time and increased likelihood of graduation (Brown \& Budsal, 2012; Fiorini et al., 2014).

\section{Methodology}

\section{Design}

The design of this study is a secondary quantitative analysis of non-experimental descriptive data collected using survey methodology. The design is ideal for this topic as the required quantitative data has already been collected by Andrews University using the National Survey of Student Engagement (NSSE). The data gathered by the NSSE allows for predictive analysis, which is used in this study.

\section{Sample}

The sample used by the sample was relatively diverse based on the demographic variables. First-year students identified as 23.5\% Asian, 22.1\% Black or African American, 33.1\% White, and the remaining $21.3 \%$ were of other or mixed races and ethnicities. About two thirds (66.9\%) of first-year students were women and the largest portion of responders were majoring in health professions $(25.7 \%)$, biological and related sciences $(20.6 \%)$, and arts and humanities (19.1\%). About two thirds (66.95\%) had completed their degree at Andrews University at the time of this data collection. Senior students identified as 14.6\% Asian, 22.6\% Black or African American, 47.3\% White, and the remaining $15.5 \%$ were of other or mixed races and ethnicities. A majority $(61.9 \%)$ of 
senior students were women and the largest portion of responders were majoring in arts and humanities (23.8\%), health professions (21.3\%), and biological and related sciences (11.7\%). Most (92.5\%) had completed their degree at Andrews University at the time of this data collection.

\section{Instrumentation}

The instrument used is The College Student Report (The Report), which is administered as part of the National Survey of Student Engagement (NSSE). The instrument was developed by a panel of experts as an alternative measure of program quality. The current version launched in 2013, has 84 questions, as well as a number of demographic questions.

All of the questions are self-report Likert-type items, most of which are on a fourpoint scale (ex., very often, often, sometimes, never). Many of these items are grouped into ten engagement indicators, which are then grouped into four engagement themes: Academic Challenge (theme) - Higher-Order Learning, Reflective \& Integrative Learning, Quantitative Reasoning, and Learning Strategies; Learning with Peers Collaborative Learning, and Discussions with Diverse Others; Experiences with Faculty - Student-Faculty Interaction, and Effective Teaching Practices; Campus Environment Quality of Interactions, and Supportive Environment. Cronbach's alpha scores for these Engagement Indicators fall within acceptable ranges (.77-.91) and indicate that they are reliable. Validity was established using response process (cognitive interviews and focus groups) and predictive evidence (demonstrated through the instrument's ability to predict retention of first-year students). 


\section{Procedure}

The sample for this study consisted of the students who participated in the 2013 and 2015 iterations of the NSSE at Andrews University, and access to the data was gained by going through the IRB procedures and requesting that the institutional research department share the data. Requests were made for student GPA scores and degree completion data to be added to the data. The requested information was added and all identifying data was removed before the data was sent to the primary investigator of this study. After receiving the data, statistical analysis was conducted using SPSS Version 25 \& SPSS Amos Version 25 for Windows.

\section{Results}

\section{Engagement Indicators}

Engagement Indicator scores range from zero (no engagement) to sixty (highest possible engagement). Within this sample, first-year students' engagement scores fell between nineteen and forty, indicating not particular very high or very low engagement areas. First-year students reported their highest engagement scores in Quality of Interactions $(M=39.98, S D=12.72)$, Higher-Order Learning $(M=38.75, S D=13.97)$, and Learning Strategies $(M=38.52, S D=15.31)$, which indicated that they were "often" engaged in these or that they had better than okay relationships with others. They reported Quantitative Reasoning $(M=22.41, S D=15.69)$ and Student-Faculty Interaction $(M=19.37, S D=12.61)$ engagement scores that were notably well below all other engagement scores, indicating that they engaged in these only "sometimes." All the remaining scores fell in the mid-to-low thirties, indicating that they were generally leaning towards "often" engaged in these areas. 
Senior students' engagement scores fell between twenty-three and forty-one, indicating not particular very high or very low engagement areas. Senior students reported their highest engagement scores in Quality of Interactions $(M=40.75, S D=$ 11.05), Higher-Order Learning $(M=39.75, S D=14.39)$, and Effective Teaching Practices $(M=38.29, S D=13.22)$, which indicated that they were "often" engaged in these or that they had better than okay relationships with others. They reported StudentFaculty Interaction $(M=25.15, S D=13.61)$ and Quantitative Reasoning $(M=23.36, S D$ $=16.76$ ) engagement scores that were notably well below all other engagement scores, indicating that they engaged in these only "sometimes." All the remaining scores fell in the mid-to-low thirties, indicating that they were generally leaning towards "often" engaged in these areas.

In general, senior students reported higher engagement scores than first-year students. The most notable difference between the groups is in Student-Faculty Interaction, as seniors are much more likely to interact with faculty ( $M=25.15$ vs. $M=$ 19.37). Within this, it is apparent that seniors are more likely to talk about their career plans with faculty, work with faculty on activities other than coursework, and discuss a course with faculty outside of class. Seniors were only slightly more likely to discuss their academic performance with faculty than first-year students. Another difference was that seniors reported more Reflective $\&$ Integrative Learning $(M=37.08$ vs. $M=33.90)$ within Academic Challenge. This held true for all the sub-items but was most notable in combining ideas from different courses when completing assignments $(M=2.79$ vs. $M=$ 2.49). The other notable difference between first-year and senior students on the Engagement Indicators was Supportive Environment. First-year students reported a more 
Supportive Environment than seniors $(M=36.76$ vs. $M=33.53)$. First-year students reported higher scores on every subarea, but especially in using learning support services ( $M=3.10$ vs. $M=2.80$ ), [school providing support by] helping you manage your nonacademic responsibilities ( $M=2.30$ vs. $M=2.02$ ), and [school] providing support for your overall well-being ( $M=3.02$ vs. $M=2.78)$. Although there was only a minor overall difference between the groups on their Learning Strategies, it is worth noting that firstyear students reported reviewing their notes after class more than seniors $(M=2.85$ vs. $M$ $=2.59$ ). Also, while only small differences in Quality of Interactions exist, both groups report very high quality of interactions with other students, academic advisors, and faculty. Seniors report notably higher quality of interactions with academic advisors ( $M=$ 5.49 vs. $M=5.19)$ and faculty $(M=5.42$ vs. $M=5.13)$.

\section{Engagement \& GPA}

\section{First-Year Students}

Analysis of the hypothesized SEM model for first-year students indicated that the model somewhat fit the data $\left(\chi^{2}=50.68, d f=25, p=.002\right.$, GFI $=.932$, CFI $=.901$, RMSEA $=.087)$. This model provided evidence that the way that the engagement factors were hypothesized to predict first-year student GPA had the potential to fit the data well with some adjustments. After modifying the model by removing non-significant path coefficients, the final model was determined $\left(\chi^{2}=21.25, d f=24, p=.22\right.$, GFI $=.963$, $\mathrm{CFI}=.979, \mathrm{RMSEA}=.043)$.

The final model predicts 19\% of first-year student GPA, with Academic Challenge and Student-Faculty Interaction remaining as the two direct predictors of GPA. Academic Challenge, which is composed of Higher-Order Learning, Reflective and 
Integrative Learning, Learning Strategies, and Quantitative Reasoning, was the strongest predictor of the first-year-students' GPA scores. Student-Faculty Interaction, Effective Teaching Practices, and Supportive Environment were all important predictors of Academic Challenge.

These findings suggest that students engaging in courses and coursework that requires them to apply, analyze, evaluate, synthesize, connect, include diverse perspectives, examine strengths and weaknesses, try to understand others' views, analyze numerical information, and take time outside of class to review and summarize their learning were more likely to earn better grades. These findings also suggest that students achieve better grades when they spend less time with faculty. For first-year students, engaging in certain kinds of learning, spending time outside class to review class topics, and interacting less frequently with faculty outside of class are the most important engagement activities related to earning good grades. Perhaps most interestingly is the fact that Student-Faculty Interaction is the best and a positive indirect predictor of GPA at about the same strength it is a direct predictor $(\beta=.21)$. This indicates that while interaction with faculty directly predict a lower GPA score, interactions with faculty also contribute to student learning through academic challenge, which in turns predicts better GPA. Indirectly through Academic Challenge, a supportive environment in which to learn $(\beta=.17)$ and the use of effective teaching practices are also helpful $(\beta=.16)$. Concurrently, it is worth noting that collaborative types of learning and the quality of a student's interactions with their peers, staff, faculty, academic advisors, and administration do not contribute to better grades. The lack of a predictive relationship between Quality of Interactions and Supportive Environment is somewhat curious. 


\section{Senior Students}

Initial analysis of the hypothesized SEM model for senior students indicated that it fit the data somewhat $\left(\chi^{2}=44.92, d f=25 p=.009, \mathrm{GFI}=.966, \mathrm{CFI}=.956, \mathrm{RMSEA}=\right.$ .058). This finding provided a good indication that further adjustment of the model would result in a good-fitting model for using engagement factors to predict senior GPA. After modifying the model by removing non-significant path coefficients, the final model was determined $\left(\chi^{2}=35.93, d f=29, p=.176, \mathrm{GFI}=.971, \mathrm{CFI}=.985\right.$, RMSEA $\left.=.032\right)$.

Despite the good fit with the data, the model predicted for only $9 \%$ of senior student GPA. Quality of Interactions is the best and only significant predictor of senior GPA scores $(\beta=.27)$. The predictive relationship between Academic Challenge and GPA was retained for the integrity of the model. Besides Quality of Interactions, the only other significant predictor was Supportive Environment, which weakly and indirectly predicted GPA $(\beta=.15)$. Within the model, Supportive Environment $(\beta=.34)$ and Effective Teaching Practices $(\beta=.23)$ directly contribute to the Quality of Interactions factor. Supportive Environment is a better indirect predictor of Academic Challenge $(\beta=.26)$ than it is a direct predictor $(\beta=.22)$. Student-Faculty Interaction $(\beta=.25)$, Effective Teaching Practices $(\beta=.26)$, and Collaborative Learning $(\beta=.41)$ all indirectly contribute to Academic Challenge. This indicates that the quality of interactions seniors have, as well as how well the institution supports them, is what predicts for their academic achievement. Interestingly then, the types of learning, quality of interactions with others on campus, interactions with faculty, and the study habits of seniors all are not helpful in trying to predict their grades. 


\section{Engagement \& Degree Completion}

\section{First-Year Students}

The discriminant function analysis for first-year students was statistically significant $\left(\Lambda=.87, \chi^{2}(9, N=136)=17.84, p<.04\right)$, classifying students who completed their degree and those who did not complete their degree with about $67 \%$ accuracy. Therefore, the evidence suggests that the null hypothesis can be rejected; that there is support for the research hypothesis. Most of the predictive power of this model came from two types of engagement: Learning Strategies and Reflective \& Integrative Learning. Both of these contribute to the latent variable Academic Challenge and indicate the class preparation and that challenging and connecting learning from multiple classes best predict whether a first-year student will complete their degree at their current institution. The other two variables that makeup Academic Challenge, Higher-Order Learning and Quantitative Reasoning, also contributed to the model. First-year students engaging in more Learning Strategies, Reflective \& Integrative Learning, and HigherOrder Learning, along with less Quantitative Reasoning, are more likely to complete their degree. Students engaged in more Collaborative Learning, that have a more Supportive Environment, and have teachers that use fewer Effective Teaching Strategies are also more likely to graduate.

\section{Senior Students}

The linear combination of senior student engagement variables was nonsignificant and unable to correctly classify whether a student would finish their degree. Therefore, engagement factors are not important for predicting degree completion for seniors. These findings will be discussed further in the following section. 


\section{Discussion}

\section{Engagement Indicators}

Students in this sample reported engagement indicator scores generally above the middle score between the most and least possible engagement, although even the best engagement scores were still only about $33 \%$ lower than the highest possible engagement score (generally indicating a response of 'often'). This slight skew towards greater engagement may be related to the sample's relatively high mean GPA score $(M=3.47$, $S D=.58$, skewness $=-2.05)$, indicating that the sample was skewed towards higher achievement students.

For both first-year and senior students, Quality of Interactions had the highest scores, indicating the highest quality of interactions with peers, academic advisors, faculty, students services staff, and other administrative staff, respectively. Seniors report higher quality of interactions with academic advisors and faculty, which is likely because of the increased opportunities they have had interact and benefit from those individuals. With the sample being drawn from a relatively smaller university, there are clearly good opportunities for positive interactions with academic advisors, faculty, and even other employees. The faculty also seem to be engaging them best in Higher-Order Learning (analyzing, applying, evaluating, and forming new ideas) when compared with other types of learning.

The third most engaged area differs between first-years and seniors in somewhat of a surprising way. First-year students report slightly more engagement in Learning Strategies, but especially in reviewing their notes after class, than seniors. While firstyear students may be truly putting more energy into these types of class preparation 
activities, it is possible that senior students are more honest or are better judges of their class preparation. Another possibility is that senior students engage in other types of class preparation that are not measured by the Learning Strategies indicator or by reviewing their notes after class. For seniors, the third highest engagement score is in Effective Teaching Practices. While the sub-scores are similar, it does appear that seniors have been more likely to receive prompt and detailed feedback on a test or assignment. This is consistent with smaller upper division classes in which faculty have more time to engage with each individual student's work.

Besides the Engagement Indicators most highly rated, there were three other particularly interesting engagement ratings: Supportive Environment, Quantitative Reasoning, and Student-Faculty Interaction. Despite rating Quality Interactions as the highest Engagement Indicator, both first-year and senior students rated Supportive Environment much lower (first-year $M=36.76$; senior $M=33.53$ ); which includes providing support to help students succeed academically, using learning support services, encouraging contact among students from different backgrounds, providing opportunities to be involved socially, providing support for overall well-being, helping students manage non-academic responsibilities, attending campus activities, and attending events that address important issues. Somehow, the quality interactions students are having do not come with the feelings of being supported by the institution that might be expected. Also, first-year students reported a more Supportive Environment than seniors which may be the result of the institution taking special care to make new students feel welcome and supported in order to increase retention. 
Quantitative Reasoning was ranked in the bottom two in terms of engagement for both first-year and senior students. This indicates that students are not encountering many opportunities to analyze and evaluate problems and conclusions using numbers. It may be that numerical analysis remains in mathematics and statistics courses, while the other learning methods (areas of Academic Challenge) are more widely applied across classes of various topics.

Finally, Student-Faculty Interaction also had one of the lowest scores, which is consistent with previous research that indicates that students have few opportunities to interact with their professors (Alderman, 2008; Anaya \& Cole, 2001; Cotton \& Wilson, 2006; Keup, 2007). This is also an area in which the largest difference between first-year and senior students is in Student-Faculty Interaction (first-year $M=19.37$; senior $M=$ 25.15); this includes talking about career paths with a faculty member, working with a faculty member on activities other than coursework, discussing course topics outside class with a faculty member, and discussing one's academic performance with a faculty member. This may result from students having more opportunities to interact with faculty over time and in small upper-division classes which encourage more interaction and mentorship outside the classroom. This is supported by the sub-item findings that suggest that seniors are more likely to talk about their career plans with faculty, work with faculty on activities other than coursework, and discuss a course with faculty outside of class.

\section{Engagement \& GPA}

While the evidence provided by this study for engagement indicators being predictive of GPA is not as strong as academic institutions might desire, there is still considerable evidence that specific types of engagement are important for how well 
students do in their coursework. Yes, engagement indicators predict for GPA, with the most important types of engagement depending on whether first-year or senior students are being surveyed. This contradicts some work on the previous version of the NSSE, which did not find significant relationships between NSSE benchmarks and GPA (Bowden, 2014; Schlinsog, 2010; Zhou, 2010). This study does, however, lend support to the numerous studies that have found that student engagement is predictive of GPA (Carini et al., 2006; Fuller et al., 2011; Gordon et al., 2008; Kuh, 2009; Kuh et al., 2008; Kuh, 2001; Pascarella \& Terenzini, 2005; Pike et al., 2008; Zhou, 2010).

For first-year students, academic engagement predicts 19\% of GPA, with Academic Challenge and Student-Faculty Interaction remaining as the two direct predictors of GPA, and three significant indirect predictors: Student-Faculty Interaction, Supportive Environment, and Effective Teaching Practices. As for seniors, their academic engagement only predicts $9 \%$ of GPA, meaning that academic engagement is far more important for predicting first-year student academic achievement. Within the senior model, Quality of Interactions is the best and only significant direct predictor of senior GPA scores (with the direct relationship between Academic Challenge and GPA only being retained for the integrity of the model), while Supportive Environment was the only significant indirect predictor. The differences between the models are notable. Firstyear students succeed when having more and less contact with faculty (discussed further below), and engaging in traditional and somewhat expected learning strategies, as well as benefitting from good teaching practices and a supportive environment. For seniors, academic achievement is linked to quality relationships and a supportive environment. 


\section{Academic Challenge}

The ability of Academic Challenge to predict first-year student GPA emphasizes the importance of courses that require them to apply, analyze, evaluate, synthesize, connect, include diverse perspectives, examine strengths and weaknesses, try to understand others' views, analyze numerical information, and take time outside of class to review and summarize their learning were more likely to earn better grades. As these activities are considered important to good learning (Chickering \& Gamson, 1987; Kuh, 2001; Kuh, 2003; Kuh, 2009), this is consistent with the idea that students who are learning better will earn higher grades. Predictably then, this positive relationship in the first-year student model between activities within the Academic Challenge latent variable and student GPA has also been found in other studies (Carini et al., 2006; Fuller et al., 2011; Fursman, 2012; Gamm, 2011; Gordon et al., 2008; Khaira, 2016; Kuh, 2002; Kuh et al., 2008; Rugutt \& Chemosit, 2005). What might be considered surprising is that Academic Challenge does not significantly predict for senior students' GPA, considering that good learning activities would be expected to predict academic achievement. This difference is, in fact, consistent with previous studies that found Academic Challenge predicted first-year, but not senior GPA (Fuller et al., 2011; Fursman, 2012; Gordon et al., 2008).

The predictive value of Academic Challenge on first-year student GPA was stronger in this study than in previous studies, possibly supporting previous research that indicates engagement is more predictive of academic success for students belonging to racial and ethnic minority groups as well as students who are lower-performing (Carini, Kuh, \& Klein, 2006; Cole, 2010; Greene et al., 2008). These are likely the same reasons 
that Academic Challenge was found to be predictive of first-year, but not senior GPA. The first-year student group was significantly more diverse than the senior group $(66.9 \%$ vs. $52.7 \%$ racial and ethnic minorities), and therefore may be benefitting more from engagement. This senior group may be less diverse because of attrition, or simply because it was less diverse to begin with. Another conceivable contributor is that the first-year students were, overall, lower-performing than their senior counterparts. While the GPA data appears very similar (first-year: 3.47; senior: 3.48), first-year students have only completed their first semester, which tends to be more introductory, as opposed to the seniors who have completed multiple quarters of upper division coursework. Maintaining such a strong GPA is challenging, and therefore we may have a group of senior students who are better academically than their first-year peers, because of attrition or that students that make it to their senior year tend to become stronger academically than they were to begin with. Finally, it is possible that first-year students taking coursework or majors with greater levels of Academic Challenge simply benefit more from this - whether the additional challenge and engagement pushes them to perform better academically or that those programs simply require better grades (Fursman, 2012). When one has reached senior year, it may be that one is motivated to perform well based on internal factors or other external factors unrelated to the Academic Challenge factors within their courses.

\section{Student-Faculty Interaction}

Student-Faculty Interaction is likely the most interesting predictor within firstyear student model, while contributing very little to the senior student model. Within the first-year model, Student-Faculty Interaction is a negative direct predictor of GPA while 
simultaneously being a slightly stronger positive indirect predictor of GPA through Academic Achievement. Based on its direct predictive relationship with GPA, first-year students have better GPA scores when they have fewer interactions with faculty. Simultaneously, more interactions with faculty predict for a higher GPA score indirectly through Academic Challenge. The direct relationship contradicts much of the available research on the relationship, while the indirect relationship supports existing findings (Anaya \& Cole, 2001; Astin, 1993; Carini et al., 2006; Cole, 2010; Delaney, 2008; Gordon et al., 2008; Hern, 1987; LaNasa et al., 2007; Pascarella \& Terenzini, 2005; Rugutt \& Chemosit, 2005; Sax et al., 2005; Ullah \& Wilson, 2007). Like some of these studies, the present study found student-faculty interaction to be one of the best and only predictors of student GPA (Carini et al., 2006; Gordon et al., 2008; Rugutt \& Chemositt, 2005).

The use of SEM analyses in the present study has revealed relatively unique about the Student-Faculty Interaction and GPA relationship. Evidently, interaction with faculty can be both helpful and harmful to a first-year student's GPA. The model suggests that interaction with faculty that occurs during activities that make up Academic Challenge, or activities that involve good and challenging learning, are those that benefit these firstyear students. Another possibility is that first-year students who meet with faculty are more likely to come to perceive that their courses require them to engage in the Academic Challenge activities more often. At the same time, the model also suggests, based on the negative direct relationship, that direct contact with faculty is harmful for first-year students, which suggests that one or two situations may be occurring independently or in combination to produce this effect. This first is that first-year students 
do not have much contact with faculty, which is supported by the fact that they rate Student-Faculty Interaction as their least frequent form of engagement and much lower than senior students. This lack of contact is likely due to the fact that first-year students tend to take large, general education courses in their first year, in which faculty do not have time to make contact and interact with every member of the class. The second situation follows the first, in that students who are struggling in a class are much more likely to receive or seek contact with faculty in an attempt to correct course and improve the student's performance. Another possible contributor is that faculty in programs that tend to have students with higher GPAs in their first semester do not interact as much with their students until further into the program, again leaving those who are struggling to receive more contact than their higher achieving peers. The combination of these situations with the benefits received from interacting with faculty provide a plausible explanation for the unique ability of Student-Faculty Interaction to both positively and inversely predict from first-year student GPA. The present study reveals a more nuanced understanding and further examination of this variable are needed going forward.

As for senior students, Student-Faculty Interaction was not found to be a significant predictor of GPA, contradicting many studies including one by Gordan and colleagues (2008) that found a GPA increase specific to seniors. One possible reason for this is that seniors are simply engaging in more interaction with faculty regardless of their GPA scores. This is supported by the fact that senior students reported much higher scores on Student-Faculty Interaction. Also, this may result from the fact that the sample was gathered from a relatively small institution, indicating that senior-level classes are likely small, providing faculty and students plenty of opportunities to interact (it may in 
fact, be difficult to avoid at least some interaction). If both high- and low-achieving students are interacting with faculty more frequently and in situations where interaction is required or at least highly likely, it is likely that any potential positive relationship between interaction and GPA is reduced or nullified.

\section{Campus Environment}

Campus Environment, which has also been found to be an important predictor of student GPA in previous research, was found to be indirectly related to student GPA in this study (Carini et al., 2006; Fursman, 2012; Gordon et al., 2008; Korobova \& Starobin, 2015). In the present study, Campus Environment is a latent variable represented by Quality of Interactions and Supportive Environment. In the first-year model, Supportive Environment indirectly predicted GPA through both Academic Challenge and StudentFaculty Interaction. For senior students, Supportive Environment indirectly predicted GPA scores through Quality of Interactions and was the only statistically significant indirect predictor. Both models provide evidence that Supportive Environment is at least somewhat important for students' academic achievement, which is consistent with the idea that students benefit from an academically and socially supportive which helps them be successful in their coursework.

The present study also provided further evidence that the Campus Environment is more important for senior student GPA scores than for first-year students (Fursman, 2012; Gordon et al., 2008). The Quality of Interactions factor, which is another component of Campus Environment, was the only significant direct predictor in the senior model and was removed from the first-year model. Although first-year students only have a slightly lower Quality of Interactions score, it may be that they are still 
building those relationships or that those relationships are yet to have a significant impact on them academically, which is why their relationship quality may not be predictive of their GPA. In other words, first-year students are rating their interactions based on one semester, while seniors are rating them based on seven. For seniors, Quality of Interactions is most important, and alongside Supportive Environment (which are both part of Campus Environment), the model seems to suggest that seniors who find the institution more supportive and who have built better relationships succeed more than those who have not. Senior year is often filled with students' most advanced and trying courses, and while the kinds of learning they are engaged in and the frequency of interactions with faculty do not predict their academic achievement, the model strongly suggests that a good support network is what helps students succeed when faced with these challenges.

\section{Collaborative Learning}

Unlike many previous studies, this study did not find evidence that collaborative learning was a significant predictor of student academic success (Astin, 1993; Carini et al., 2006; Conard, 2006; DeBard \& Sacks, 2011; Fauria \& Fuller, 2015; Fiorini et al., 2014; Fuller et al., 2011; Gordon et al., 2008; Hawkins, 2010; Kuh, 2002; Kuh et al., 2007; Kuh et al., 2008; Long, 2012; Ullah \& Wilson, 2007; Webber et al., 2013; Yin \& Lei, 2007; Zacherman \& Foubert, 2014). Collaborative Learning was removed from the first-year student model and only had an indirect relationship through Academic Challenge in the senior model. This indirect relationship was weak considering that the Academic Challenge in the senior model was a very weak and nonsignificant predictor of GPA. The difficulty in comparing the current Collaborative Learning engagement 
indicator to much of the previous research evidence is that the previous benchmark system included a measure of active learning as well (ACL - Active \& Collaborative Learning). Some research indicates that individual items from the ACL benchmark that are the best predictors are actually active learning items or a combination of collaborative and active learning; such as tutoring other students, making class presentations, class attendance, and contributing to the class through discussions and questions (Conard, 2006; Fauria \& Fuller, 2015; Fiorini et al., 2014; Ullah \& Wilson, 2007). Therefore, there may be little or no conflict between the present and previous studies that appears to exist.

While collaborative learning has been recognized as a good learning tool and is enjoyed by students in many contexts, it may be that it is simply not a good contributor to GPA. Another possibility is that not all parties involved in collaborative learning benefit, or that the benefits of some are balanced by the no change or even the detriment of others within the collaboration. For example, it may be that those who ask for help are not benefitting enough to offset the zero gains made by those that are helping them. Another possibility is that certain collaborative learning activities do predict an increase in GPA, but others do not, nullifying the overall predictive ability of collaborative learning. For example, while those asking for help and those helping may benefit from their interaction, those working on group projects or studying in a group may not because they are distracted or engage in social loafing.

\section{Other Model Similarities}

One area in which the first-year and senior student models are similar are on the configuration of three variables within the model: Supportive Environment, StudentFaculty Interaction, and Effective Teaching. All three were maintained in both models, 
despite only Supportive Environment being a significant indirect predictor in both, while Student-Faculty Interaction (direct and indirect) and Effective Teaching (indirect) were only significant predictors of first-year GPA. In both models, Supportive Environment predicts a majority of the other variables in the model, including Student-Faculty Interaction and Effective Teaching Practices. Student-Faculty Interaction and Effective Teaching Practices are both significant predictors of Academic Challenge. For both firstyear students and seniors, these variables connect to one another and are all key in predicting Academic Challenge, indicating a basic core of required variables that predict 46.5\% for first-year students and with the addition of Collaborative Learning, predict $54.5 \%$ for seniors. Therefore, it appears that the need for an academically and socially supportive campus, the use of effective teaching practices, and interaction with faculty are all important for an academically challenging and engaging undergraduate environment. While Effective Teaching Practices logically connects with the learning practices that make up Academic Challenge, the Student-Faculty Interaction and Supportive Environment indicate the need for human connection and support as part of a good learning environment.

\section{Senior Students}

When discussing the findings for senior students, it is worth making a couple of considerations. In the cases of both the first-year and senior students, this study gathers engagement data at their current academic standing (first-year or senior) and uses it to predict their final GPA scores upon leaving the academic institution. Compared to firstyear students, senior students have very little time (less than one year) and ability (they already have a large number of credits with which the new grades will average) to make 
changes in their GPA. This is likely a contributing factor in explaining why the senior student model is less predictive of GPA as compared with the first-year student model. However, as discussed, it is also interesting to note the difference in what predicts that final GPA score. Somewhere between the first and final year of their undergraduate degree, there is a significant shift in what best predicts students' likelihood of earning good grades. First-year students need Academic Challenge, certain kinds of faculty interaction, a supportive environment, and effective teaching methods, while seniors need quality interactions and a supportive environment.

\section{Engagement \& Degree Completion}

The results of the present study are somewhat mixed. There does appear to be some value in using student engagement to predict for degree completion, but only for first-year students. The discriminant function analysis for first-year students was able to classify students who completed their degree and those who did not complete their degree with about $67 \%$ accuracy. As for seniors, the linear combination of engagement variables was non-significant and unable to correctly classify whether a student would finish their degree. Simply, engagement variables are able to predict poorly for first-year student degree completion but are not able to predict the same for seniors. In the case of the senior students, the findings are inconsistent with the senior student engagement and GPA model, which found Quality of Relationships and Supportive Environment to be significant predictors. In the case of other variables that fail to predict GPA such as Academic Challenge and Student-Faculty Interaction, the results of this analysis are similar in that these variables are also unable to predict degree completion. It is worth noting that this failure of engagement to predict for degree completion in seniors is likely 
due in large part to the lack of variability in the degree completion variable. Of the senior group, $92.5 \%$ went on to complete their degree, leaving the need for certain distinctive (statistically significant) differences in engagement between a group of 18 (did not complete) and a group of 221 (completed). With a larger sample and more noncompleters it may be possible to determine what engagement factors are important for seniors to complete their degree.

For first-year students, engagement variables do seem helpful in predicting degree completion. Most of the predictive power of this model came from two types of engagement: Learning Strategies and Reflective \& Integrative Learning. Therefore, studying and preparing for class are the best predictors of degree completion. These practices not only encourage academic success but are also a likely indicator of dedication to learning and academic success. As mentioned earlier, Higher-Order Learning and Quantitative Reasoning also contribute to the model, indicating that the latent variable, Academic Challenge, is responsible for differentiating between those who finish their degree and those who do not. This finding is consistent with the findings on GPA (with the exception of Quantitative Reasoning), as Academic Challenge is important for predicting both first-year student GPA scores and the likelihood that they will graduate. In the case of degree completion, Quantitative Reasoning is a negative predictor, while it is positively predicted by Academic Challenge in the GPA model. This alteration, besides the difference in the direction of the relationship, may occur because students taking statistics or courses requiring quantitative reasoning earlier on in their undergraduate degree are more likely to drop out or transfer to a different institution than those who do not. First-year students engaging in more Learning Strategies, Reflective \& 
Integrative Learning, and Higher-Order Learning, along with less Quantitative Reasoning, are more likely to complete their degree.

Another notable difference in this model compared with the GPA model is that Student-Faculty Interaction is not a good predictor of degree completion. Increased faculty interaction seems to have little impact on whether these first-year students will graduate. Based on the both positive and negative predictive relationship found in the GPA model, it is possible that the positive faculty interactions (ex. Talking with faculty about career plans) are nullifying the less positive interactions (ex. Students who are interacting with faculty more because they are struggling in their classes) which leads Student-Faculty Interaction being a poor predictor of degree completion.

Finally, Students engaged in more Collaborative Learning, that have a more Supportive Environment, and have teachers that use fewer Effective Teaching Strategies are also more likely to graduate. Similar to the GPA model, a more supportive environment also appears to contribute to degree completion. Unlike the GPA model, however, is the inverse relationship between Effective Teaching Strategies and degree completion. The GPA model indicates that this is a positive indirect predictor. This result is surprising, as it is unclear as to why teaching with clear goals and explanations, in an organized way, using examples, and providing students with detailed feedback would lead to fewer students finishing their degree. While this relationship needs further investigation, it is possible that programs with professors that consistently use these practices in their teaching have higher attrition rates. Collaborative Learning as a positive predictor of degree completion is another deviation from the first-year engagement-GPA model. A plausible explanation is that these collaborative learning activities are being 
used by students who are most invested in completing their degree (ex. Asking someone for help or helping others understand course material) or that they are building relationships with peers that help keep them at the institution and moving towards graduation.

In the midst of a discussion of what engagement variables are important for predictor first-year student degree completion, it is important to keep in mind that the model was only somewhat successful at doing so. Clearly there are other important factors to consider when predicting first-year students' degree completion that are beyond the scope of this study. One of these factors might be student motivation, which might be best embodied in the Learning Strategies indicator. Another important part of this discussion is the limitation of the degree completion variable, which was only able to capture whether a student finished their degree at the institution where the sample was drawn. Students may have transferred and completed their degree elsewhere. This is measure of degree completion is the best that can be done without knowing the identities of the students in the sample and tracking anyone who left the institution before completing their degree.

In general, these findings provide weak evidence in support of a number of other studies that have found student engagement to be predictive of degree completion (Astin, 1993; Brown \& Burdsal, 2012; Hood, 2014; Kuh, 2009; Kuh et al., 2006; Pascarella \& Terenzini; 2005; Russell, et al., 2007; Svanum \& Bigatti, 2009; Tinto, 1987). The support for these studies in general changes when looking at specific studies. For example, this study did not account for on-time (Fiorini et al., 2014) nor early (Svanum \& Bigatti, 2009) graduation, and therefore cannot provide support specific to these findings. 
Another example is that this study did not find specific support for Hood's (2014) findings, which indicated that the ACL benchmark significantly predicted for degree completion. In contrast, the engagement items that this study did find to be predictive of degree completion for first-year students fit with the LAC benchmark, which supports the findings of Pike (2013). The support for Pike's (2013) findings and failure to support Hood's (2014) findings may be due to Pike using a multiracial/multiethnic sample, while Hood limited his sample to African American students. The findings of this study also do not provide support for specific findings in a number of studies, such as quality relationships with peers being related to an increased likelihood and shorter time needed to graduate (Brown \& Budsal, 2012; Fiorini et al., 2014). Other predictors of degree completion found by Fiorini and colleagues (2014) were not supported, such as participation in co-curricular activities and working hard to meet faculty expectations. This study also did not find support for working on research with faculty as a predictor for degree completion as some others have (Russell et al., 2007). In contrast, this study also does not provide good evidence that engagement is not a predictor of likelihood of graduation as found by Schlinsog (2010). The mixed results found in this study indicate that engagement indicators have some value in predicting first-year student graduation but are not able to predict the likelihood of degree completion for senior students.

\section{Limitations of the Study}

The results of this study must be considered in the context of several limitations. The primary limitation is that the items on the NSSE instrument are self-report, and therefore may be subject to inaccuracies related to faulty memory or social desirability (the way that the pressure on respondents to respond to questions in the way that they 
believe is most acceptable or desired instead of what is most accurate is reflected in their answers). The second limitation is that the NSSE instrument is distributed by email, which may lead to response rate bias; the representativeness of the results depends on the response rate. A third limitation is that this study is not able to examine causal relationships between variables, merely correlations. With correlational relationships, it is difficult to determine the directionality, as well as eliminate the possibility that a spurious relationship exists between the correlated variables. A fourth limitation is that the NSSE instrument only gathers data from first-year and senior undergraduate students. Finally, accurate graduation data is difficult to capture, as one institution's data cannot differentiate between students who drop out, and those that simply transfer and complete their degree elsewhere. As such, only students who completed their degree at Andrews University are indicated as degree completers in the data. The fifth limitation was that the sample for this study was skewed towards students with higher GPA levels, which may limit the generalizability of this study to more poorly performing students. Finally, a large portion of the original dataset had to be removed due to missing data.

\section{Conclusion}

The present study contributes to the current understanding of how student engagement predicts academic success; particularly for first-years students. Using SEM analysis, this study presents an engagement model that predicts almost $20 \%$ of first-year student final GPA. The model reinforces existing literature that indicates that the kind of learning students are engaged in, but also provides new information on the relationship between interaction with faculty and academic achievement. Other factors, especially 
effective teaching practices and a supportive environment, also play a key indirect role in student success. As for seniors, this study further reinforces findings that the campus environment is most important for predicting their success, as the quality of interactions they have with others and how supportive they perceive the institutional environment to be combine to weakly predict they grades.

This study also contributes to the understanding of first-year student degree completion. Certain types of learning engagement, Learning Strategies and Reflective \& Integrative Learning, are important indicators of the likelihood first-year students will finish their degree. This study has shown that, at least in the examined population, using only engagement variables to predict degree completion does not yield a strong model. This means that certain kinds of learning engagement are important, but not sufficient, to explain likelihood of graduation.

The present study provides a reminder that academic standing is a key factor in understanding how different types of engagement predict for the academic performance and degree completion. Engagement was a poor predictor of senior performance, with only the quality of their interactions on campus being significant. Engagement also did not predict for their likelihood of graduation. Therefore, this study helps to highlight the need for further research to understand senior success.

\section{Recommendations}

\section{Practice}

The overarching goal of this study has been to gain a better understanding of how to help students succeed, and the results should be applied in this way. While further investigation of many of these relationships and variables is needed in order to make the 
best possible recommendations, the findings from the present study are sufficient to make a number of suggestions for institutional and faculty practice. This is mostly true for firstyear students, but there are some recommendations that can be made on behalf of senior students as well.

Beginning with senior students, the findings from the present study indicate that the campus environment, including the quality of their interactions with others on campus as well as how supportive they perceive their environment is, are what predicts a small portion of their academic achievement. Also, while they report slightly higher Quality of Interactions than first-year students, they report notably lower Supportive Environment scores. As this supportive environment is important to seniors' success, it is recommended that additional steps be taken towards increasing support for them academically, socially, in overall well-being, providing activities and events, and hosting events on relevant current issues.

As for first-year students, the best way to help students achieve at high levels academically is by engaging them in learning activities associated with Academic Challenge. Professors should be encouraged to engage their students in higher-order learning, reflective and integrative learning, quantitative reasoning, and teach students to engage in class preparation and review activities. Integrating these types of learning can become part of faculty, peer, or advancement processes. Besides these, professors should also be encouraged to use effective teaching practices such stating goals for their classes, arranging class in an organized way, using examples to help explain concepts, and providing feedback to students as much as possible in their courses with first-year students. 
Colleges and universities should also make it a priority to connect new students with faculty. They should also provide opportunities for students to talk with faculty about their career plans, course topics, their academic performance, and give them opportunities to work on projects with faculty outside of class. They should organize specific dates/times when students can meet with professors to discuss these topics. And they should incentivize or create opportunities for faculty and students to work together on projects, related and unrelated to coursework (ex. Volunteering or other projects). The findings of the present study show that greater interaction with faculty can have both a positive and negative impact on first-year student GPA; however, it is likely that this negative effect is the result of faculty mostly focusing their attention and interactions on students who are struggling. If all students, including those who are succeeding or exceling, could have more interactions with faculty, it seems likely that they would benefit academically. First-year students also benefit academically from a supportive environment, so the institution might prioritize its practices to ensure that academic, social, well-being, and responsibility management support is readily available to them will help them succeed.

As for retaining and increasingly the likelihood that first-year students will graduate, emphasis should be placed on the use of the Academic Challenge practices in the classroom, with the exception of Quantitative Reasoning, which inversely predicts degree completion. Finding ways to increase Reflective \& Integrative Learning, HigherOrder Learning - especially the class preparation behaviors that makeup Learning Strategies - are the most promising. Beyond these, relationship and atmosphere building will also help. Finding ways to increase the support first-year students feel and providing 
them with opportunities to learn with others also help to predict graduation. In order to combine some of these, higher education institutions might encourage group studying and learning by creating and maintain spaces that are inviting and ideal for this type of learning.

\section{Future Research}

Throughout the course of this research study, other possible approaches to this topic have become apparent based on the existing research, as well as on the limitations, scope, and results of this study. Although this study gathers much of the information and answers much of what was intended, there is still much to investigate. Also, much of the knowledge generated by this study will contribute to future research in this area. Further research is necessary to investigate the nuance that exists in this area and to provide clearer answers to the questions that drive this study.

There are a number of ways that future research could improve upon the current study. One way is to gather a larger sample, especially of first-year students. Gathering this sample from multiple small, diverse institutions could improve the sample size. Even gathering small samples from other similar schools is recommended in order to support or contest the findings of the current study. To further improve the sample and data, it is recommended that the researchers work with the institution gathering the data to implement tactics to reduce missing data. The data for the present study was collected via emailed survey link. Using multiple methods to collect data would help to reduce response bias and improve the response rate.

Another suggestion for future research is to improve the degree completion (or graduation) variable. In the current study this variable was limited, as it could not 
distinguish between students who had dropped out and never completed their degree and those that had transferred to another school and completed their degree at the new institution. In order to fix this problem, it is recommended that a method to track students across institutions be developed, or a sample could be selected before participants attend their chose institution of higher education. This would allow for a more accurate degree completion variable.

Further research should also investigate Student-Faculty Interaction and its apparent positive and negative predictive relationship with GPA. There are a number of potential explanations for this relationship, including differences in the kinds of interactions that students are having based on the environment and their own academic success or struggles. Research needs to gather more detailed and nuanced information about these interactions students have with faculty, in order to determine which specific interactions are predicting lower academic achievement, and which are predicting greater achievement. A better understanding of this relationship will allow for better recommendations regarding student and faculty interactions to maximize the benefits to students.

Based on the findings of the current study, it is evident that first-year and senior students need different kinds of support to succeed academically. Future research should investigate these differences, and equally importantly, how to implement the kinds of support needed by each group. Future research should also investigate the student engagement of sophomore and junior students and how it relates to their academic success. Finally, new ways of investigating student engagement should be explored. These explorations could help improve the understanding of student engagement, 
improve existing measures, and potentially discover news ways to support students' academic success and overall positive experience in higher education. One recommendation for this exploration would be to further investigate spiritual activities and learning communities, both of which have been shown to have a positive relationship with academic performance (Fiorini et al., 2014). Finally, it will be important to investigate what drives senior student academic performance and likelihood of degree completion, as engagement appears to be a poor predictor of these outcomes. While there is much more research needed to understand the nuance in this area, the findings of this study provide small, diverse institutions of higher education a good place to start to improve their students' academic success. 
APPENDIX A

IRB APPROVAL 


\section{Andrews $₫$ University}

March 16, 2020

Michael Milmine

Tel.

Email: milmine@andrews.edu

RE: APPLICATION FOR APPROVAL OF RESEARCH INVOLVING HUMAN SUBJECTS

IRB Protocol \#:20-036 Application Type: Original Dept.: Graduate Psychology \& Counseling Review Category: Exempt Action Taken: Approved Advisor: nosworthy@andrews.edu Title: Measures of student engagement as predictors of GPA and degree completion at Andrews University.

Your IRB application for approval of research involving human subjects entitled: "Measures of student engagement as predictors of GPA and degree completion at Andrews University" IRB protocol \# 20-036 has been evaluated and determined Exempt from IRB review under regulation CFR 46.104 (4)(ii): Research involving analysis of anonymized dataset. You may now proceed with your research.

Please note that any future changes made to the study design and/or informed consent form require prior approval from the IRB before such changes can be implemented. Incase you need to make changes please use the attached report form.

While there appears to be no more than minimum risks with your study, should an incidence occur that results in a research-related adverse reaction and/or physical injury, this must be reported immediately in writing to the IRB. Any research-related physical injury must also be reported immediately to the University Physician, Dr. Katherine, by calling (269) 473-2222.

We ask that you reference the protocol number in any future correspondence regarding this study for easy retrieval of information.

Best wishes in your research.

Sincerely,

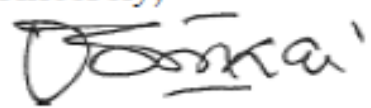

Mordekai Ongo, PhD.

Research Integrity and Compliance Officer

Institutional Review Board - 8488 E Campus Circle Dr Room 234 - Berrien Springs, MI 49104-0355

Tel: (269) 471-6361 E-mail: $\underline{\text { irb@andrews.edu }}$ 
APPENDIX B

NSSE 2000-2012 \& 2013-PRESENT COMPARISON 
Removed due to copyright regulations. 
APPENDIX C

NSSE THE REPORT 2013 
Removed due to copyright regulations. 
Removed due to copyright regulations. 
Removed due to copyright regulations. 
Removed due to copyright regulations. 
Removed due to copyright regulations. 
Removed due to copyright regulations. 
Removed due to copyright regulations. 
Removed due to copyright regulations. 
Removed due to copyright regulations. 
Removed due to copyright regulations. 
APPENDIX D

NSSE THE REPORT 2015 
Removed due to copyright regulations. 
Removed due to copyright regulations. 
Removed due to copyright regulations. 
Removed due to copyright regulations. 
Removed due to copyright regulations. 
Removed due to copyright regulations. 
Removed due to copyright regulations. 
Removed due to copyright regulations. 
Removed due to copyright regulations. 
Removed due to copyright regulations. 


\section{REFERENCES}

Alderman, R. V. (2008). Faculty and student out-of-classroom interaction: Student perceptions of quality of interaction (Unpublished doctoral dissertation). Texas A\&M University in College Station, TX. Retrieved from https://oaktrust.library.tamu.edu/handle/1969.1/ 85919

Allen, W. (1992). The color of success: African-American college student outcomes at predominantly white and historically black public colleges and universities. Harvard Educational Review, 62(1), 26-45. doi:10.17763/haer.62.1.wv5627665007v701

Allen, J., Robbins, S. B., Casillas, A., \& Oh, I. (2008). Third-year college retention and transfer: Effects of academic performance, motivation, and social connectedness. Research in Higher Education, 49(7), 647-664. doi:10.1007/s11162-008-9098-3

Anaya, G., \& Cole, D. G. (2001). Latina/o achievement: Exploring the influence of studentfaculty interactions on college grades. Journal of College Student Development, 42(1), 3-14.

Andrade, M. (2007). Learning communities: Examining positive outcomes. Journal of College Student Retention Research Theory and Practice, 9(1), 1-20. doi:10.2190/E132-5X73681Q-K188

Andrews University (n.d.). Office of Research and Creative Scholarship: Research at Andrews. Retrieved from https://www.andrews.edu/services/research/

Astin, A. W. (1973). The impact of dormitory living on students. Educational Record, 54, 204-210.

Astin, A. W. (1977). Preventing students from dropping out. San Francisco, CA: Jossey-Bass.

Astin, A. W. (1977). Four critical years. San Francisco, CA: Jossey-Bass.

Astin, A. W. (1993). What matters in college?: Four critical years revisited. San Francisco, CA: Jossey-Bass.

Astin, A. W. (1999). Student involvement: A developmental theory for higher education. Journal of College Student Development, 40(5), 518-529. (Reprinted from "Student involvement: A developmental theory for higher education. (1984). Journal of College Student Personnel, 25, 287-308.)

Axelson, R. D., \& Flick A. (2011). Defining student engagement. Change: The Magazine of Higher Learning, 43(1), 38-43. doi: 10.1080/00091383.2011.533096

Baird, L. L. (1985). Do grades and tests predict adult accomplishment? Research in Higher Education, 23(1). 3-85. 
Beeson, S. A., \& Kissling, G. (2001). Predicting success for baccalaureate graduates on the NCLEX-RN. Journal of Professional Nursing, 17(3), 121-127.

doi:10.1053/jpnu.2001.23382

Bentler, P. M., \& Chou, C. P. (1987). Practical issues in structural modeling. Sociological Methods \& Research, 16(1), 78-117. doi:10.1177/0049124187016001004

Berkner, L., \& Choy, S. (2008). Descriptive summary of 2003-2004 beginning postsecondary students: Three years later (NCES 2008-174). National Center for Education Statistics, Institute of Education Sciences, U.S. Department of Education. Washington, D.C.

Bono, T. J. (2011). What good is engagement? Predicting academic performance and college satisfaction from personality, social support, and student engagement (Unpublished doctoral dissertation). Washington University in St. Louis, St. Louis, MO.

Bowden, B. (2014). The impact of engagement on the academic success of black males at a predominantly white institution (Doctoral dissertation). Retrieved from ProQuest. (3637948)

Braxton, J. M., Milem, J. F., \& Sullivan, A. S. (2000). The influence of active learning on the college student departure process: Toward a revision of Tinto's theory. The Journal of Higher Education, 71(5), 569-590. doi:10.1080/00221546.2000.11778853

Brown, S. K., \& Burdsal, C. A. (2012). An exploration of sense of community and student success using the national survey of student engagement. The Journal of General Education, 61(4), 433-460. doi:10.1353/jge.2012.0039

Bryan, N. B., Eagle, B. W., Wright, B. M., \& Icenogle, M. L. (2012). Construct validity and invariance properties of NSSE benchmarks across institutional types. Paper presented at the Association for Institutional Research Forum, New Orleans, LA.

Buckles, K., Malamud, O., Morrill, M., \& Wozniak, A. (2012). The effect of college education on health. Forschungsinstitut zur Zukunft der Arbeit (6659). Retrieved from http://hdl.handle.net/10419/62437

Bush, E. C., \& Bush L. (2010). Calling out the elephant: An examination of African American male achievement in community colleges. Journal of African American Males in Education, 1(1), 40-62. Retrieved from http://www.learningworksca.org/wpcontent/uploads/2012/02/Calling-Out-the-Elephant.pdf

Cabrera, A. F., Burkum, K. R., \& LaNasa, S. M. (2005). Determinants of transfer and degree completion. College student retention: A formula for student success. Westport, CT: ACE/Praeger, 174-214.

Cachia, M., Lynam, S., \& Stock, R. (2018). Academic success: Is it just about the grades? Higher Education Pedagogies, 3(2), 434-439. doi:10.1080/23752696.2018.1462096 
Campbell, C. M., \& Cabrera, A. F. (2011). How sound is NSSE? Investigating the psychometric properties of NSSE at a public, research-extensive institution. The Review of Higher Education, 35(1), 77-103.

Carini, R. M., Kuh, G. D., \& Klein, S. P. (2006). Student engagement and student learning: Testing the linkages. Research in Higher Education, 47(1), 1-32.

Casuso-Holgado, M. J., Cuesta-Vargas, A. I., Moreno-Morales, N., Labajos-Manzanares, M. T., Barón-López, F. J., \& Vega-Cuesta, M. (2013). The association between academic engagement and achievement in health sciences students. Biomedical Central Medical Education, 13(33). doi:10.1186/1472-6920-13-33

CCSSE (2005). Engaging students, challenging the odds: 2005 findings. Community College Survey of Student Engagement. Austin, TX: The University of Texas at Austin.

Chapman, E. (2003). Alternative approaches to assessing student engagement rates. Practical Assessment, Research \& Evaluation, 8(13). Retrieved from https://pareonline.net/getvn.asp?v=8\&n=13

Cole, D. (2010). The effects of student-faculty interactions on minority students' college grades: Differences between aggregated and disaggregated data. Journal of the Professoriate, 3(2), 137-160.

college. 2021. In Merriam-Webster.com. Retrieved February 28, 2021, from https://www.merriam-webster.com/dictionary/college

Conard, M. A. (2006). Aptitude is not enough: How personality and behavior predict academic performance. Journal of Research in Personality, 40(3), 339-346. doi:10.1016/j.jrp.2004.10.003

Cotton, S. R., \& Wilson, B. (2006). Student-faculty interactions: Dynamics and detriments. Higher Education, 51(4), 487-519. Doi:10.1007/s10734-004-1705-4

Chickering, A. W., \& Gamson, Z. F. (1987). Seven principles for good practice in undergraduate education. AAHE Bulletin, 39(7), 3-7. Retrieved from https://eric.ed.gov/?id=ED282491

Chickering, A. W., \& Gamson, Z. F. (1999). Development and adaptions of the seven principles for good practice in undergraduate education. New Directions for Teaching \& Learning, 80, 75-81. doi: 10.1002/tl.8006

Coates, H. (2007). A model of online and general campus-based student engagement. Assessment \& Evaluation in Higher Education, 32(2), 121-141. doi:10.1080/02602930600801878 
Conway, C., Zhao, H., \& Montgomery, S. (2011). The NSSE national data project report. Toronto, ON: Higher Education Quality Council of Ontario.

Courtner, A. S. (2014). Impact of student engagement on academic performance and quality of relationships of traditional and nontraditional students. International Journal of Education, 6(2), 24. doi:10.5296/ije.v6i2.5316

Cruce, T. M., Wolniak, G. C., Seifert, T. A., \& Pascarella, E. T. (2006). Impacts of good practices on cognitive development, learning orientations, and graduate degree plans during the first-year of college. Journal of College Student Development, 47(4), 365383. doi:10.1353/csd.2006.0042

Delaney, A. M. (2008). Why faculty-student interaction matters in the first-year experience. Tertiary Education and Management, 14(3), 227-241. doi:10.1080/13583880802228224

DeBard, R., \& Sacks, C. (2011). Greek membership: The relationship with first-year academic performance. Journal of College Student Retention: Research, Theory \& Practice, 13(1), 109-126. doi:10.2190/CS.13.1.f

de Brey, C., Musu, L., McFarland, J., Wilkinson-Flicker, S., Diliberti, M., Zhang, A., ... Wang, X. (2019). Status and trends in the education of racial and ethnic groups 2018 (NCES 2019-038). National Center for Education Statistics, Institute of Education Sciences, U.S. Department of Education. Washington, D.C.

DeNeui, D. (2003). An investigation of first-year college students' psychological sense of community on campus. College Student Journal, 37(2), 224-234.

Dexter, P. D. (2015). The influence of engagement upon success and persistence of online undergraduates (Unpublished doctoral dissertation). Retrieved from ProQuest. (3723157)

Durkheim, E. (1951). Suicide: A study in sociology. Glencoe, IL: Free Press.

Durm, M. W. (1993). An a is not an a is not an a: A history of grading. The Educational Forum, 57(3), 294-297. doi:10.1080/00131729309335429

Ethington, C. A., \& Horn, R. (2007). An examination of Pace's model of student development and college impress. Community College Journal of Research and Practice, 31(3), 199-215. doi:10.1080/10668920600857222

Fauria, R. M., \& Fuller, M. B. (2015). Transfer student success: Educationally purposeful activities predictive of undergraduate GPA. Research \& Practice in Assessment, 10, 39-52. Retrieved from https://files.eric.ed.gov/fulltext/EJ1064764.pdf 
Fiorini, S., Shepard, L., Liu, T., \& Ouimet, J. (2014). Using NSSE to understand student success: A multi-year analysis. Paper presented at the National Symposium on Student Retention 2014, University of Oklahoma.

Fischer, M. J. (2007). Settling into campus life: Differences by race/ethnicity in college involvement and outcomes. The Journal of Higher Education, 78(2), 125-161. doi:10.1080/00221546.2007.11780871

Fredricks, J. A., Blumenfeld, P. C., \& Paris, A. H. (2004). School engagement: Potential of the concept, state of the evidence. Review of Educational Research, 74(1), 59-109. doi:10.3102/00346543074001059

Fuller, M. B., Wilson, M. A., \& Tobin, R. M. (2011). The national survey of student engagement as a predictor of undergraduate GPA: a cross-sectional and longitudinal examination. Assessment \& Evaluation in Higher Education, 36(6), 735-748. doi:10.1080/02602938.2010.488791

Furr, S. R., \& Elling, T. W. (2000). The influence of work on college student development. NASPA Journal, 37(2), 454-470. doi:10.2202/1949-6605.1108

Fursman, P. M. (2012). The national survey of student engagement as a predictor of academic success (Unpublished master's thesis). Minnesota State University, Mankato, MN. (155)

Gamm, C. A. (2011). Comparing engagement: Predicting African American student success at predominately White institutions and historically Black colleges and universities (unpublished doctoral dissertation). University of Louisville, Louisville, KY. (476)

Garcia, J., \& Gustavson, A. R. (1997). The science of self-report. Association for Psychological Science Observer, 32(7). Retrieved from https://www.psychologicalscience.org/observer/the-science-of-self-report

Gibson, A. M., \& Slate, J. R. (2010). Student engagement at two-year institutions: Age and generational status differences. Community College Journal of Research and Practice, 34(5), 371-385. doi:10.1080/10668920802466384

Gonyea, R. M., Kinzie, J., \& McCormick, A. C. (2013). Refreshing engagement: NSSE at 13. Change: The Magazine of Higher Learning, 45(3), 6-15.

doi:10.1080/00091383.2013.786985

Gordon, J., Ludlum, J., \& Hoey, J. J. (2008). Validating NSSE against student outcomes: Are they related? Research in Higher Education, 49(1), 19-39. doi:10.1007/s11162-0079061-8

grade point average. 2021. In Merriam-Webster.com. Retrieved February 28, 2021, from https://www.merriam-webster.com/dictionary/grade\%20point\%20average 
graduate [Noun Def. 1]. (n.d.). In Lexico Dictionary, Retrieved August 21, 2019, from https://www.lexico.com/en/definition/graduate

Greene, T. G., Marti, C. N., \& McClenney, K. (2008). The effort-outcome gap: Differences for African American and Hispanic community college students in student engagement and academic achievement. The Journal of Higher Education, 79(5), 513-539. doi:10.1080/00221546.2008.11772115

Grubb, F. (2006). Does going Greek impair undergraduate academic performance? American Journal of Economics and Sociology, 65(5), 1085-1110. doi:10.1111/j.15367150.2006.00457.x

Guiffrida, D. A. (2004). How involvement in African American student organizations supports and hinders academic achievement. NACADA Journal, 24(1-2), 88-98. doi:10.12930/0271-9517-24.1-2.88

Gunuc, S. (2014). The relationships between student engagement and their academic achievement. International Journal on New Trends in Education and Their Implications, 5(4), 216-231. Retrieved from: http://www.ijonte.org/FileUpload/ks63207/File/19..gunuc.pdf

Hague-Palmer, T. A. (2013). Academic and campus experiences of African American males: Implications for collegiate satisfaction and student engagement (Unpublished doctoral dissertation). Bowling Green State University, Bowling Green, OH.

Harper, S. R. (2004). The measure of a man: Conceptualizations of masculinity among highachieving African American male college students. Berkeley Journal of Sociology, 48, 89-107.

Harper, S. R. (2012). Black male student success in higher education: A report from the national Black male college achievement study. Philadelphia, PA: University of Pennsylvania, Center for the Study of Race and Equity in Education. Retrieved from https://web-app.usc.edu/web/rossier/publications/231/Harper\%20(2012)\%20Black\% 20Male\%20Success.pdf

Harper, S. R., Carini, R. M., Bridges, B. K., \& Hayek, J. C. (2004). Gender differences in student engagement among African American undergraduates at historically Black colleges and universities. Journal of College Student Development, 45(3), 271-284. doi:10.1353/csd.2004.0035

Hawkins, A. L. (2010). Relationship between undergraduate student activity and academic performance (Unpublished master's thesis). Purdue University, West Lafayette, IN. (13).

Hearn, J. C. (1987). Impacts of undergraduate experiences on aspirations and plans for graduate and professional education. Research in Higher Education, 27(2), 119-141. 
higher learning. 2021. In Merriam-Webster.com. Retrieved February 28, 2021, from https://www.merriam-webster.com/dictionary/higher\%20learning

Hood, G. M. (2014). The influence of student engagement on the six-year graduation rates of African American students at a predominantly white university. (Ed.D.), University of Alabama, Ann Arbor, MI. (3639120)

Hu, S., \& Kuh, G. D. (2003). Maximizing what students get out of college: Testing a learning productivity model. Journal of College Student Development, 44(2), 185-203. doi:10.1353/csd.2003.0016

Hu, S., \& Kuh, G. D. (2002). Being (dis)engaged in educationally purposeful activities: The influences of student and institutional characteristics. Research in Higher Education, 43(5), 555-575. doi: 10.1023/A:1020114231387

Hyatt, R. L. (2011). The influence of time spent by students engaged in co-curricular involvement, online social networking and studying and doing coursework on their academic achievement (Doctoral dissertation). Retrieved from https://scholarcommons.usf.edu/etd/3417/

Hylton, L. (2013). The impact of student-faculty interaction on academic achievement and college satisfaction for black males at predominately white institutions (Doctoral dissertation). Retrieved from ProQuest. (3587781)

institution of higher learning. 2021. In Merriam-Webster.com. Retrieved February 28, 2021, from https://www.merriam-webster.com/dictionary/institution\%20of\%20higher $\%$ 20learning

Jeffreys, M. (2012). Nursing student retention: Understanding the process and making a difference. New York, NY: Springer.

Johnson, D. W., Johnson, R. T., \& Smith, K. A. (1998). Active learning: Cooperation in the college classroom. Edina, MN: Interaction.

Kezar, A. J. (2006). The impact of institutional size on student engagement. NASPA Journal, 43(1), 87-114. doi:10.2202/1949-6605.1573

Keup, J. R. (2007). Great expectations and the ultimate reality check: Voices of students during the transition from high school to college. NASPA Journal, 44(1), 3-31. doi:10.2202/1949-6605.1752

Khaira, R. (2016). Characteristics, engagement and academic performance of first-year nursing students in selected Ontario universities (Unpublished doctoral dissertation). University of Toronto, Toronto, Canada. 
Kinzie, J., Thomas, A. D., Palmer, M. M., Umbach, P. D., \& Kuh, G. D. (2007). Women students at coeducational and women's colleges: How do their experiences compare? Journal of College Student Development, 48(2), 145-165. doi:10.1353/csd.2007.0015

Komarraju, M. Musulkin, S., \& Bhattacharya, G. (2010). Role of student-faculty interactions in developing college students' academic self-concept, motivation, and achievement. Journal of College Student Development, 51(3), 332-342. doi:10.1353/csd.0.0137

Korobova, N., \& Starobin, S. S. (2015). A comparative study of student engagement, satisfaction, and academic success among international and American students. Journal of International Students, 5(1), 72-85. Retrieved from https://files.eric.ed.gov/fulltext/EJ1052833.pdf

Kuh, G. D. (1995). The other curriculum: Out-of-class experiences associated with student learning and personal development. Journal of Higher Education, 66(2), 123-155. doi: $10.2307 / 2943909$

Kuh, G. D. (2001). Assessing what really matters to student learning: Inside the national survey of student engagement. Change: The Magazine of Higher Learning, 33(3), 1017. doi:10.1080/00091380109601795

Kuh, G. D. (2002). The national survey of student engagement: Conceptual framework and overview of psychometric properties. Bloomington, IN: Indiana University, Center for Postsecondary Research. Retrieved from http://nsse.indiana.edu/pdf/psychometric_framework_2002.pdf

Kuh, G. D. (2003). What we're learning about student engagement from NSSE: Benchmarks for effective educational practices. Change: The Magazine of Higher Learning, 35(2), 24-32. doi:10.1080/00091380309604090

Kuh, G. D. (2009). The national survey of student engagement: Conceptual and empirical foundations. New Directions for Institutional Research, 141, 5-20. doi:10.1002/ir.283

Kuh, G. D., Cruce, T. M., Shoup R., Kinzie, J., \& Gonyea, R. M. (2008). Unmasking the effects of student engagement on first-year college grades and persistence. The Journal of Higher Education, 79(5), 540-563. doi:10.1353/jhe.0.0019

Kuh, G. D., Hayek, J. C., Carini, R. M., Ouimet, J. A., Gonyea, R. M., \& Kennedy, J. (2001). NSSE technical and norms report. Bloomington, IN: Indiana University for Postsecondary Research and Planning.

Kuh, G. D., Kinzie, J., Buckley, J. A., Bridges, B. K., \& Hayek, J. C. (2006). What matters to student success: A review of the literature. Report prepared for the National Symposium on Postsecondary Student Success: Spearheading a Dialog on Student Success. 
Kuh, G. D., Kinzie, J., Cruce, T. M., Shoup, R. \& Gonyea, R. M. (2007, Revised). Connecting the dots: Multi-faceted analyses of the relationships between student engagement results from NSSE, and the institutional practices and conditions that foster student success. Bloomington, IN: Indiana University Center for Postsecondary Research.

Kuh, G. D., Kinzie, J., Schuh, J. H., \& Whitt, E. J. (2005). Never let it rest: Lessons about student success from high-performing colleges and universities. Change: The Magazine of Higher Learning, 37(4), 44-51. doi:10.3200/CHNG.37.4.44-51

Kuh, G. D., Pace, C. R., \& Vesper, N. (1997). The development process indicators to estimate student gains associated with good practices in undergraduate education. Research in Higher Education, 38(4), 435-454. doi:10.1023/A:1024962526492

Kuh, G. D., Schuh, J., Whitt, E., Andreas, R., Lyons, J., Strange, C., .. \& MacKay, L. (1991). Involving colleges: Successful approaches to fostering student learning and personal development outside the classroom. San Francisco: Jossey-Bass.

Kuh, G. D., \& Vesper, N. (1997). A comparison of student experiences with good practices in undergraduate education between 1990 and 1994. The Review of Higher Education, 21(1), 43-61. doi:10.1353/rhe.1997.0014

Laird, T. F., Korkmaz, A., \& Chen, P. D. (2008). How often is "often” revisited: The meaning and linearity of vague quantifiers used on the National Survey of Student Engagement. Paper presented at the Annual Meeting of the American Educational Research Association. San Diego, CA. Retrieved from http://cpr.indiana.edu/uploads/aera_how\%20often.pdf

Lamport, M. A. (1993). Student-faculty informal interaction and the effect on college student outcomes: A review of the literature. Adolescence, 28(112), 971-990.

LaNasa, S. M., Olson, E., \& Alleman, N. (2007). The impact of on-campus student growth on first-year student engagement and success. Research in Higher Education, 48(8), 941966.

Long, L. D. (2012). A multivariate analysis of the relationship between undergraduate fraternity/sorority involvement and academic performance. Oracle: The Research Journal of the Association of Fraternity/Sorority Advisors, 7(2), 37-46.

Lutz, M. E., \& Culver, S. (2010). The national survey of student engagement: A universitylevel analysis. Tertiary Education and Management, 16(1), 35-44.

doi:10.1080/13583881003629814

Matthews, K. E., Andrews, V., \& Adams, P. (2011). Social learning spaces and student engagement. Higher Education Research \& Development, 30(2), 105-120. doi:10.1080/07294360.2010.512629 
Merwin, J. C. (1984). Involvement in learning: Realizing the potential of American higher education. Washington, DC: U.S. Department of Education.

Meyers, L. S., Gamst, G., Guarino, A. J. (2013). Applied multivariate research: Design and interpretation ( $2^{\text {nd }}$ ed.). Thousand Oaks, CA: Sage.

Milem, J. F., \& Berger, J. B. (1997). A modified model of college student persistence: Exploring the relationship between Astin's theory of involvement and Tinto's theory of student departure. Journal of College Student Development, 38(4), 387-400. Retrieved from https://scholarworks.umass.edu/cie_faculty_pubs/11

Miller, P. S., \& Kerr, G. (2002). The athletic, academic and social experiences of intercollegiate student athletes. Journal of Sport Behavior, 25(4), 346-367. Retrieved from https://www.thefreelibrary.com/The+athletic\%2C+academic+and+social+ experiences+of+intercollegiate...-a094335187

National Center for Education Statistics. (2016a). Enrollment in elementary, secondary, and degree-granting postsecondary institutions, by level and control of institution, enrollment level, and attendance status and sex of student: Selected years, fall 1990 through fall 2025. Retrieved from https://nces.ed.gov/programs/digest/d15/tables/dt15_105.20.asp?current=yes

National Center for Education Statistics. (2016b). Fast facts: Income of young adults. Retrieved from https://nces.ed.gov/fastfacts/display.asp?id=77

National Center for Education Statistics. (2016c). Fast facts: Employment rates of college graduates. Retrieved from https://nces.ed.gov/fastfacts/display.asp?id=561

National Center for Education Statistics. (2019a). College student employment. Retrieved from https://nces.ed.gov/programs/coe/pdf/coe_ssa.pdf

National Center for Education Statistics. (2019b). Fast facts: Graduation rates. Retrieved from https://nces.ed.gov/fastfacts/display.asp?id=40

National Center for Education Statistics. (2019c). Fast facts: Tuition costs of colleges and universities. Retrieved from https://nces.ed.gov/fastfacts/display.asp?id=76

National Center for Education Statistics. (2019d). Status and trends in the education of racial and ethnic groups: Indicator 23: Postsecondary graduation rates. Retrieved from https://nces.ed.gov/programs/raceindicators/indicator_red.asp

National Survey of Student Engagement. (2001). Our origins and potential. Retrieved from http://nsse.indiana.edu/html/origins.cfm 
National Survey of Student Engagement. (2010). Working with NSSE data: A facilitator's guide. Retrieved from

http://nsse.indiana.edu/_2010/img/NewNI/Facilitators_Guide.pdf

National Survey of Student Engagement. (2012). National survey of student engagement 2012: The college student report. Retrieved from http://nsse.indiana.edu/pdf/survey_ instruments/2012/NSSE2012_US_English_Paper.pdf

National Survey of Student Engagement. (2017). Internal Consistency of the Engagement Indicators (NSSE 2017). Retrieved from http://nsse.indiana.edu/pdf/2017/Internal ConsistencyOfTheEngagementIndicators2017.pdf

National Survey of Student Engagement. (2018). NSSE Report Builder - Public. Retrieved from https://bl-educ-cprtest.ads.iu.edu/SAS/rb_nsse.html

National Survey of Student Engagement. (2019a). About NSSE. Retrieved from http://nsse.indiana.edu/html/about.cfm

National Survey of Student Engagement. (2019b). Announcements in depth. Retrieved from Retrieved from http://nsse.indiana.edu/html/announcements.cfm

National Survey of Student Engagement. (2019c). Information about the 2013 update. http://nsse.indiana.edu/nsse-update/

National Survey of Student Engagement. (2019d). Institutional reporting. Retrieved from http://nsse.indiana.edu/html/institutional_reporting.cfm

National Survey of Student Engagement. (2019e). NSSE 2019 English version. Retrieved from http://nsse.indiana.edu/pdf/survey_instruments/2019/NSSE19_Screenshot_US_ English.pdf

National Survey of Student Engagement. (2019f). NSSE 2015 English version. Retrieved from http://nsse.indiana.edu/pdf/survey_instruments/2015/NSSE\%202015\%20$\% 20$ US\%20English.pdf

National Survey of Student Engagement. (2019g). Reliability. Retrieved from http://nsse.indiana.edu/html/reliability.cfm

National Survey of Student Engagement. (2020a). Engagement Indicators. Retrieved from https://nsse.indiana.edu/nsse/survey-instruments/engagement-indicators.html

National Survey of Student Engagement. (2020b). NSSE's Conceptual Framework. Retrieved from https://nsse.indiana.edu/nsse/psychometric-portfolio/conceptual-framework-newversion.html 
National Survey of Student Engagement. (2020c). NSSE Cognitive Interview and Focus Group Study. Retrieved from https://nsse.indiana.edu/nsse/psychometricportfolio/index.html

National Survey of Student Engagement. (2020d). NSSE Predictive Validity Study. Retrieved from https://nsse.indiana.edu/nsse/psychometric-portfolio/predictive.html

National Survey of Student Engagement. (2020e). NSSE's Psychometric Portfolio. Retrieved from https://nsse.indiana.edu/nsse/psychometric-portfolio/index.html

Nauffal, D. I. (2012). Assessment of student engagement: An analysis of trends. Tertiary Education and Management, 18(2), 171-191. doi:10.1080/13583883.2012.656696

Nichols, A. H., \& Evans-Bell, D. (2017). A look at black student success: Identifying top-and bottom-performing institutions. Washington, DC: The Education Trust. Retrieved from https://edtrust.org/wp-content/uploads/2014/09/A-Look-at-Black-Student-Success.pdf

Pace, C. R. (1980). Measuring the quality of student effort. Current issues in higher education, 2, 10-16.

Pace, C. R. (1982). Achievement and the quality of student effort. Los Angeles, CA: Higher Education Research Institute, University of California.

Pace, C. R. (1984). Measuring the quality of college student experiences: An account of the development and use of the college student experiences questionnaire. Los Angeles, CA: Higher Education Research Institute, University of California.

Pascarella, E. T. (1980). Student-faculty informal contact and college outcomes. Review of Educational Research, 50(4), 545-595. doi: 10.3102/00346543050004545

Pascarella, E. T., Seifert, T. A., \& Blaich, C. (2010). How effective are the NSSE benchmarks in predicting important educational outcomes? The Magazine of Higher Learning, 42(1), 16-22. doi:10.1080/00091380903449060

Pascarella, E. T., \& Terenzini, P. T. (1976). Informal interaction with faculty and freshman ratings of academic and non-academic experience in college. Journal of Educational Research, 70(1) 35-41.

Pascarella, E. T., Terenzini, P. T., \& Hibel, J. (1978). Student-faculty interaction settings and their relationship to predicted academic performance. Journal of Higher Education, 49(5), 450-463.

Pascarella, E. T., \& Terenzini, P. T. (1980). Predicting freshman persistence and voluntary dropout decisions from a theoretical model. Journal of Higher Education, 51(1), 60-75. 
Pascarella, E. T., \& Terenzini, P. T. (1991). How college affects students: Findings and insights from twenty years of research. San Francisco, CA: Jossey-Bass.

Pascarella, E. T., \& Terenzini, P. T. (2005). How college affects students. A third decade of research (Vol. 2). San Francisco, CA: Jossey-Bass.

Pike, G. R. (1999). The constant error of the halo in educational research outcomes. Research in Higher Education, 40(1), 61-86.

Pike, G. R. (2004). Measuring quality: A comparison of "U.S. News" rankings and NSSE benchmarks. Research in Higher Education, 45(2), 193-208.

Pike, G. R. (2013). NSSE benchmarks and institutional outcomes: A note on the importance of considering the intended uses of a measure in validity studies. Research in Higher Education, 54(2), 149-170. doi:10.1007/s11162-012-9279-y

Pike, G. R., Kuh, G. D., \& Massa-McKinley, R. (2008). First-year students' employment, engagement, and academic, achievement: Untangling the relationship between work and grades. Journal of Student Affairs Research and Practice, 45(4), 560-582. doi:10.2202/1949-6605.2011

Pike, G. R., Kuh, G. D., \& McCormick, A. C. (2011). An investigation of the contingent relationships between learning community participation and student engagement. Research in Higher Education, 52(3), 300-322. doi:10.1007/s11162-010-9192-1

Porter, S. R. (2011). Do college student surveys have any validity? Review of Higher Education: Journal of the Association for the Study of Higher Education, 35(1), 45-76. doi:10.1353/rhe.2011.0034

Richards, D. A., \& Awokoya, J. T. (2012). Understanding HBCU retention and completion. Fairfax, VA: Frederick D. Patterson Research Institute, UNCF. Retrieved from https://www.uncf.org/wp-content/uploads/PDFs/Understanding_HBCU_Retention _and_Completion.pdf

Robbins, S. B., Lauver, K., Le, H., Davis, D., Langley, R., \& Carlstrom, A. (2004). Do psychosocial and study skill factors predict college outcomes? A meta-analysis. Psychological Bulletin, 130(2), 261-288. doi:10.1037/0033-2909.130.2.261

Rugutt, J. K., \& Chemosit, C. C. (2005). A study of factors that influence college academic achievement: A structural equation modeling approach. Journal of Educational Research \& Policy Studies, 5(1), 66-90.

Russell, S. H., Hancock, M. P., \& McCullough, J. (2007). Benefits of undergraduate research experiences. Science, 316(5824), 548-549. doi:10.1126/science.1140384 
Salamonson, Y., \& Andrew, S. (2006). Academic performance in nursing students: Influence of part-time employment, age and ethnicity. Journal of Advanced Nursing, 55(3), 342351. doi: 10.1111/j.1365-2648.2006.03863_1.x

Salamonson, Y., Andrew, S., \& Everett B. (2009). Academic engagement and disengagement as predictors in pathophysiology among nursing students. Contemporary Nurse, 32(12), 123-132. doi:10.5172/conu.32.1-2.123

Sax, L. J., Bryant, A. N., \& Harper, C. E. (2005). The differential effects of student-faculty interaction on college outcomes for women and men. Journal of College Student Development, 46(6), 642-659. doi:10.1353/csd.2005.0067

Schlinsog, J. (2010). Engagement in the first-year as a predictor of academic achievement and persistence of first-year students (Unpublished doctoral dissertation). University of Louisville, Louisville, KY. (1271)

school. 2021. In Merriam-Webster.com. Retrieved February 28, 2021, from https://www.merriam-webster.com/dictionary/school

Schreiber, J. B., Nora, A., Stage, F. K., Barlow, E. A., \& King, J. (2006). Reporting structural equation modeling and confirmatory factor analysis results: A review. Journal of Educational Research, 99(6), 323-338. doi:10.3200/JOER.99.6.323-338

Shapiro, D., Dundar, A., Huie, F., Wakhungu, P., Bhimdiwala, A., \& Wilson, S. (2019). Completing college: A state-level view of student completion rates (Signature Report No. 16a). Herndon, VA: National Student Clearinghouse Research Center.

Shaughnessy, J. J., Zechmeister, E. B., \& Zechmeister, J. S. (2015). Research methods in psychology. New York, NY: McGraw-Hill Education.

Sheard, J., Carbone, A., \& Hurst, A. J. (2010). Student engagement in first-year of an ICT degree: Staff and student perceptions. Computer Science Education, 20(1), 1-16. doi:10.1080/08993400903484396

Shulman, L. S. (2002). Making differences: A table of learning. Change: The Magazine of Higher Learning, 34(6), 36-44. doi: 10.1080/00091380209605567

Strayhorn, T. L. (2008). The role of supportive relationships in facilitating African American males' success in college. NASPA Journal, 45(1), 26-48. doi:10.2202/1949-6605.1906

Strayhorn, T. L., \& DeVita, J. M. (2010). African American males' student engagement: A comparison of good practices by institutional type. Journal of African American Studies, 14(1), 87-105. doi:10.1007/s12111-009-9110-9 
Svanum, S., \& Bigatti, S. M. (2009). Academic course engagement during one semester forecasts college success: Engaged students are more likely to earn a degree, do it faster, and do it better. Journal of College Student Development, 50(1), 120-132. doi:10.1353/csd.0.0055

Swigart, T. E., \& Murrell, P. H. (2001). Factors influencing estimates of gains made among African-American and Caucasian community college students. Community College Journal of Research and Practice, 25(4), 297-312. doi:10.1080/106689201750122406

Tabachnick, B. G., \& Fidell, L. S. (2019). Using multivariate statistics (7 $7^{\text {th }}$ ed.). New York, NY: Pearson.

The Carnegie Classification of Institutions of Higher Education (2017). Home > Carnegie Classifications. Retrieved from https://carnegieclassifications.iu.edu/

The Carnegie Classification of Institutions of Higher Education (n.d.). Basic classification description. Retrieved from https://carnegieclassifications.iu.edu/classification_ descriptions/basic.php

Tinto, V. (1975). Dropout from higher education: A theoretical synthesis of recent research. Review of Educational Research, 45(1), 89-125.

Tinto, V. (1987). Leaving college: Rethinking the causes and cures of student attrition. Chicago, IL: The University of Chicago Press.

Tinto, V. (1993). Leaving college: Rethinking the causes and cures of student attrition. $\left(2^{\text {nd }}\right.$ ed.). Chicago, IL: The University of Chicago Press.

Tinto V. (1997) Classrooms as communities: Exploring the educational character of student persistence. Journal of Higher Education, 68(6), 599-623. doi:10.1080/00221546.1997.11779003

Tross, S. A., Harper, J. P., Osher, L. W., Kneidinger, L. M. (2000). Not just the usual cast of characteristics: Using personality to predict college performance and retention. Journal of College Student Development, 41(3), 323-334.

Twale, D., \& Sanders, C. S. (1999). Impact of non-classroom experiences on critical thinking ability. NASPA Journal, 36(2), 133-146. doi:10.2202/1949-6605.1078

Tyler, R. (1969). Educational evaluation: New roles, new means: The sixty-eighth yearbook of the national society for the study of education: Part II. Chicago, IL: University of Chicago Press.

Ullah, H., \& Wilson, M. A. (2007). Students' academic success and its association to student involvement with learning and relationships with faculty peers. Project Innovation, $41(4)$. 
Umbach, P. D., \& Wawrzynski, M. R. (2005). Faculty do matter: The role of college faculty in student learning and engagement. Research in Higher Education, 46(2), 153-184. doi:10.1007/s11162-004-1598-1

university. 2021. In Merriam-Webster.com. Retrieved February 28, 2021, from https://www.merriam-webster.com/dictionary/university

Walberg, H. J. (1982). Educational productivity: Theory, evidence, prospects. Australian Journal of Education, 26(2), 115-122. doi: 10.1177/000494418202600202

Walberg, H. J., Fraser, B. J., \& Welch, W. W. (1986). A test of a model of educational productivity among senior high school students. Journal of Educational Research, 79(3), 133-139. doi:10.1080/00220671.1986.10885664

Weaver, R. R., \& Qi, J. (2005). Classroom organization and participation: College students' perceptions. The Journal of Higher Education, 76(5), 570-601. doi:10.1080/00221546.2005.11772299

Webber, K. L., Krylow, R. B., \& Zhang, Q. (2013). Does involvement really matter? Indicators of college student success and satisfaction. Journal of College Student Development, 54(6), 591-611. doi:10.1353/csd.2013.0090

Wolf-Wendel, L., Ward, K., \& Kinzie, J. (2009). A tangled web of terms: The overlap and unique contribution of involvement, engagement, and integration to understanding college student success. Journal of College Student Development, 50(4), 407-428. doi:10.1353/csd.0.0077

Woodside, B. M., Wong, E. H., \& Wiest, D. J. (1999). The effect of student-faculty interaction on college students' academic achievement and self concept [sic]. Education, 119(4), 730-733.

Xu, J., Kochanek K. D., Murphy, S. L., \& Tejada-Vera, B. (2010). Deaths: Final data for 2007. National Vital Statistics Reports, 58(19). Retrieved from https://www.cdc.gov/nchs/data/nvsr/nvsr58/nvsr58_19.pdf

Yin, D. \& Lei, S. A. (2007). Impacts of campus involvement on hospitality student achievement and satisfaction. Education, 128(2), 282-293.

Zacherman, A., \& Foubert, J. (2014). The relationship between engagement in co-curricular activities and academic performance: Exploring gender differences. Journal of Student Affairs Research and Practice, 51(2), 157-169. doi:10.1515/jsarp-2014-0016

Zhao, C. M., \& Kuh, G. D. (2004). Adding value: Learning communities and student engagement. Research in Higher Education, 45(2), 115-138. Retrieved from: http://www.nsse.indiana.edu/pdf/research_papers/Zhao_Kuh_Learning_Communities.p df 
Zhou, J. (2010). The impact of engagement on the academic performance and persistence of first-year college students at a four-year public institution (Doctoral dissertation).

Retrieved from ProQuest. (3462374) 
CURRICULUM VITAE 


\section{Michael Milmine}

milmine@andrews.edu

\section{Education}

Andrews University, Berrien Springs, MI

PhD Educational Psychology (May 2021), Summa Cum Laude

Andrews University, Berrien Springs, MI

MA Educational Psychology with Research Emphasis (August 2015), Summa Cum

Laude

Southern Adventist University, Collegedale, TN

BA Psychology, Entrepreneurship Minor (May 2013), Summa Cum Laude

\section{Professional Appointments}

2020-present, Assistant Professor of Psychology \& Chair

Pacific Union College, Department of Psychology \& Social Work

2017-2020, Assistant Professor of Psychology

Pacific Union College, Department of Psychology \& Social Work

\section{Selected Publications \& Presentations}

- Lopez, M., \& Milmine, M. (2019). Finding your rhythm: The effects of drumming circles on undergraduate students. Poster session presented at the meeting of the Western Psychological Association, Pasadena, CA.

- Alvarado, M., Hoffman, E., Quijada, S., \& Milmine, M. (2019). The effects of music on attention/memory processes and arousal. Poster session presented at the meeting of the Western Psychological Association, Pasadena, CA.

- Milmine, M., \& Gabriel, E. (2018). Shielding students from stereotype threat: Instructional and developmental implications. Journal of Adventist Education, 80(3), 2631.

- Milmine, M., \& Nosworthy, N. (2017). The Television Viewing, Dating, and Academics of Young Adults. Poster presented at the meeting of the Midwest Psychological Association (MPA), Chicago, IL. 